\title{
DETECCIÓN DE NECESIDADES EN PACIENTES TERMINALES A TRAVÉS DE LA ENTREVISTA PROFUNDA Y SU CONSECUENTE APOYO PSICOLÓGICO HUMANISTA Y TANATOLÓGICO
}

\author{
Iliana Jiménez Zaraín ${ }^{1}$
}

\begin{abstract}
RESUMEN
La presente investigación de tipo cualitativo, tuvo como objetivo detectar las necesidades psicológicas y físicas de los pacientes con alguna enfermedad terminal. Se llevó a cabo en un Hospital del I.S.S.S.T.E, en donde mediante la aplicación de un instrumento proporcionado por el hospital y la técnica de la entrevista profunda se recolectaron una serie de datos, cada entrevista duró entre 1 y 2 hrs. Se realizaron 6 entrevistas con cada uno de los 3 pacientes entrevistados para detectar sus necesidades; se buscó que se encontraran en un cuarto aislado para establecer un ambiente de mayor confidencialidad. Las entrevistas no siempre se efectuaron de manera continua debido a la disposición de los pacientes que en ocasiones se veía obstaculizada por su enfermedad o su estado de ánimo. A cada paciente se le brindó apoyo psicológico de orientación humanista y acompañamiento tanatológico para facilitar que lograra la satisfacción de sus necesidades.
\end{abstract}

\begin{abstract}
The recent investigation of qualitative type had as a target to detect the psychological and physics necessities of the patients with some kind of terminal sickness. This took place in the I.S.S.S.T.E hospital, where through the application of an instrument proportionate by the hospital and the technical of a deep interview it was recollected some information, each interview had duration between 1 and 2 hours.

It was realized 6 interviews with each one of the 3 patients, already interviewed and it was searched that this one was found on an isolated room to establish a confidential environment, those interviews were not realized in a continuous way propered to the patients disposition that in some occasions it was obstructed by their sickness or by their courage.

To each patient it was offered psicologic therapy with human and tanatologic focus; for their necessities.
\end{abstract}

PALABRAS CLAVE:

Enfermedad terminal, Muerte, Apoyo psicológico y Tanatológico.

\footnotetext{
${ }^{1}$ Universidad Intercontinental, México. Correo electrónico: iliana15 @ yahoo.com
} 


\section{INTRODUCCIÓN}

Se han hecho varios estudios para poderle dar al paciente con enfermedad terminal una mejor calidad de vida durante el transcurso de su enfermedad. En esta investigación nos referiremos a este tipo de pacientes con la abreviatura P.E.T (paciente con enfermedad terminal).

Una de las áreas dedicadas a apoyar a este tipo de personas es la Tanatología, según Behar. (2003), este término fue acuñado en 1901 por el médico ruso Elías Metchnikoff, quién en el año de 1908 recibiera el Premio Nóbel de Medicina. En ese momento la Tanatología fue considerada como una rama de la medicina forense que trataba de la muerte y de todo lo relativo a los cadáveres desde el punto de vista medicolegal.

Según el mismo autor en 1930 como resultado de grandes avances en la medicina empieza un periodo en el que se confina la muerte en los hospitales; ya para la década de los cincuentas esto se va generalizando cada vez más, así el cuidado de los enfermos en fase terminal es trasladado de la casa a las instituciones hospitalarias, dando por resultado que la sociedad de esa época "ESCONDIERA" la muerte en un afán de hacerla menos visible, para que no le recordara los horrores de la guerra que acababa de terminar.

En las décadas de 50’s y 60’s diferentes sociólogos iniciaron el estudio de la psicología de la muerte y potenciaron la aparición de programas de asesoramiento y terapias para tratar los profundos problemas emocionales asociados a la muerte que existen en la sociedad moderna.

A partir de la década de 1960 se ha prestado de nuevo atención a las necesidades de los pacientes agonizantes y de sus familiares, un ejemplo de esto son las investigaciones realizadas por el psiquiatra Eissler, quien escribió un libro enfocado a este tema titulado: "El psiquiatra y el paciente moribundo".

En esta década en Inglaterra se hace creer a todos que la muerte es algo sin importancia ya que, al ocultarla, se le despojaba de su sentido trágico convirtiéndola en un hecho ordinario, se le consideraba insignificante. 
Según Behar. (2003), la Dra. Elizabeth Kübler Ross es quién se da cuenta de los fenómenos psicológicos que acompañan a los enfermos en fase terminal durante el proceso de muerte, es ella quien aporto la definición de mayor uso actual y define la Tanatología como una instancia de atención a los moribundos. Por lo que se le considera la fundadora de la Tanatología. Es ella a través de su labor quien hace sentir a los moribundos miembros útiles y valiosos de la sociedad, y para tan fin creó clínicas cuyo lema es "Ayudar a los enfermos en fase terminal a vivir gratamente, sin dolor y respetando sus exigencias éticas".

O’Connor (2003), empieza en Inglaterra en el año de 1960 el movimiento del Hospicio, lugar que favorece que la persona con enfermedad terminal tenga en dichos lugares más y mejores cuidados para mejorar su calidad de vida.

En estos lugares ofrecen personal calificado que proporciona apoyo e información a toda la familia y al paciente, estimulan la comunicación franca y honesta con el y buscan que la persona pueda recibir a la muerte con el menor dolor posible a través de cuidados paliativos.

Según el Instituto Mexicano de Tanatología, este movimiento surgió en México desde 1994, con la apertura del Instituto el cuál se dedica a preparar futuros tanatólogos.

En los últimos años ha crecido de forma espectacular la demanda de asesoramiento individual y de grupo por parte de profesionales de la Tanatología. Lo más importante para aliviar el sufrimiento de los enfermos terminales y de sus familiares es hacer que se sientan queridos y comprendidos, desgraciadamente no siempre los seres queridos dan el apoyo suficiente a los pacientes, como resultado de esta experiencia se han creado centros de enfermos terminales, donde se ayuda al paciente a conseguir un mayor autocontrol a través de una mejor comprensión de los aspectos médicos y emocionales de la muerte. 
Actualmente la ciencia se ha preocupado por tener los recursos necesarios para prolongar la vida de la persona con enfermedad terminal. De acuerdo a Jaramillo (2001), "el morir viviendo" se puede alargar interminablemente gracias a la sofisticación de aparatos y procedimientos, mientras los pacientes y su familia se preocupan por el desenlace y por el prospecto de un morir de inquietante calidad.

En la actualidad se han hecho cosas para ayudar al enfermo terminal a tener una mejor calidad de vida y ayudarlo a satisfacer sus necesidades. Se ha buscado la mejor forma de ayudar al P.E.T y a su familia a superar de una manera más efectiva el proceso de duelo; sin embargo según Roccatagliata (2000), nuestra sociedad no nos prepara para enfrentar el dolor, para consolar y menos para responder a las pérdidas, es por esto que la presente investigación pretende detectar las necesidades de los enfermos terminales para ayudarlos a enfrentar el dolor ante su pérdida, consolarlos y apoyarlos a cubrir dichas necesidades mediante el apoyo y/o acompañamiento tanatológico, apoyo psicológico de orientación humanista y/o la terapia ocupacional, es necesario hacer todo esto porque "incurabilidad no es igual a no hay nada más que hacer." (Jaramillo, 2001). 


\section{JUSTIFICACIÓN}

La presente investigación tendrá un abordaje cualitativo, se realizará estudio de casos con 3 pacientes y se hará una descripción exacta de los datos obtenidos con cada uno de ellos. Con este método se pretende lograr el objetivo de esta investigación, la cual es el detectar las necesidades de la persona con enfermedad terminal (P.E.T), tanto las psicológicas como las físicas.

Las de tipo psicológico se detectaran para dar un adecuado apoyo psicológico con enfoque humanista, así como apoyo y acompañamiento tanatológico para brindar contención en el proceso de duelo; por otra parte las necesidades de tipo físico serán satisfechas por el personal médico el cual esta interesado en esta investigación.

Estas necesidades serán detectadas con un instrumento proporcionado por el hospital en donde se realizo la presente investigación y también se utilizara la técnica de la entrevista profunda.

El dar apoyo a estos pacientes cada vez es más necesario, ya que lamentablemente el índice de enfermos terminales va en aumento y hay pocos profesionales entrenados para dar apoyo psicológico y tanatológico adecuados; entendiendo por adecuado el que ayuden a las P.E.T a preparar y elaborar el final de su vida.

Es necesario tomar en cuenta que los P.E.T por lo general presentan sentimientos de inutilidad, se sienten diferentes a los demás, y esto causa que se depriman, y que utilicen como mecanismos defensivos la negación y en algunos casos el aislamiento.

Es importante trabajar por un lado la aceptación de la enfermedad terminal y, por otro lado, trabajar en el sentido de que la persona descubra y haga conciencia de que tiene varias posibilidades aún dentro de su enfermedad, para tener una adecuada calidad de vida. Este proceso se facilita si la persona cuenta con el respaldo y apoyo emocional de su familia. y/o seres queridos.

Lo más común es que cuando una persona se enferma, la familia lo sobreproteja o, por el contrario, deje al paciente en el olvido. Estas dos maneras de tratar al P.E.T son erróneas ya que si se le sobreprotege podemos aumentar el sentimiento de inutilidad y el que la familia los olvide y prefiera dejarlos en hospitales o asilos por miedo a no darles el apoyo o cuidados necesarios. Desgraciadamente, no toman en cuenta que para una persona enferma lo más importante y la mejor medicina es el apoyo interpersonal que puede recibir de la familia y amigos; y así sentirse acompañado, querido y comprendido hasta el último día de su vida.

Según Jaramillo, (2001), la muerte tiene que ocurrir siempre dentro del respeto por la dignidad humana para lo cual, la P.E.T debe de poseer la información acerca de su enfermedad, debe de tener acceso a los auxilios espirituales adecuados a sus creencias religiosas, y el derecho a poder despedirse de sus seres queridos. Lo anterior sería un camino sano a recorrer por este tipo de pacientes sin embargo, observamos que cada vez 
más se les deja en manos del personal médico y en un total abandono por parte de la familia.

Se piensa que para dar un cuidado integral al paciente con enfermedad terminal es necesario contar con apoyo no solo médico, sino también psicológico y tanatológico. Es necesario asesorar a la familia del P.E.T ya que el hecho de estar con una persona enferma y permanecer en espera observando como se deteriora y consume requiere de una gran capacidad de asimilación para confrontar emociones encontradas y difíciles de manejar, y esto puede ser facilitado si la familia y el paciente reciben orientación psicológica y tanatológica.

Cuando una persona sabe que el final se acerca, sufre sentimientos de angustia, tristeza y minusvalía. Es necesario que el paciente comprenda lo que esta viviendo, cuales serán los efectos de su tratamiento y tomar en cuenta que no se le debe mentir con falsas esperanzas de curación y menos si el paciente ya está desahuciado.

Hay que entender que aunque se le oculte la verdad y no se le informe al P.E.T sobre la gravedad de su enfermedad por creer que no se da cuenta de que está muriendo, ellos suelen tener conciencia de su cuerpo y percibir cuando su final se acerca, por esto es mejor decirles la verdad para que ellos sientan que pueden confiar y expresar libremente lo que piensan en cuanto a su muerte esperada.

Para Mallet (2003), al P.E.T se le debe dar todo el apoyo posible: familiar, médico, psicológico - tanatológico y es importante considerar al paciente siempre como el verdadero dueño del problema, ya que es él quien va a ser el receptor del tratamiento, "depositario de las angustias y preocupaciones de la familia y seres queridos, ese paciente que es testigo activo de la perdida de la salud, héroe de mil batallas, conejillo para protocolos y galardones de los investigadores." (p.17). En esta investigación no se están tomando a los pacientes como conejillos de indias, solo se les esta brindando un apoyo para ayudarlos a tener mejor calidad de vida, y si este apoyo les sirve para satisfacer sus necesidades se tratara de promover y utilizar con otros pacientes.

Se presenta ante nosotros, débil, impotente, enojado, asustado y temeroso, ha perdido su salud, su casa y su mundo social y se atreve a confrontar al médico, a la soledad y al ambiente generalmente agresivo en un hospital.

Hay que tratar de evitar que el P.E.T pase por sentimientos de minusvalía y soledad y que el ambiente del hospital sea lo menos agresivo para él, por eso es necesario que no solo la familia, y el P.E.T reciban apoyo tanatológico y psicológico, sino que se requiere que la tanatología y las herramientas psicológicas se expandan a los hospitales, a los médicos y todo el personal de salud, es importante que todos empecemos a tomar conciencia de que el ambiente en el que un paciente se encuentra, por lo general hace de sus últimos días la peor experiencia de su vida. Es necesario que esto cambie en nuestra sociedad, hay que humanizarnos y tomar conciencia de que hay que vivir con la mayor calidad posible porque nadie esta exento de la posibilidad de padecer una enfermedad 
terminal y mucho menos de morir, es por esto que es necesario el saber todo lo que conlleva una enfermedad terminal para que en el momento de estar cerca de una situación así ya sea con la enfermedad de un ser querido o la nuestra se sepa como actuar.

Las enfermedades terminales conllevan una serie de cambios fuertes y violentos en lo psicológico, económico, moral y espiritual, tanto en la P.E.T como en su familia, ya que este tema nos recuerda nuestra propia mortalidad, y puede llegar a despertar una gran ansiedad, la cual genera que la probabilidad del duelo patológico se acentúe y por lo tanto la necesidad de recibir el apoyo de un profesional en esta área se vuelve más necesario.

Nuestra sociedad debe tratar de cambiar su concepción de muerte y no temerle, esto no quiere decir que anulemos los sentimientos que nos puede provocar la muerte de algún ser querido. Es normal que una persona sienta enojo, tristeza, depresión, estos sentimientos propios del duelo no son patológicos siempre y cuando no interfieran con las actividades normales del doliente y él pueda seguir con su vida.

La presente investigación pretende detectar y generar propuestas de intervención acordes con las necesidades del paciente, para añadir más vida a sus días, entendiéndose por esto a dar más calidad de vida. 


\section{CAPITULO I}

\section{LA MUERTE}

\section{LA ÚLTIMA VEZ}

Si supiera que hoy fuera la última vez que te voy a ver dormir, te abrazaría fuertemente y rezaría al Señor para poder ser el guardián de tu alma.

Si supiera que esta fuera la última vez que te vea salir por la puerta, te daría un abrazo, un beso y te llamaría de nuevo para darte más.

Si supiera que esta fuera la última vez que voy a oír tu voz, grabaría cada una de tus palabras para poder oírlas una y otra vez indefinidamente.

Si supiera que estos son los últimos minutos que te veo, diría te quiero y no asumiría, tontamente que ya lo sabes.

Siempre hay un mañana y la vida nos da otra oportunidad para hacer las cosas bien, pero por si me equivoco y hoy es todo lo que nos queda, me gustaríaa decirte cuanto te quiero y que nunca te olvidare.

El mañana no le esta asegurado a nadie, joven o viejo. Hoy puede ser la última vez que veas a los que amas. Por eso no esperes mas, hazlo hoy, ya que si el mañana nunca llega, seguramente lamentaras el día que no tomaste tiempo para una sonrisa, un abrazo, un beso, y que estuviste muy ocupado para concederle a alguien un ultimo deseo.

Mantén a los que amas cerca de ti, diles al oído lo mucho que los necesitas, quiérelos y trátalos bien, toma tiempo para decirles lo siento, perdóname, por favor, gracias y todas las palabras de amor que conoces.

"Nadie te recordara por tus pensamientos secretos. Pide al Señor la fuerza y sabiduría para expresarlos".

Vamos, no te resistas, vence ese falso orgullo, demuéstrale a tu familia y amigos cuanto te importan, nunca tengas miedo de expresarte. Toma esta oportunidad para decirle a alguien lo que esa persona significa para ti. Tomate el día, y no tengas ningún arrepentimiento, pero lo más importante, mantente cerca de tu familia y amigos porque ellos te han ayudado a ser la persona que eres hoy y deberá de ser todo para ti de cualquier forma.

ANÓNIMO 


\subsection{DEFINICIONES DE MUERTE DESDE VARIAS PERSPECTIVAS}

La muerte y la vida forman una curiosa y extraña simbiosis, ¿Quién sabe si lo que llamamos muerte sea vida, y la muerte vida? (Euripides).

La vida, toda vida sensata, es una preparación para la muerte. (Basave, 1983).

Gracias a la muerte podemos intensificar la vida. (Basave, 1983).

Lo único que nos asegura que vemos a morir es el hecho de estar vivos.

(Martínez, 2002).

Para iniciar esta investigación es importante saber ¿Qué es la muerte?, La muerte misma puede ser desconocida, pero la separación y la pérdida son una terrible realidad tanto para quienes deben irse como para quienes se quedan. Se deja atrás toda una vida de pensamientos, sentimientos y relaciones cuando finalmente nos despedimos.

Según Martínez, (2002), si la persona puede darse cuenta de que existe también puede darse cuenta de que puede dejar de hacerlo en cualquier momento. Lo único que nos asegura qua vamos a morir es el hecho de estar vivos.

De acuerdo a Yalom, (1984), la incorporación de la muerte a la vida enriquece a esta y permite a los individuos liberarse de trivialidades sofocantes, vivir de una manera más intencional y auténtica. La conciencia plena de la muerte provoca a veces un cambio radical en la persona.

No resulta sencillo determinar cuando es que una persona ha muerto, de acuerdo a Vincent (1980), la sociedad occidental, ve la muerte como una ruptura, como algo radicalmente opuesto a la vida y lo que más miedo nos causa no es la muerte en si misma ya que cuando llega no la vemos, sino a la forma en que podemos morir, le tememos al sufrimiento.

Por otra parte y de acuerdo al mismo autor, en la sociedad negro -Africana la muerte es aceptada, ya que ven a la muerte como parte de la vida, es decir la integran a su vida diaria y viven cada día como si la muerte llegara por ellos en cualquier momento, curiosamente esta cultura le teme a los muertos ya que creen que estos vuelven para vengarse.

En cambio en la cultura mexicana, no se le teme los muertos, al contrario se les festeja, se les hacen ofrendas y se acuerdan de ellos de ellos con humor, pero en el momento en que se tiene que afrontar la próxima muerte de un ser querido que padece una enfermedad terminal no se sabe como actuar, ni que decirle para hacerlo sentir mejor, se suele evadir el tema por completo. 
Ahora bien Louis Vincent Thomas, (1980), habla sobre niveles en el proceso de morir, los cuales se mencionan a continuación:

1) Muerte aparente: especie de sincope prolongado, insensibilidad, desaparición del tono muscular, paro respiratorio y debilitamiento de la actividad cardiaca y circulatoria, en donde el sujeto puede volver a la vida de 2 maneras, la primera es de forma espontánea y voluntaria y la segunda es como consecuencia de las medidas de reanimación.

2) Muerte clínica: cesa la actividad circulatoria y respiratoria, sin embargo el retorno a la vida es posible salvo cuando la irrigación sanguínea falta al cerebro por mas de 5 a 8 minutos.

3) Muerte absoluta: Es la muerte cerebral, aquí ya es irreversible, también se le conoce como vida vegetativa, el daño es en el tronco encefálico, este momento es ideal para la donación de órganos porque estos siguen manteniendo vivos.

Cabe aclarar que no es lo mismo muerte cerebral que estado de coma, el estado de coma es un sueño profundo, no hay daño en el tronco encefálico sino entre el tálamo y el bulbo raquídeo, es reversible, el paciente sigue vivo y despierta como si nada hubiera pasado.

Tras la muerte, se producen varios cambios que sirven para determinar el momento y las circunstancias de la muerte: la frialdad cadavérica, enfriamiento del cuerpo después de la muerte está determinada principalmente por la temperatura ambiental y por lo general no es de gran ayuda; la rigidez cadavérica, que aparece en los músculos esqueléticos y se inicia entre las cinco y las diez horas posteriores a la muerte y desaparece después de tres o cuatro días; coloración violácea que aparece en las partes declives del cuerpo, y que es el resultado de la acumulación de la sangre.

La muerte de los órganos se produce a distintos ritmos. Aunque las células cerebrales no pueden sobrevivir durante más de cinco minutos después de la muerte somática, las del corazón lo hacen durante alrededor de quince minutos, y las del riñón cerca de treinta.

Después de haber definido lo que es la muerte, se considera apropiado definir las fases del proceso de muerte, las cuales se mencionan a continuación.

\subsubsection{FASES DEL PROCESO DE MUERTE}

Las fases del proceso de muerte son mencionadas por Sánchez, (2005), y son las siguientes:

Patrón de pensamiento: en esta etapa el paciente sospecha de una posible enfermedad.

Pruebas de laboratorio: ante la sospecha de una posible enfermedad el paciente acude a realizarse estudios médicos para saber si padece o no alguna enfermedad. 
Diagnóstico: aquí el paciente recibe la noticia de que padece una enfermedad terminal, es decir se le dicta la sentencia.

Una vez dados los resultados, es decir la evidencia de que el paciente padece una enfermedad, puede comenzar el duelo, antes de esta evidencia el psicólogo y el tanatólogo trabaja con puras suposiciones, no hay un trabajo terapéutico, solo de contención.

La siguiente etapa se llama acceso médico y tratamiento: es cuando el paciente trata de buscar alguna cura a su enfermedad, la característica principal es la esperanza de vida que el paciente mantiene.

Manejo de alternativas: se ven los posibles tratamientos para la cura, esto es solo a nivel físico.

Síntomas: en esta fase el paciente empieza a darse cuenta de que la muerte esta cerca, también se le llama fase de estigma, el paciente se siente marcado por su enfermedad y empieza a darse cuenta de que va a morir.

Problemas crónicos: los problemas físicos causados por la enfermedad cada vez son más severos, la muerte es aún más cercana y evidente, en esta fase el paciente empieza a desapegarse y el apoyo psicológico consiste principalmente en que empiece a cerrar ciclos.

Fase terminal: en esta etapa es con la que se va a trabajar en esta investigación, detectando las necesidades físicas y psicológicas de los pacientes para que tengan satisfechas dichas necesidades y así mejore su calidad de vida.

Agonía: esta etapa se caracteriza por la falta de emociones evidentes, es decir el paciente esta lleno de emociones internas pero ya no las externa, casi no hay comunicación verbal.

Una vez teniendo la evidencia de que el paciente tiene una enfermedad terminal, es normal que se empiece a presentar el duelo, el cual es una reacción normal ante cualquier pérdida en este caso es la de la salud y de la vida, en el siguiente apartado se menciona más ampliamente el significado del duelo y sus etapas.

\subsection{EL DUELO COMO REACCIÓN NORMAL ANTE LA PÉRDIDA}

Se debe dejar que hable el dolor, porque la pena que no habla, gime en el corazón hasta que lo rompe. ( Shakespeare).

Tarde o temprano toda persona experimenta en algún momento de su vida la pérdida de un ser querido y no queda más remedio que afrontarlo, esto se hace mediante un proceso cuya duración depende de la persona, a este proceso se le conoce como "duelo".

Duelo viene de: Dolus: dolor o dolere: sufrir.

El duelo en alemán se traduce como: traer: aflicción, y consiste en una situación transitoria, que desaparece al cabo de cierto tiempo. 
El duelo ocurre tras cualquier clase de pérdida, es la respuesta emocional y personal ante la pérdida, según O’Connor (2003), este proceso tiene una duración aproximada de 1 a 2 años.

Roccatagliata (2000), afirma que le duelo es un proceso activo de adaptación ante la pérdida y que implica llevar a cabo cambios que generan ansiedad, inseguridad y temor.

El duelo es personal, emocional y restitutivo, personal porque cada quien lo vive a su manera, nadie va a poder sentir lo mismo que uno siente, emocional porque despierta ira, depresión, tristeza, desesperación, etc... Y restitutivo si se supiera y viviera ese duelo, para superar el duelo debe vivirse y sentirse, no evadir emociones, no reprimir sentimientos.

El duelo es una herida, y como tal necesita tiempo para sanar, y aunque deja una cicatriz que hace que se recuerde la pérdida, si es cuidada adecuadamente, habrá mayores posibilidades de superarla.

A continuación se presenta un fragmento de un libro de Grollman (2000), el cual describe lo que el doliente y muestra que es una reacción normal ante cualquier pérdida:

\section{Y DUELE:}

Cuando pierdes, te afliges. Es duro tener completamente rotos los vínculos con tu pasado.

Nunca más oirás la risa de tu ser querido, debes renunciar a los planes que habías hecho; abandonar tus ilusiones.

Como todas las personas que sufren la pérdida de alguien a quien amaban, estás pasando por un proceso de dolor. El momento es AHORA.

No suprimas o ignores tus reacciones de dolor, si lo haces, tus sentimientos serán como ascuas latentes, que más tarde pueden llegar a encenderse y causar una explosión más peligrosa.

La aflicción es una angustia insoportable, es tristeza, es soledad, puesto que amabas, el dolor camina a tu lado.

El dolor es una de las emociones humanas más básicas.

El dolor es muy, muy normal. 
Earl A. Grollman. (2000).

El dolor es un sentimiento universal ya que todo el mundo lo ha sentido alguna vez pero al mismo tiempo es individual ya que cada persona vive el duelo de manera distinta, no hay ninguna manera de poder predecir como se sentirá, no se les puede obligar a sentirse de una determinada forma, ya que cada persona vive y sufre su duelo, y el tiempo de este sufrimiento también es variado, por eso en el siguiente apartado se hablara de los tipos de duelo que existen.

El duelo es una reacción normal ante la pérdida, en el caso de la persona con enfermedad terminal es normal esta reacción ya que se encuentra enfrentando la pérdida de su salud. Por otra parte la familia y seres queridos del P.E.T, pasan por un doble duelo el primero ocurre en el momento de recibir la noticia de que su ser querido padece una enfermedad terminal y el segundo duelo se da cuando este ser querido muere.

En el proceso de duelo del paciente se busca lo siguiente:

- Aceptar la realidad

- Trabajar las emociones y el dolor

- Adaptarse a las nuevas circunstancias y vivirlas con calidad y dignidad

- Prepararse para la muerte, cerrar círculos y despedirse.

En cambio en la familia y los seres queridos se busca:

- Que acepten la realidad de la pérdida

- Trabajar con las emociones y el dolor de la pérdida

- Lograr que se adapten a un medio en el que el fallecido está ausente

- Lograr que puedan continuar con su vida.

No todas las personas viven el duelo de la misma forma, es por esto que a continuación se mencionan los tipos de duelo que una persona puede presentar.

\subsubsection{TIPOS DE DUELO}

\subsubsection{Duelonormal:}

El duelo normal por una pérdida significativa se inicia desde el momento en que se da la pérdida y se soluciona cuando se acepta el pasado sin quererlo cambiar, se vive el presente y se planea el futuro sin aquello que se ha perdido. 
Este tipo de duelo es el que propicia el tanatólogo o psicólogo especialista en el tema, para que el paciente no se quede estancado en alguna de las etapas de duelo que posteriormente serán descritas.

\subsubsection{Dueloanticipatorio}

Aunque sepas que alguien se está muriendo, nunca puedes estar realmente preparado para su muerte. Nunca estamos totalmente preparados para la muerte de un ser querido. Cuando llega, todavía puede parecer irreal y conmocionante. (Wolfelt,2003).

El duelo anticipado comienza desde el anuncio del diagnóstico, se presenta tanto en la P.E.T, así como en su familia, según Kübler Ross (1975), un proceso de duelo normal deberá transitar por las 5 etapas descritas por ella: negación, ira, negociación, depresión y aceptación, lo que no significa que necesariamente se caminen en ese orden, sino que en ocasiones se puede ir y venir de una etapa hacia otra.

El duelo anticipado se da principalmente en la familia y seres queridos del paciente, aunque este también puede llegar a presentar este tipo de duelo y se manifiesta cuando ya no le interesa hacer nada por el porque sabe que va a morir y ya no le encuentra caso a hacer algo por ayudarse, se comporta como si ya estuviera muerto.

Por otra parte, la familia en ocasiones puede mostrar como distancia emocional hacia el enfermo o bien el tener la necesidad familiar de largas conversaciones a propósito de la persona enferma.

Cabe aclarar que el luto anticipatorio familiar, en ocasiones puede dañar el vínculo de la P.E.T con su familia ya que esta puede caer en una desesperanza sobre las posibilidades o el tiempo de vida del paciente diagnosticado como terminal.

Gil, (1998) encontró que las familias que se han adaptado a un futuro sin su familiar, tenían serias dificultades cuando su ser querido sobrevive a la enfermedad crónica. Se requiere ayuda profesional para reintegrar al paciente a la familia.

Cuando el paciente responde bien médicamente, la amenaza inmediata de pérdida se hace remota y los familiares se trasladan de un estado de duelo anticipatorio a una esperanza incrementada de cura. (Kübler- Ross, 1975).

En los casos de enfermedad terminal, los miembros de la familia y los amigos del enfermo suelen empezar el duelo por la pérdida mucho antes de la muerte en sí, pero esto no quiere decir que cuando llegue la muerte ya se haya superado ya que después de esta empezará un segundo duelo para los seres queridos de la persona que murió. 
El duelo anticipatorio tiene como finalidad el preparar a las personas a aceptar la inminente pérdida sin embargo, puede tener su aspecto negativo ya que, en ocasiones, se anticipa una muerte que no sucede. La definición de duelo anticipatorio se puede resumir en este caso citado por Yalom, (1984):

Me sentía ya mucho mejor y más feliz, pero mis padres empezaron a tratarme como si de verdad fuera a morir y me acometió la terrible sensación de que ellos me daban por muerta. Debido a un error y a una falta de comunicación, yo no existía ya para mi familia; casi me lo creí y me fue muy difícil regresar a la vida, pero aún fue peor mas adelante, cuando empecé a sentirme algo mejor; de pronto la familia se dio cuenta de mi mejoría y volvieron a la rutina de siempre, dejándome al margen porque me consideraban muerta, lo que me resultaba insoportable. Todavía tengo miedo y me esfuerzo por cruzar la frontera que tengo delante: la frontera entre la vida y la muerte. (p.150).

\subsubsection{DueloComplicadoopatológico}

Algunas personas no tienen la oportunidad de desarrollar un duelo adecuado ya que las demandas, familiares o laborales no lo permiten; en otras ocasiones el problema es que la pérdida no es vista como algo propio o se niega el hecho de que un ser querido esta muriendo o ya murió.

Existen varios factores, circunstancias o fenómenos identificados como elementos de riesgo durante el duelo; la presencia de uno o más de ellos puede hacer que el proceso de recuperación tras la pérdida de un ser querido sea más. Por supuesto, cuantos más factores de riesgo estén presentes, más difícil la recuperación.

Los factores de riesgo de duelo complicado identificados son:

1. Edades extremas (muy viejo, muy joven): Cuando el superviviente (el deudo) es muy joven (niño) o muy viejo hay más riesgo de complicaciones puesto que las características del duelo a estas edades son diferentes.

2. Igual edad del difunto a la de otra persona significativa muerta en el pasado: La coincidencia de edades de las dos pérdidas hace que la recuperación sea más difícil.

3. Pérdidas múltiples o acumuladas: Las pérdidas acumuladas (pérdidas graves en distintos momentos de un mismo proceso de recuperación: mientras la persona intenta recuperarse de una viene la otra, y así) o múltiples (perder varios seres queridos al mismo tiempo o perder varias cosas además del ser querido) hacen que el proceso de recuperación sea extremadamente difícil. 
4. Crisis concurrentes: La presencia de otros problemas importantes o graves que resolver, además de la pérdida del ser querido, puede hacer que la persona se vea en la necesidad de "aplazar" el duelo para otro momento pues los problemas concurrentes tienen "prioridad" o son muy urgentes de resolver.

5. Duelo no resuelto de pérdida previa (no necesariamente de un ser amado, también de otro tipo de pérdidas: trabajo, rol social, etc.): Si nos encontramos en un proceso de recuperación de una pérdida, y le añadimos otra, el proceso puede bloquearse o no darse sin ayuda adecuada.

6. Pobres o ausentes sistemas de apoyo emocional y social: Todos, para recuperarnos de una pérdida, utilizamos dos fuentes importantes de ayuda: las internas (de la personalidad, de la experiencia, de la madurez) y las externas (relaciones interpersonales).

7. La persona puede optar por hacerlo solo con los recursos internos, utilizando muy poco o nada los recursos externos, o viceversa, u optar por utilizarlos a ambos. Los mejores resultados del duelo (mayor éxito en el proceso de recuperación) se obtiene cuando se utilizan ambas fuentes, sacándoles el máximo provecho a ambas.

8. Relación altamente ambivalente o dependiente con el difunto: Cuando la relación con la persona fallecida ha sido ambivalente (mezcla de amor y odio, relaciones tensas y complicadas), el trabajo de recuperación puede verse trastornado.

9. Muerte repentina e imprevista, ya que no existe el tiempo suficiente para elaborar el duelo y aceptar la pérdida a diferencia de las personas que mueren después de una larga enfermedad.

10. Muerte por Suicidio. Este tipo de muerte puede crear en la familia sentimientos de culpa.

Los 2 puntos anteriores producen una reacción inicial muy intensa, el proceso de recuperación puede complicarse.

11. Aquellos que pueden estar disuadidos de expresar su congoja (dolor) o no tienen oportunidad de hacerlo: Este tipo de comportamiento es muy frecuente: las personas son animadas a no llorar o a no expresar su dolor; esto solo lleva a complicar el proceso de recuperación.

12. Aflicción aguda inusitadamente intensa: Si la respuesta inicial es muy intensa (como para tener que haber consultado un servicio médico-psicológico o haber presentado cualquier tipo de crisis), el proceso de recuperación puede verse afectado.

13. Reacción aguda con ataques de pánico: Al igual que en el caso anterior, este tipo de reacción puede afectar el proceso de recuperación. 
14. Una incierta o no visualización de la pérdida (no ver el cuerpo muerto: ahogados, guerra, etc.): puede llevar a que el proceso de recuperación no se inicie o se complique, ya que los familiares al no tener ese contacto físico con la persona ya fallecida, pueden generar un exceso de fantasías tendientes a la negación, lo que complica el proceso de duelo.

15. Pérdida social inaceptable (relación homo/heterosexual que era secreta, muerte por asesinato, suicidio, SIDA, etc.): Estas muertes (en sí mismas), por su dramatismo o su especialidad, pueden llevar a complicaciones serias del proceso de recuperación.

16. Pérdida que es socialmente negada (aborto, homicidio piadoso, etc.): Igual que en el caso anterior, estas muertes pueden llevar a complicaciones serias del proceso de recuperación.

17. Situación socio-económica conflictiva: Este tipo de circunstancia añade, como crisis concurrente que es, un problema al proceso de recuperación.

18. Negación intelectual/emocional de la pérdida: Esta reacción suele ser muy problemática para el proceso de recuperación; la mayor parte de las veces exige consulta especializada.

19. Fase del ir-muriéndose de larga evolución (enfermedad terminal que duró de 6 meses a 1 año): Como hemos visto antes, esto puede agotar demasiado al deudo y llevar a que tenga poca energía para invertir en el proceso de recuperación.

20. Obligaciones múltiples (crianza de los hijos, economía familiar, etc.): Este tipo de circunstancia añade, como en el $\mathrm{N}^{\circ} 16 \mathrm{y}$ como crisis concurrente que es, un problema al proceso de recuperación.

21. Síntomas depresivos de diverso grado de intensidad desde el inicio del duelo: Esta reacción es ya, de por sí, una complicación del proceso de recuperación.

Independientemente del tipo de duelo que presente el paciente, cada uno de ellos se conforma de fases o etapas, las cuales tampoco se presentan en un orden determinado e inclusive pueden llegar a no presentarse todas, en la siguiente parte de la investigación se explican cada una de estas fases y sus características principales, las cuales son mencionadas por Kübler Ross, (1975).

\subsection{ETAPAS DEL PROCESO DE DUELO}

Estas etapas son vividas por los familiares del enfermo terminal, así como por este último al tener conciencia de su enfermedad Kübler Ross (1975).

Las etapas que a continuación se mencionan no necesariamente ocurren en un determinado orden e inclusive en ocasiones ni siquiera se presentan, tampoco se presentan de la misma forma ni con la misma duración, de acuerdo a O'Connor (2003), a algunas personas les es difícil salir de una etapa a otra e inclusive no llegan a la fase final de aceptación y reconstrucción de su vida, otras experimentan ciertos 
sentimientos más de una vez, es decir el haber pasado una fase no quiere decir que no se pueda volver a pasar.

\subsubsection{NEGACIÓN:}

Consideró importante iniciar este subtítulo citando a 2 autores los cuales retoman el concepto de negación en el duelo no como tal, pero considero que leyéndolos se explica el significado de esta fase del duelo:

La represión fundamental no es el sexo, sino la muerte.

La muerte es el último y principal tabú... el crecimiento espiritual corre parejo a la aceptación de la muerte...

La negación de la muerte es equiparable a la negación de Dios...

Los filósofos existenciales han señalado de múltiples maneras cómo esta negación de la muerte desemboca en que nuestra vida resulta mucho menos vital y activa... Negar la muerte es también negar la vida.

Cuando nos asusta la muerte vivimos de manera extremadamente cautelosa y preocupada ante la posibilidad de que algo pueda sucedernos.

Así que, cuanto más tememos a la muerte, más tememos a la vida y por lo tanto, menos vivimos

. (Wilber, 1995).

En lo más profundo de su corazón sabía que estaba muriendo, pero no estaba acostumbrado a esta idea y además no podía captarla. Es imposible que yo tenga que morir!!, Sería demasiado terrible. (Tolstoi, 1975).

Muchas personas creen como Iván Illich, que la mortalidad es para los demás y no para nosotros.

La negación de la enfermedad es un componente inicial que presentan los pacientes frente a su condición. Se manifiesta que no existe temor, que la enfermedad no puede ser tan grave y se enmascaran los síntomas o molestias que pueda presentar por miedo a preocupar a su familia. Al igual la familia trata de minimizar la enfermedad por medio de la sobreprotección y la preocupación excesiva por procurar un ambiente menos doloroso para el paciente; situación que desencadena conflicto entre ambas partes, ya que el paciente pretende no estar enfermo y su familia busca la mejor forma de ayudarlo. 
Ante la presentación de un diagnóstico, la negación es habitual en casi todos los pacientes, no solo durante las primeras fases de la enfermedad o al enterarse de su estado, sino también más adelante y de manera recurrente.

No todos los pacientes pasan por esta etapa debido a que tal ves tienen una fuerza muy grande, una fe en dios, creen en la reencarnación, etc., y jamás sienten miedo ante la muerte.

Los familiares también pasan por esta etapa es muy común ver a la familia diciendo "no, debe de haber un error", "mi papá estaba sano, "seguramente él médico se equivocó en él diagnostico", etc...

Esta posición no sirve de nada porque lo que realmente interesa es que el paciente se sienta apoyado por su familia y si este ve que sus familiares no creen que él esta enfermo y el ya supero la fase de negación le será imposible compartir sus sentimientos con ellos por temor a lastimarlos o enfadarlos.

El siguiente fragmento también es un ejemplo de negación:

\section{¡No, no mi hijo!}

¿Fibrosis quística? ¿Qué es eso?

¿Cuánto tiempo lo tendrá? ¿Hasta los seis o los dieciséis?

Doctor dígame todo lo que sepa.

¿Se curará algún día?

Un minuto de serenidad. Espera. No entiendo.

¿Hay que hacerle tratamientos manuales?

Tengo que presionarle el pecho tres veces al día,

Para que elimine la mucosidad que no puede expulsar.

¿Ha dicho siempre? ¿Tendrá esta enfermedad mientras viva?

¿Mi pequeño Gary? Dígame que no es cierto, ipor favor!

¿No puede tratarse de un error? ¿No le hará mas pruebas?

Debe de haber confundido sus radiografías con las de otro niño.

¿Terapia de vapor? ¿Drenaje postural? ¿Enzimas y pastillas?

Me esta diciendo que esta enfermedad debilita y mata.

Dice que no tiene cura iesta seguro?

¡Oh Dios! No mi hijo. No, él no. Eso no.

Kübler E. (1983).Lo anterior es una clara muestra de una persona que se encontraba en la etápa de negación, esto lo escribió D.A.G, en mayo de 1974.

Muchas veces ante una noticia de un diagnóstico fatal, entendiendo por esto que se cuenta con poco tiempo de vida, las personas reaccionan con negación es decir no pueden creer o aceptar lo que les esta sucediendo, por eso se consideró importante agregar el fragmento anterior para que el concepto de negación quede mas claro. 


\subsubsection{IRA:}

Cuando una persona está en la etapa de ira suele hacer comentarios como los siguientes:

¡Mira a ese niño, todo el día da lata, no es como mi hijo!

¿Por qué no se enferma él y no mi hijo?

Es todo tan injusto

¡Dios, ¿porque permites esto?.

Cuando no se puede seguir manteniendo la negación, esta es sustituida por sentimientos de ira y resentimiento, el paciente suele preguntarse ¿por qué yo? Y también es común oírlos maldecir a los médicos, a su familia y a Dios.

Suele comportarse de forma agresiva con la finalidad de llamar la atención es como una forma de decir: Aquí estoy, se portara grosero, alzará la voz únicamente para ver si alguien acude a su grito, quizás cuando alguien llegue a ayudarlo este se porte grosero pero sabrá que cuenta con alguien y sentirá alivio y posteriormente se le pasara.

En esta etapa los pacientes pueden llegar a sentir envidia por los que tienen buena salud y seguirán viviendo, puede haber deseos de que otra persona muera en su lugar.

También es común que lleguen a asumir el papel de niños dependientes, esto lo hacen con la finalidad de que se les ponga atención y se les escuche.

La familia por su parte al encontrarse en esta fase también suelen hacerles reproches a los médicos y en un caso extremo enojarse con el moribundo como si él tuviera la culpa de su enfermedad; esta es la fase más difícil para los familiares del paciente ya que la ira se desplaza en varias direcciones y se proyecta contra todo lo que les rodea siendo los médicos su principal blanco.

En ambos esta sensación de ira es causada por el miedo a lo desconocido, y en el paciente estas manifestaciones son expresiones de su miedo no tanto a la muerte sino al sufrimiento. El proceso de dolor siempre se acompaña de ira. 
En esta etapa es necesario que se le deje tanto al paciente como a la familia expresar su ira para que al sacar lo que sienten puedan superar esta etapa más rápido, claro que es necesario que el médico y las enfermeras los apoyen, aunque no es muy sencillo aguantar gritos y groserías pero al menos motivarlos a decir lo que les molesta y lo que sienten, si estos no son capaces de hacerlo entonces recurrir a un profesional en el tema ya que en este momento de crisis es necesario que se sientan acompañados y apoyados, sin embargo es importante no decirles a los familiares como deben de actuar o sentirse ante la pérdida ya que en lugar de ayudarlos los perjudicamos, es importante dejar que expresen su enojo y no limitarlos, ni aconsejarlos.

\subsubsection{NEGOCIACIÓN:}

Esta fase es menos conocida ya que dura muy poco tiempo y además los enfermos casi nunca suelen verbalizar estos pactos. La mayoría de las veces, los pactos se hacen con Dios y generalmente se guardan en secreto pero es muy importante para el paciente, es cuando la etapa de ira queda atrás, y el paciente terminal suele sentir un cierto remordimiento de haberse enojado con Dios y los médicos, y suelen recurrir a los buenos tratos con la esperanza de que Dios o los médicos lo curen por su buen comportamiento, la mayoría de los pactos los hacen con Dios.

La negociación del P.E.T, antes de que ocurra la muerte, puede consistir en desear que se descubra la cura milagrosa que lo va a salvar o desean que el diagnóstico este equivocado.

En el caso de los familiares también les llega este periodo de ligera tranquilidad y le piden a Dios que cure a su ser querido haciéndole promesas, a diferencia del paciente que le comunica a todos que le prometió a Dios portarse bien si éste lo curaba, los familiares suelen mantener su promesa en secreto.

Es a partir de esta fase cuando ya no solo se puede brindar apoyo tanatológico, también acompañamiento tanatológico ya que desde esta etapa el paciente acepta todo con la esperanza de sentirse mejor tanto a nivel físico como psicológico, en esta fase el paciente se vuelve mas accesible y buscara hacer todo con tal de salvarse y sentirse mejor, también es mas fácil tratar de que cambie sus actitudes, aceptan consejos, etc.

\subsubsection{DEPRESIÓN:}

O'Connor (2003), define la depresión como el enojo dirigido hacia adentro, esto incluye sentimientos de desamparo y perturbaciones del estado de ánimo en donde la persona suele alejarse de la gente y de las actividades.

Cuando el paciente se ve obligado a someterse a más y más operaciones, ya no puede negar que se encuentra enfermo de gravedad, se empiezan a manifestar las reacciones del tratamiento, es en este momento cuando el paciente cae en una terrible depresión y los familiares empiezan a sentir una gran sensación de pérdida. 
A la familia le ayudaría que el enfermo comparta con ella sus sentimientos.

En esta etapa tanto la familia como el paciente necesitan estar más unidos que nunca y apoyarse para no sentirse solos.

Los profesionales en este tema recomiendan que se digan todo lo que quieran decirse, que no repriman palabras, ni emociones, si quieren llorar que lo hagan y que sientan un apoyo mutuo para salir de esta etapa que quizás sea la más duradera.

Es importante también que él médico deje al paciente decidir lo que quiere hacer, y obviamente se espera que la familia lo apoye para que este no se sienta solo.

Nuestra sociedad tiene varios mitos negativos sobre el dolor y la forma en como se debe de vivir el duelo, algunos de ellos según Wolfelt, 2003, son los siguientes:

Tienes que ser fuerte y seguir adelante

Las lágrimas son un signo de debilidad

Tienes que reponerte a tu dolor

No se debe hablar de la muerte

Estos son solo mitos, son afirmaciones falsas que pueden llegar a ser perjudiciales para el doliente, lo cierto es que cada persona vive su duelo de manera distinta y hay que respetarlo porque solo esa persona sabe lo que siente.

\subsubsection{ACEPTACIÓN:}

Un ser querido ha muerto y ya no volverá. Esto es algo muy difícil de aceptar, pero es cierto. (Wolfelt,2003).

Después de haber llorado y expresado sus sentimientos el paciente irá aceptando su destino: morir.

Si el paciente aun sigue con vida después de la etapa depresiva, este ya habrá aceptado su destino y la muerte no le asustara, comenzara a hacer una serie de preguntas como: ¿qué es la muerte?, ¿A dónde voy a ir?, ¿Cómo es el cielo?, etc. Estas preguntas pueden ser respondidas por los médicos, la propia familia, si estos no pueden hacerlo, un profesional en el tema, ya sea un tanatólogo, psicólogo, un consejero espiritual adecuado con las creencias del paciente intervendrá en esta etapa para responder todas las dudas del paciente. ( Kübler Ross, 1983).

En esta etapa es donde más dudas surgen con respecto a la muerte pero es importante que se respondan de una manera correcta y sutil principalmente al enfermo para que no vuelvan a recaer en cualquiera de las etapas anteriores. 
La familia por su parte tarda mas en salir del estado depresivo, aunque cabe aclarar que esto no es una regla universal ya que hay casos donde la familia lo acepta más rápido que el propio paciente e inclusive lo apoya para salir de la etapa depresiva.

Si la familia se encuentra en esta etapa también es necesario que se sienta apoyada y que tenga a alguien que conteste sus dudas.

Después de ocurrida la muerte, cuando la familia pueda pensar en el ser amado sin tener intensos sentimientos de tristeza se puede decir que esta ha llegado a la aceptación.

También puede ocurrir que si la persona fallecida sufrió largo tiempo, llegue a causar una sensación de alivio, esto no es nada que deba avergonzar ni inspirar remordimientos, puesto que no se trata de un pensamiento egoísta, sino todo lo contrario, esto quiere decir que la persona se fija más en lo que le afectaba a esa persona y no en lo que le afectaba a el mismo. (Markham, 2000).

La aceptación es un paso que en ocasiones puede ser difícil ya que existen recaídas, es importante lograr que el doliente acepte su pérdida, esto se ejemplifica con el siguiente fragmento:

\section{ACEPTA TU PÈRDIDA}

Tu ser querido no se ha ido a realizar un largo viaje:

Ha ido por delante

Ha partido

Ha desaparecido

Tu ser querido ha muerto.

Intenta evitar las evasiones, los eufismos, los cuentos de hadas.

Renuncia al mundo de la fantasía.

Lo que es, lo que no puede cambiarse, debe aceptarse.

Aunque sea la cosa más difícil que hayas hecho en tu vida, ahora debes afrontar la realidad.

La negación de la tragedia, no significa salud mental, la salud mental es el reconocimiento del dolor y el intento de vivir con él.

El funeral ha terminado

Las flores se han marchitado,

Ahora la pérdida se hace real,

Tu ser querido está muerto. 
Earl. A. Grollman. (2000).

\subsection{LA ESPERANZA:}

La esperanza es básica en cada una de las etapas mencionadas anteriormente y se manifiestan de la siguiente manera:

○ En la etapa de negación el P.E.T y la familia tienen la esperanza de que todo sea un error.

- En la etapa de ira tienen la esperanza de que él médico encontrará la cura o que Dios lo salvará.

- En la etapa de pacto tanto el paciente como la familia tienen la esperanza de un milagro que claro pagaran con la promesa antes hechas.

- En la etapa de depresión tienen la esperanza de que se van a curar, de que no van a sentir tanto dolor, de que no van a sufrir.

- En la etapa de aceptación a pesar de hacer superado el miedo mantienen un poco de esperanza de que tal vez se curen, claro que en esta etapa la esperanza ya es mínima.

Cuando el enfermo deja de manifestar esperanza es generalmente una señal de muerte inminente, comienza a despedirse y arreglar asuntos pendientes para poderse ir con tranquilidad, en esta etapa el paciente ya no tiene miedo, se le ve tranquilo, relajado y listo para partir. (Kübler E,1975).

Al igual que los enfermos que agonizan, sus amigos y familiares atraviesan estados de rechazo y de resignación, por lo que es necesario apoyarlos.

La fase de desconsuelo que sigue a la muerte es más larga y difícil de soportar si se produce inesperadamente.

Durante este periodo, los afectados generalmente lloran, tienen dificultades para dormir y pierden el apetito. Algunos pueden sentirse asustados, enojados, o agraviados al ser abandonados.

Después, el dolor puede convertirse en depresión, lo que generalmente ocurre cuando las formas convencionales de apoyo social cesan y la gente deja de ofrecer ayuda y consuelo, pudiendo surgir la soledad. Finalmente, el superviviente empieza a sentirse menos aquejado, recupera energía y reanuda sus relaciones con los demás. 
A pesar de que no todas las personas viven igual el duelo, ya que su forma de pensar y sentir son completamente diferentes entre ellos, se consideró necesario mencionar las reglas del duelo, las cuales pueden ayudar a cualquier persona a superar y trabajar de una manera mas adecuada su duelo, esto no quiere decir que se sigan al pie de la letra y que todas las reglas les sirvan a todas las personas, pero puede haber algunas que les sirvan a los dolientes, por eso se consideró apropiado mencionarlas.

\subsection{REGLAS DE DUELO}

Estas reglas fueron escritas por la Organización Española de Tanatología y publicadas por Montoya, (2003), (las cuales se encuentran disponibles en red), proponen la manera en que el duelo debe de ser vivido.

\section{REGLA N ${ }^{\circ} 1$}

Las personas no reaccionan igual ante la muerte de un ser querido; como se menciono anteriormente cada persona vive su duelo de manera particular, también influyen factores como la edad de la persona fallecida y el tipo de relación que se tenía con esta.

\section{REGLA $\mathrm{N}^{\circ} 2$}

Disimular el dolor no conduce a nada positivo: bloquea la comunicación con otros familiares que pueden estar atravesando el mismo proceso de duelo. Es normal que el que el fallecimiento de un ser querido provoque dolor, y no es conveniente reprimirlo.

\section{REGLA N ${ }^{\circ} 3$}

Tras la muerte de un ser querido ES NORMAL pensar que el mundo se vuelva caótico e inseguro, es importante saber que toda pérdida conlleva a un cambio y hay que ajustarse a este.

\section{REGLA $\mathrm{N}^{\circ} 4$}

La pérdida de un ser querido no se supera, la persona se recupera de las pérdidas, estas nunca se dejan atrás del todo ya que aunque no duelan siempre en ocasiones recordamos la pérdida y vuelve a doler: como lo suele hacer una cicatriz

El hecho de superar el proceso de duelo no significa olvidar a la persona fallecida, sino aprender a seguir adelante a pesar de que esa persona ya no esta, pero en cualquier momento es posible recordarla con cierta melancolía.

\section{REGLA $N^{\circ} 5$}


Recordar la experiencia (la causa de la muerte o lo que condujo o conducirá a esta). Facilita la integración de la realidad de la pérdida, (todo lo contrario a lo que la gente suele hacer o aconseja).

\section{REGLA N ${ }^{\circ} 6$}

Es importante expresar los sentimientos con amplia libertad.

Según Roccatagliata, S. (2000), llorar es humano y es una reacción normal ante la muerte de un ser amado. Llorar juntos y consolarse es muy importante, porque de esa manera se demuestra el apoyo mutuo, nos demostramos que nos necesitamos unos a los otros.

Por otra parte también se debe de considerar que el llanto no es la única forma de expresión, por lo que no debemos desesperarnos si las lágrimas no vienen, ya que no es la única forma de expresar el dolor.

\section{REGLA N ${ }^{\circ} 7$}

La Institución más importante en la cual la persona puede apoyarse para recuperarse de la pérdida de un ser querido es: LA FAMILIA.

De acuerdo a Kübler Ross. (1983): Una familia siempre rebosa amor y alegría.

\section{REGLA $\mathrm{N}^{\circ} 8$}

Un duelo del que no se habla es un duelo que no se cura; es importante que en cada etapa del duelo se expresen los sentimientos con libertad y no se repriman, ya que de esta manera el proceso de duelo cerrará con mayor rapidez.

Después de haber hablado sobre el duelo y sus etapas, es importante mencionar como se le puede ayudar al doliente a superar este proceso, en el siguiente apartado se mencionan los apoyos tradicionales con los que una persona cuenta, los cuales influyen en su concepto de muerte y en la forma en como viven este proceso, estos pueden ser la filosofía y la religión de cada persona, a continuación se explican mas a detalle.

Como se ha dicho anteriormente es importante vivir el duelo, no se debe permitir que los demás digan como tenemos que actuar, cada persona vive de manera particular sus perdidas y no pueden aconsejar sobre el como vivirlo, es por esto que a continuación se muestra un fragmento que ejemplifica lo importante que es el vivir el duelo y no hacer caso de lo que los demás aconsejan:

\section{CONSEJOS NO SOLICITADOS}

Todo el mundo sabe lo que es mejor para ti, la gente te ofrece palabras de consuelo:

"Sé perfectamente lo que sientes", (Quieres gritarle: "No, no lo sabes, ¿Cómo puedes saber lo que estoy pasando?). 
“Los estas superando muy bien”, (¿Tu que sabes como me siento cuando tu te vas?).

“Tu ser querido vivió lo que tenía que vivir”, (A cualquier edad la muerte es un robo).

"Otros también lo han pasado", (No me importan los demás, en estos momentos quien me importa soy yo).

"Es la voluntad de Dios", (Entonces este rencoroso y vengativo Dios debe ser mi enemigo).

Tu corazón esta destrozado y los demás te ofrecen frases hechas.

ES que ellos también están asustados, se sienten amenazados y molestos, pero comparten tu dolor lo mejor que pueden.

Acepta su solidaridad, pero no tienes por qué seguir sus consejos, puedes decirles sencillamente: "Gracias por venir".

Y luego haz lo que sea mejor para ti.

Earl A. Grollman.

(2000).

\subsection{APOYOS TRADICIONALES AL PROCESO DE DUELO}

Las personas pertenecientes a diferentes culturas afrontan la muerte de manera muy distinta, cada persona tiene su propio concepto de muerte y por lo tanto la forma de afrontar este hecho es muy variable, esto depende de su cultura y costumbres, así como de la religión, es por eso que en este apartado se muestran las diversas costumbres que tienen las personas de acuerdo a su religión, así como los rituales y ceremonias que se practican para afrontar este hecho.

De acuerdo a Valera, (1990), todas las culturas han elaborado rituales que se expresan en prácticas socialmente reguladas de los mitos predominantes en esa cultura. Esos rituales con sus correlatos míticos son esenciales para el trabajo de la elaboración de duelo.

Primeramente se mencionaran las costumbres que tienen las personas dependiendo su religión, esta puede influir mucho, ya que algunos le temen mas a la muerte dependiendo sus costumbres y a otros les pasa lo contrario, es por esto que es necesario conocer por lo menos de manera muy básica y breve las costumbres e ideas de cada religión para que en el momento que al terapeuta le toque trabajar con alguien que tenga otra religión , sepa como manejarlo y que es lo que debe o no hacer para no agredir o irritar al paciente y respetarlo sin hacer ningún juicio.

\section{$\underline{\text { 1.6.1 Religión }}$}


La mayoría de las personas tienen una religión, sin importar cual sea esta influye en la forma de pensar sobre el tema de la muerte, es por esto que se considera importante mencionar de manera muy general las características básicas de las grandes religiones, ya que estas forman parte del concepto ideológico de las personas en cuanto a la vida y la muerte.

Independientemente de tus creencias religiosas, ahora recurre a tu fé. Con fé se pueden comprender y sobrellevar las dificultades que plantean la vida y la muerte. Además, la fé también ofrece la seguridad de saber que la muerte aporta paz y serenidad. ( Wolfelt, ,2003).

\subsubsection{1 $\quad \underline{\text { Catolicismo }}$}

La figura principal de la religión cristiana es la figura de Jesucristo, quien ante todos los cristianos, ha sido tanto humano como ser divino.

Los cristianos tratan de seguir las enseñanzas de Jesucristo escritas en el Nuevo Testamento.

Creen que a través de la muerte de Jesús la humanidad se ha reconciliado con Dios, y a través de su resurrección, el mundo esta a salvo de la muerte ya que a todos aquellos que crean en él tendrán la vida eterna, es decir los cristianos creen en la resurrección.

Los pacientes terminales, en los últimos momentos de su vida pueden desear que un sacerdote este presente para orar con él y la familia del moribundo, esta oración, desde la creencia cristiana, sirve para encomendarle a Dios el cuidado del paciente y para que la familia de este reciba fuerzas para superar este hecho.

Ante la situación por la que pasa el paciente terminal es común que se pida la presencia de un sacerdote quien orará por él y encomendará al moribundo con Dios, le dará la extremaunción, cumpliendo así con el último sacramento, y finalmente el paciente se arrepentirá de sus pecados.

Desde el punto de vista no ortodoxo, los cristianos no tienen ninguna objeción religiosa para que se lleve a cabo una autopsia ni para la donación de órganos para transplante.

\subsubsection{2 $\quad$ Judaísmo(LatradiciónHebrea)}

El judaísmo es una de las religiones más antiguas de la historia.

El judaísmo tiene como característica principal: el monoteísmo radical, es decir, la creencia de que un solo Dios creo el universo y es él mismo que los gobierna.

\section{CREENCIAS SOBRE LA MUERTE}


Hay dos consideraciones básicas en las leyes del luto y el duelo, una se relaciona con la regla de honrar el cuerpo del fallecido, tratándolo con respeto y cuidado, la otra consideración tiene que ver con el respeto al vivo, preocupándose por su bienestar.

La ley judía ordena no ignorar los sentimientos de los dolientes y también ordena el procurar $\mathrm{y}$ aligerar sus necesidades.

Otro aspecto importante es el concepto de la resignación, se enfatiza el hecho de que a pesar de lo devastadora que es la pérdida, es nuestro deber seguir adelante. La muerte está fuera del control del hombre, sin embargo si es posible tener cierto control en cuanto a la manera en cómo reaccionamos ante ella y la manera en como decidimos vivir nuestra vida.

Los judíos tienen oraciones especiales para momentos de enfermedad y oraciones para cuando se acerca la muerte, pero en el Judaísmo no es necesario que un intermediario proporcione los últimos ritos, por lo tanto el judío que esta agonizando puede solicitar o no, ver al Rabino.

Después de la muerte una de las costumbres es dejar al muerto por espacio de 20 a 30 minutos sobre la cama y posteriormente bajarlo al suelo con sumo cuidado y con gran respeto, deben enderezarse sus miembros y acomodarle sus pies hacia la puerta de la habitación, debe estar completamente desnudo y colocarle una almohada o un a piedra bajo la cabeza para que este ligeramente elevada.

Alma y cuerpo se despiden definitivamente en el momento del entierro, para que el alma pueda partir, por esto es necesario acelerar el momento del entierro.

Dependiendo del sexo del difunto, un compañero o compañera preparan el cuerpo en presencia de 3 miembros de la comunidad.

Es necesario procurar que el cadáver sea enterrado el mismo día de la muerte o después de no más de 24 horas, a excepción de días festivos.

La religión prohíbe que los órganos sean donados después de la muerte, ya que una de sus creencias es el poner el cuerpo completo a la tierra después de morir.

\section{REGLAS PRINCIPALES DESPUES DE LA PÉRDIDA}

Se cubren los espejos de la casa, ya que tienen la creencia de que el alma ronda por la casa y sería difícil para ella verse reflejada sin su cuerpo; algunas personas acostumbran cubrir los retratos. 
Otra de las razones por las que se cubren los espejos es porque el doliente no debe de preocuparse por su aspecto físico.

Se colocan vasijas con agua en las ventanas, para anunciar que ha habido una muerte en casa.

Los dolientes se sientan a no más de $30 \mathrm{cms}$ del suelo, el significado de esta costumbre es el percatarse que la vida no es la misma y que el doliente quiere estar más cerca de la tierra en donde su ser querido yace ahora.

Significa también que el doliente esta en un momento bajo de su vida.

\subsubsection{Hinduismo}

Según Valera (1990), El código ético hindú, presupone la supervivencia del alma y su trasmigración (samsara), según la bondad o maldad de las acciones de la existencia previa, es la ley del Karma la que premia o castiga de acuerdo a como se te haya comportado la persona en vida.

De acuerdo a la doctrina de los Upanisads, el hombre tiene 2 caminos que puede seguir después de su muerte, la primera es la reencarnación y la segunda es el camino de la liberación, este último camino es el de los Dioses.

El Hinduismo menciona que el alma no sufre cambio alguno, es el cuerpo el que cambia.

Para el hinduista el reencarnar no es un premio, no lo ven como una segunda oportunidad como otras religiones, ellos lo ven como algo pesimista ya que según ellos la vida es un valle de lágrimas, a pesar de eso el hinduista ve la muerte como un momento en donde se reinicia otro ciclo, el cuerpo cesa sus funciones pero la vida continua.

El hinduista, no le ve problema a las transfusiones de sangre, ni al transplante de órganos, no les agrada la idea de la autopsia pero la realizan si el forense la solicita, y se espera que el cuerpo sea liberado lo mas pronto posible para llevarlo al funeral y cremar el cuerpo (en la mayoría de los casos los cuerpos se creman, casi no hay entierros).

Cuando los enfermos están en fase terminal, los familiares les leen parte de algún libro sagrado como el Bhagavad Gita.

Muchas veces los pacientes, hindúes, solicitan la presencia de un sacerdote Hindú para que le ayude a entender la muerte de una manera filosófica, inclusive puede atar al cuello o a la cintura del paciente un hilo como bendición. 
El paciente Hindú puede solicitar ser acostado en el suelo para estar más cerca de la madre tierra al momento de su muerte y así facilitar una nueva encarnación. Después de la muerte los parientes lavan el cuerpo y lo visten con ropa nueva antes de sacarlo del hospital y posteriormente cremarlos.

\subsubsection{4 $\quad \underline{\text { Budismo }}$}

El Budismo es la doctrina expuesta por Siddharta Gautama Buda.

Religión no teísta, el Buda es un hombre no un Dios y muere a los 80 años.

Para el Buda, el ciclo de nacimientos y muertes es producto de la ignorancia acerca de la verdadera naturaleza de este mundo. Valera, (1990).

El Budismo menciona que el ser humano se entiende como una manifestación sumamente compleja, que son impulsados por una fuerza llamada Karma, esta fuerza es la que rige el flujo continuo de la vida.

De acuerdo al Karma el hombre puede renacer en cinco estadios:

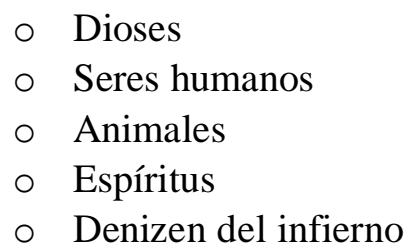

El nacimiento del ser humano esta casi en lo alto de esta escala, sin embargo puede descender, o mediante la iluminación llegar a la meta final (Dioses) y así liberarse de otra reencarnación.

Como los budistas creen en la reencarnación, deben aceptar la responsabilidad acerca de la forma de ejercer su libertad, dado que las consecuencias afectan vidas posteriores.

Los Budistas hacen mucho énfasis en no matar por lo que no acepta el aborto ni la eutanasia, pero si aceptan las transfusiones de sangre y transplantes de órganos ya que en sus creencias es fundamental ayudar al prójimo.

En los moribundos puede rechazarse la administración de medicamentos que puedan obnibular la conciencia, es decir medicamentos que interfieran con la capacidades para meditar, especialmente porque los pacientes moribundos meditan sobre su propia muerte, ya que tienen la creencia de que esto ejercerá influencias en la siguiente reencarnación. 
Los budistas por lo general creman a sus muertos con el fin de que su alma pueda ser liberada del cuerpo para entrar en otro cuerpo, es decir tener otra existencia.

Después de que el médico declara al paciente "como muerto", el cuerpo es envuelto en una sábana lisa, sin ningún símbolo, el tiempo del depósito depende del calendario lunar y puede variar de 3 a 7 días.( Behar, 2003).

La mayoría de los budistas estarían satisfechos de poder proporcionar el nombre de la persona a la que se debe llamar cuando el enfermo muera.

En conclusión, todo lo anterior sirve para poder explicar algunas de las reacciones que puede tener el enfermo terminal y su familia, dependiendo sus creencias religiosas, ya que esto influye para que el paciente tenga una agradable aceptación a la muerte o un miedo petrificante, es importante que el psicólogo, tanatólogo y las personas encargadas de atender a pacientes terminales tengan conocimiento sobre las distintas ideologías religiosas que existen, para poder entender ciertas reacciones que son producto de estas creencias, también es importante considerar que por ningún motivo hay que tratar de cambiar al paciente de ideas, o de imponerles creencias religiosas, ni juzgar al paciente por las suyas, porque como dice Speck (1978), es necesaria una actitud sensible por parte de aquellos que cuiden de los moribundos y de su familia para que puedan apoyar y ayudar a la persona como ser completo más que poner una escrupulosa atención a los detalles de un rito religioso.

Independientemente de la religión tanto la persona terminal como su familia, sufren ante la pérdida.

Cualquier patrón religioso influye en el pensamiento y conducta tanto del enfermo terminal como de su familia, lo cuál puede ayudar a que se acepte este hecho o se le tema más a la muerte.

La religión solamente es un recurso que como se menciono anteriormente puede incrementar o decrementar el miedo a la muerte; es posible que la religión proporcione una base filosófica para afrontar momentos de oscuridad y desesperación.

En el siguiente apartado se mencionaran algunos autores y se revisara de manera breve su filosofía de muerte, para ver como el concepto de muerte ha cambiado con el tiempo y como muchos de los conceptos aun siguen vigentes. 


\subsubsection{Islamismo}

\section{EL CREDO MUSULMÁN}

El credo musulmán es muy simple, todo él esta contenido en la Sahada, la profesión de fe inicial del Corán. Se resume en cinco artículos de fe, a los que es preferible llamar <<actos de fe> $>$

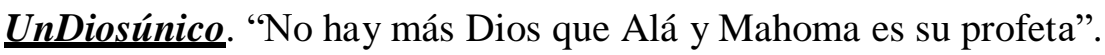

Anunciadoporlosprofetas. Todos los profetas vienen de dios, es una obligación creer en todo lo que ellos dijeron en su nombre.

Manifestadoporlosángeles. Por debajo de los profetas hay otros servidores de Alá: los ángeles. El término que los designa: "ruh", equivale a soplos de dios.

El Islam, dada su condición de Religión natural (Din al Fitra), permite expresar estados de ánimo, siempre que sean en forma moderada: llorar-gemir-gritar, pero advierte contra los excesos. El realismo que caracteriza a la Doctrina Islámica hace de la muerte un escalón difícil, una especie de sendero que conduce hacia la gloria, en otras palabras, la muerte para un musulmán es un suceso triste y penoso, pero no catastrófico.

El llanto por la muerte de un ser querido es una manifestación sincera e innata de los sentimientos, por lo tanto es imposible contenerlo totalmente, pero sí es posible aliviarlo y moderarlo. Por otra parte, el Islam, dada su condición de Doctrina basada en la justicia y la equidad, condiciona la salvación a la obra y actitud personal de cada ser viviente que es, en definitiva, la suma del bien y del mal, realizada a lo largo de su vida mundana. Ser musulmán no es un salvoconducto hacia el paraíso.

Después de la muerte física, habrá un juicio y un veredicto, luego una condena justa o un premio merecido, y en último caso el Soberano tendrá la última palabra, confirmar la condena, rebajarla, u otorgar su amnistía a quién Él designe.

La comunidad del fallecido tiene la obligación colectiva de despedir ritualmente a los muertos, a los que se anticiparon hacia la otra vida. Este adiós debe abarcar el tiempo anterior, durante y posterior al hecho de la muerte.

Es obligación de los musulmanes el realizara testamento, este documento debe comprender dos hechos importantes, las deudas a favor y en contra, así como la división de su herencia, garantizando la equidad entre sus herederos, de acuerdo a los preceptos islámicos establecidos.

La esposa del fallecido deberá aguardar inexorablemente un período de espera antes de volver a casarse, con el fin de asegurarse no estar embarazada. En caso de estarlo y, si 
llegare a dar a luz, tendrá idéntico derecho que sus hermanos en la herencia de su padre. Además, este período de tiempo le servirá para meditar su futuro y el de su familia.

El período de espera antes de contraer matrimonio, fue establecido en el Generoso Corán $2 / 24$ y, es de cuatro meses y diez días, a contar desde la muerte de su esposo.

\section{EL MOMENTO DE LA MUERTE}

En el momento inmediatamente posterior al óbito (o sea último suspiro, que es cuando el alma abandona al cuerpo), después de pasados los primeros minutos de dolor por parte de los presentes, alguien de sus allegados deberá subir la mandíbula del fallecido, luego pasar la mano de arriba hacia abajo sobre sus ojos para cerrar sus párpados y cubrir el cadáver con una prenda o trozo de tela.

Informar de su muerte.

Anunciarla, lo más rápido posible, de acuerdo a las formas y circunstancias del medio en que se vive, a través de diarios, radios o simplemente por medio de los miembros de la Comunidad.

Es necesario conocer si el fallecido habría comunicado sus últimos deseos a su cónyuge o a sus hijos o a cualquier otra persona de su conocimiento, referente a su entierro o a cualquier otra diligencia a realizar. Todo tipo de deseo factible de cumplir, no estando en contra de los principios islámicos, deberá intentar realizarse, por ejemplo ser enterrado al lado de sus parientes, si ellos están inhumados en el cementerio de la ciudad donde éste murió. Trasladar el féretro hasta otra ciudad, va en contra de nuestros preceptos, por lo tanto es aconsejable enterrar a un musulmán en el cementerio de la localidad donde murió. Hacer de su tumba un monumento tampoco es aprobado, ni construir una mezquita o algo fastuoso sobre ella.

\section{PREPARATIVOS PARA EL ENTIERRO}

Obtenido el certificado de defunción y el permiso de inhumación, se procederá a preparar al fallecido según el ritual islámico, que consiste en:

$\varnothing \quad$ Bañar al fallecido (Ghusul).

$\varnothing \quad$ Amortajarlo (Takfín)

$\varnothing \quad$ La ceremonia religiosa: Oración fúnebre y honras.

$\varnothing \quad$ Sepultarlo. 


\section{LA ABLUCIÓN FUNERAL (GHÚSUL)}

Bañar al fallecido antes de proceder a amortajarlo enterrarlo es un precepto Islámico, y el realizar es una obligación de la Comunidad (Fard Kifaya), es decir, si alguien de la Comunidad lo cumple, el resto quedará exento.

El objetivo del baño es hacerlo presentable ante aquellos que lo despedirán. No obstante, siendo un hecho ritual, tendrá que seguir las reglas Islámicas que se enumeran a continuación.

\section{¿QUIÉN DEBERÁ OCUPARSE DEL BAÑADO?}

$\varnothing \quad$ Ser una persona digna de confianza (para revelar lo que viera de las intimidades físicas del fallecido).

$\varnothing \quad$ Ser del mismo sexo del fallecido (excepción hecha para el cónyuge y para los de corta de edad).

$\varnothing \quad$ Ser conocedor de las reglas rituales fúnebres.

\section{EL AMORTAJAMIENTO}

Amortajar a un musulmán es Fard Kifaya (deber de la Comunidad). Quien lo realiza exime al resto de hacerlo.

La mortaja es simplemente una prenda o trozo de tela de extensión suficiente para envolver todo el cadáver, preferentemente de color blanco.

La Tradición profética recomienda utilizar tres paños blancos (sudarios), uno tras otro, para el hombre, y dos paños más tres elementos complementarios para la mujer (lo que veremos más adelante). Pero advierte contra el encarecimiento y la ornamentación. Estos paños, además de ser nuevos, serán de tela normal y corriente (no serán de seda ni cualquier otro tejido costoso).

\subsection{2 $\underline{\text { Filosofía }}$}

El morir comienza desde el momento de nacer. (Valera 1990).

El hombre es el único ser viviente que tiene conciencia de la muerte y, por tanto, le teme. Se nace sin conciencia de que algún día se tiene que morir, pero pronto se advierte de manera creciente de que la vida tiene un ciclo: nacer, crecer, declinar y morir. 
De acuerdo al mismo autor la vida es un viaje. La travesía es diferente para cada hombre, pero el destino es el mismo ya que nada dura, todo lo que vive, muere.

Haga lo que haga el hombre para tratar de olvidarse que debe morir, el proceso sigue adelante.

Por otra parte según Fernández (2000) es importante mencionar que solo se consideran algunos autores, los cuales serán vistos de manera cronológica.

Desde el punto de vista filosófico la muerte ha tenido varios puntos de vista, no se hará una revisión histórica de los pensamientos de los grandes filósofos ya que sería extenso pero si se retoman pensamientos de algunos filósofos y se realizara de manera muy general:

HERÁCLITO: El habla sobre el "Devenir eterno", la existencia es un espacio entre dos extremos: el nacer y el morir.

SÓCRATES: El dice que la muerte no es un acontecimiento trágico si el hombre fue feliz y busco la sabiduría, Sócrates dice: "El hombre vive para ser feliz" y "La vida es una continua búsqueda de la sabiduría”.

PLATÓN: Platón considera que filosofar es prepararse para morir, pero prepararse para morir no es otra cosa que pensar en la vida mortal en que vivimos. El saber que vas a morir es lo que hace que la vida sea única e irrepetible. Todas las tareas y cosas que hacemos o ponemos en nuestra vida lo utilizamos para resistir ante la muerte. Es la conciencia de la muerte la que convierte la vida en un asunto muy serio para cada uno.

EPICURO; Él trata de convencernos de que no hay que tenerle miedo a la muerte si reflexionamos sobre ella. Epicuro afirma que los verdugos y horrores infernales no son mas que fábulas que no deben asustarnos a la hora de pensar en la muerte ya que nunca vamos a coexistir con la muerte, si estamos nosotros no puede estar la muerte y al contrario.

SARTRE (1905-1980) El pensaba que la muerte impide que una persona siga realizando sus propias posibilidades. En el fondo la muerte reduce la propia existencia a lo que es realmente: una pasión inútil.

MARTINHEIDEGGER (1889-1970) es bien conocido por su afirmación, contenida en EL SER Y EL TIEMPO, de que el ser es la libertad hacia la muerte. La posición de Heidegger implica que la muerte es, una amenaza: la amenaza de la no existencia hacia la que todos nos dirigimos.

Por otra parte se considera importante retomar las ideas de Yalom y Frankl, ya que aunque no sean filósofos es necesario retomar sus conceptos para complementar un poco más esta investigación, también se retomaron ya que las ideas que ellos manejan se consideran importantes para el giro de la investigación ya que ambos tienen ideas humanistas. 
Para Yalom (1984), es importante que se incorpore la muerte a la vida ya que de esta manera los individuos se liberan de las trivialidades sofocantes, viven de una manera mas intencional y auténtica. La conciencia plena de la muerte provoca a veces un cambio radical en la persona.

Por otra parte el autor Frankl (1979), creador de la Logoterapia dice que las personas deben de encontrar el sentido a su propia vida ya que la vida no tiene sentido por si sola, dice que todo ser humano tiene la necesidad de tener una vida con sentido, para él todo ser humano es único por lo que el sentido de vida puede variar de un hombre a otro.

Frankl (1979), afirma que el hombre es un ser caracterizado por su singularidad, su irrepetibilidad, su relacionalidad y su finitud. El hombre es responsable de su propia finitud. Toma en cuenta las limitaciones que sean orientadas incluso a encontrar un sentido en la tragedia.

Después de haber mencionado lo que es la muerte desde un punto de vista biológico, su proceso así como la manera en como la filosofía y la religión influyen en este concepto y en el como un paciente terminal afronta este proceso, es importante mencionar que es el paciente terminal y cuales son sus necesidades, así como la forma en como se le puede dar un mejor trato, respetando siempre sus derechos y haciendo que sus últimos días estén llenos de calidad, todo esto se tratara en el siguiente capitulo.

\section{CAPITULO 2}

\section{EL PACIENTE TERMINAL Y SUS NECESIDADES}

... Lo más doloroso para Iván Ilich era que nadie tuviese compasión de él,

Tal como habría querido: en algunas ocasiones, después de largos suplicios, Lo que más deseaba, por mucho que le avergonzase reconocerlo,

Era que alguien lo tratase con cariño, como si fuese un niño enfermo. Quería que le hiciesen caricias, le besaran y llorasen con él como se acaricia y

Consuela a los niños. Sabía que era un grave personaje de barba entrecana, $Y$ por eso era imposible, pero, a pesar de todo, sentía esos deseos.

LEON TOLSTOI, La muerte de Iván Ilich.(1975).

\subsection{EL PACIENTE TERMINAL}

Empezaremos este capítulo definiendo lo que es el paciente terminal. El paciente terminal es una persona que está en una situación de muerte próxima e inevitable, por la presencia de una enfermedad avanzada, progresiva e incurable y ante la cual hay falta de posibilidades razonables de respuesta a un tratamiento específico, o sea la muerte es inminente. 
Según Figueroa (1999), el paciente terminal es aquel en quien la inminencia de la muerte es tenida como cierta y predecible a corto plazo, es decir de 6 meses a un año, debido a que su enfermedad ya no pudo ser curada, a pesar de haber recibido el tratamiento adecuado.

Según Rebolledo (2000), La Asociación Mexicana de Tanatología considera como paciente terminal a aquella persona que no le queda más de 1 año de vida.

Según Gil (1998), En la situación de enfermo terminal concurren una serie de características que son importantes, no solo para definirlas, sino también para establecer adecuadamente la terapéutica. Los elementos fundamentales son:

a Presencia de una enfermedad avanzada, progresiva e incurable.

a Falta de posibilidades razonables de respuesta al tratamiento especifico.

a Presencia de numerosos problemas o síntomas intensos, múltiples, multifactoriales y cambiantes.

a Gran impacto emocional en pacientes, familia y equipo terapéutico, muy relacionado con la presencia, explícita o no, de la muerte.

De acuerdo a Vincent (1992). El moribundo es alguien por quien nada se puede hacer para impedir que muera, pero esto no obstaculiza para que se les pueda apoyar a tener una mejor calidad de vida y ayudarlos a cubrir sus necesidades, las cuales serán mencionadas más adelante.

Desgraciadamente en algunas instituciones o inclusive la propia familia ve a los P.E.T como una carga, como intrusos, es necesario considerarlos como seres humanos y hay que tratarlos como tal, no solo son un caso clínico, ni un número de cama, son personas que tienen necesidades y derecho a ser respetados, comprendidos y amados.

Ante la situación por la que pasan las personas con enfermedades terminales, se plantea la posibilidad de mejorar su calidad de vida con una asesoría especial en la cual se puedan detectar sus necesidades.

Es importante considerar que no todos los P.E.T. reaccionan del mismo modo ante una enfermedad terminal ya que influyen varios factores como la personalidad del enfermo, su edad, etc, esto se explica a continuación. 


\subsection{FACTORES QUE INTERVIENEN EN EL MODO DE REACCIONAR DEL PACIENTE FRENTE A LA ENFERMEDAD.}

Cada Individuo cuando pierde su estado de bienestar que le proporciona su salud trata de encontrar una significación a su enfermedad según sus vivencias que haya tenido anteriormente, sus conceptos sociales, morales, religiosos, según su edad, el sexo, la raza, así como su constitución y su personalidad, todos estos factores influyen también no solo en la forma en como reaccionan al saber que tienen una enfermedad terminal, sino también en la forma en como elaboran el duelo.

Según Fernández (2000), algunos pacientes consideran su enfermedad como una prueba para valorar su resistencia y como una prueba para soportar el sufrimiento.

Otros pacientes la consideran como un castigo a su actitud y comportamiento no muy adecuado para que les permita reflexionar y adoptar una nueva actitud frente a su familia y demás personas.

O es considerado como un hecho natural ya que cualquier Individuo está propenso a sufrir alguna enfermedad en su convivencia con los riesgos de la naturaleza, su medio ambiente en el cual vive.

Según Fernández (2000), toda persona cuando enferma experimenta una serie de reacciones emocionales ante la enfermedad que tanto el médico, como el personal de salud, la familia y el psicólogo deben considerar. Existen muchos factores que intervienen en esas reacciones, entre los que destacan la personalidad del paciente, su edad, el tipo de enfermedad, etc., los cuales se explican a continuación.

\subsubsection{PERSONALIDAD DEL ENFERMO}

La personalidad del paciente influirá en los mecanismos de defensa que utilizará. Así, por ejemplo, las personas dependientes utilizarán la regresión a estadios precoces del desarrollo, y dirán: ¡Ayúdeme!, mientras que los que son muy independientes correrán el riesgo de negar la gravedad de la enfermedad y otros llegarán inclusive al aislamiento.

Fernández (2000), clasifica a los pacientes en 4 grupos basándose en la personalidad de estos:

El paciente dependiente: Se caracteriza por la necesidad de ser cuidado como un niño pequeño, lo que determina el temor de ser abandonado. Hay sentimientos de inutilidad y miedo de ser abandonado, por lo que exige cuidado y protección. Como las necesidades son tan grandes, difícilmente se les puede satisfacer más que momentáneamente y con 
frecuencia, se lamenta de la falta de cuidados hacia él por parte de los demás y critica la conducta del médico, las enfermeras y familiares.

El paciente ordenado: Este paciente teme que la enfermedad debilite su control ante todas las situaciones. Es una persona que cree poder controlar su enfermedad, por eso pregunta insistentemente acerca de ella. Es una persona que por lo general escribe en un cuaderno todos los medicamentos que toma, a que hora los debe de tomar y desde cuando los esta tomando.

El paciente demandante: Su conducta con el personal sanitario se caracteriza por relacionarse con él de manera cálida, afectivamente Intensa, muy personal, esforzándose en agradar para atraer la atención y admiración. Es una persona que exige toda la atención y se enoja cuando observa que la personal médico atiende a otros pacientes.

El paciente orgulloso: Es aquel que siente que es importante para todos los demás. Es una persona que no acepta su vulnerabilidad. Es común que este tipo de paciente se esfuerce en la medida de sus posibilidades en ser tratado por los médicos más competentes y prestigiosos. Buscan tener relaciones amistosas o de gran confianza con los médicos y el personal de salud.

\subsubsection{EDAD DEL PACIENTE}

Dependiendo de la edad del paciente es como va a reaccionar ante su enfermedad y ante su próxima muerte, Canales y cols. (2003) hacen la siguiente clasificación por edad: en el caso de los niños menores de 5 años suelen ver la muerte como algo reversible, es decir si algo muere solo es cuestión de tiempo para que "vuelva a cobrar vida", tal y como ocurre en las caricaturas.

Entre los 5 y los 7 años, los niños comienzan a entender que la muerte es irreversible, universal, o sea que todas las cosas que están vivas inevitablemente tienen que morir, también comprenden que todas las funciones de la vida terminan con la muerte.

Aún más, en esta etapa la muerte adquiere una connotación emocional mucho más intensa para el niño, que comienza a temer la muerte de sus seres queridos. El hecho de morir se tiñe en su mente con las ansiedades de su cultura, el niño de esta edad no cree que pueda morir, pero si reconoce a la muerte como una clara experiencia humana. 
Ya a la edad de 8- 10 años acepta que todos morirán, inclusive el mismo.

No todos los autores concuerdan en cuanto al grado de conciencia real que tienen los niños sobre las diferentes dimensiones de éste acontecimiento, y prefieren hablar de etapas no tan marcadas y otorgar un poco más de flexibilidad en el desarrollo de la elaboración de un concepto tan complejo como lo es la muerte.

De acuerdo a Gómez (2003), las etapas por las que un niño pasa se resumen en lo siguiente:

$1^{\circ}$ etapa en que el niño es incapaz de comprender el problema de la muerte.

$2^{\circ}$ etapa en que la muerte se relaciona con una ausencia provisional.

$3^{\circ}$ etapa en que la muerte se integra en una imagen del mundo mediante elementos culturales.

$4^{\circ}$ etapa en que el niño elabora la idea de su irremediable destrucción.

Cuando es un niño quien va a morir hay que considerar que también ellos quieren y deben saber que ocurre cuando están frente a la muerte, los niños suelen buscar la respuesta en sus padres quienes, en ocasiones, no confían en su capacidad de entender la situación y, creyendo protegerlo, lo envuelven en un manto de fantasía. Nuestra cultura nos enseña a proteger a los niños para que no piensen ni hablen del tema de la muerte, lo único que ocurre es que el niño reprimirá sus temores, miedos y dudas al ver que los adultos "odian hablar sobre ese tema"; callará para protegerlos.

Un niño también requiere expresar sus emociones, sus temores, sus inquietudes; solo requiere de un adulto capaz de escucharlo y saber explicar con palabras simples y sensibles qué es lo que ocurre, sin mentiras.

En el caso de los adolescentes; ven la muerte como algo irreversible pero ajeno a ellos, tienen pensamientos de que la muerte es solo para los viejos. Cuando los adolescentes se encuentran cara a cara con la muerte reaccionan de maneras sorprendentes y contradictorias, elevando algunos las cuotas de misticismo o religiosidad. O bien otros jóvenes enfermos optan por negar su condición y hablan como si se fuesen a recuperar aunque tienen la certeza de que eso no será así.

En el caso de los adultos; en esta etapa las personas están desarrollando sus planes de vida, por lo que la muerte lo ven como algo lejano aunque inevitable. El hecho de pensar en morir a causa de una enfermedad les enoja, la aparición de una enfermedad catastrófica se vivencia como algo muy frustrante y difícil de llevar debido a la imposibilidad de conquistar las metas anheladas. Su trabajo no ha valido de nada y esta injusticia lo enfurece, es el paciente más conflictivo y el más lábil emocionalmente. A esto se suma la dificultad del personal que 
por lo general tiene la misma edad que el paciente para tratar asertivamente a un desahuciado de su mismo grupo.

Finalmente los ancianos quienes ven la muerte con menor ansiedad, ya no les da miedo el morir sino al sufrir y dejar asuntos pendientes, tanto familiares, sociales, legales, etc.

La gran tarea del anciano es reorganizar sus pensamientos y sentimientos para aceptar su propia muerte. Los problemas físicos impiden que el anciano vea las cosas de un modo alentador y placentero, al contrario, esto hace que el anciano se vea aun más cerca del fin de su vida. Si se trata de un anciano con un autoconcepto estable y satisfactorio, y si a lo largo de su vida a estado rodeado de sus seres queridos, logrará concebir de manera más tranquila su propia muerte.

En esta investigación se va a trabajar con personas adultas y ancianas, ya que en el área de medicina interna del hospital en donde se realizó la presente investigación, predomina este tipo de población.

\subsubsection{TIPO DE ENFERMEDAD}

Las enfermedades del corazón, como las arritmias o las enfermedades de las arterias coronarias, producen mucha ansiedad y el miedo ante la muerte es constante. La insuficiencia respiratoria o la dificultad para respirar producen un estado de ansiedad agudo que se resuelve cuando la situación revierte. El diagnóstico de cáncer produce miedo y las enfermedades de transmisión sexual, como el SIDA, producen, con frecuencia, además de miedo, sentimientos de culpa. Las enfermedades crónicas, como la insuficiencia renal, artritis reumatoide o diabetes mellitus, producen diversas respuestas que van desde su aceptación hasta su negación, rechazando el tratamiento.

Ya teniendo definido lo que es un paciente terminal y ver los diferentes factores que influyen en la forma de reaccionar ante el diagnostico, es importante ver de que manera se les puede asesorar y acompañar para que tengan una mejor calidad de vida, en el siguiente apartado se explica esto.

\subsection{ASESORAMIENTO A ENFERMOS TERMINALES}

Asesorar a una P.E.T, es acompañarlo y recorrer con él el trayecto hasta su muerte.

Este tipo de asesoramiento suele estar basado en el modelo propuesto por Kübler-Ross (1975), y otros investigadores quienes consideran que el paciente terminal suele pasar por una serie de fases: negación, ira, negociación, depresión y aceptación, como se mencionó en el capítulo I. 
Si los pacientes cuentan con el apoyo de los familiares y un asesoramiento profesional adecuado, pueden llegar a aceptar su muerte y morir con serenidad.

Los enfermos terminales y sus familiares sufren un proceso de desolación. A pesar de que esta experiencia varía según las sociedades y las personas, sus aspectos básicos parecen ser universales y biológicos. Hoy en día el asesoramiento se centra en ayudar a los pacientes y a sus familiares a no reprimir sus emociones.

La etapa más difícil para el paciente y su familia es cuando el paciente empieza a estar en estado de agonía o dolor intenso, aquí el miedo a morir se hace más fuerte y se pierde la esperanza de vida.

La palabra agonía se deriva de la palabra griega agon, que etimológicamente significa 'lucha'.

Por tal motivo la palabra agonía significa la lucha que se desarrolla entre la vida y la muerte, misma que de antemano se encuentra resuelta a favor de la última, evidentemente.

Hay muchas cosas que se pueden hacer para confortar a un paciente terminal agonizante, cosas sencillas, detalles que pueden hacer que sus últimos momentos sean más llevaderos.

A continuación se presentan algunas cosas que se pueden hacer para un enfermo terminal según:*Cacoub (1992):

-Permitir que el enfermo diga lo que quiere y que tenga control de lo que quiere hacer. -Intentar que la familia y/o amigos estén cerca siempre.

-Intentar arreglar que su casa y cosas personales e importantes para el paciente sean cuidadas.

-Tener un registro de todos los que le llamen, visiten o contacten de cualquier modo, para que de esta persona se sienta querido.

-Darle un diario al paciente o una libreta para que pueda escribir sus pensamientos. -Enfocarse en cualquiera de sus inquietudes, sin importar lo insignificante que puedan parecer.

-Traerle su música o literatura favoritas al enfermo, (revistas, libros, periódico, etc.)

-Asegurarse que el enfermo tenga acceso a las cosas que necesite, cuando las necesite

-Leerle al paciente

-Abrazar al paciente

-Proporcionarle sábanas, mantas, juguetes u objetos que el paciente anhele.

Enfocarse en las quejas del paciente

-Tomar en serio sus quejas de dolor o incomodidad

-Llevar al paciente a dar un paseo cuando sea posible

-Escucharlos 
Estas son sólo algunas de las cosas que pueden hacerse para permitirle a un paciente terminal disfrutar sus últimos momentos...lo demás que se puede hacer depende principalmente de uno mismo, y del enfermo.

Hay experiencias que son comunes tras el fallecimiento de un ser querido, y éstas se pasan de forma distinta en cada persona. No se debe permitir que otras personas digan cómo uno 'debe' o 'no debe' sentirse.

Según Wolfelt (2003), es normal y apropiado sentirse bien al morir un ser querido: 'Sufrió tanto, de verdad me alegra que se haya terminado por fin!!!. Asimismo, es normal llorar a la persona, especialmente tras muchos años de estar juntos.

Probablemente llegue a darse el caso de necesitar a un consejero o un especialista similar, y si este es el caso, debe acudirse a él cuanto antes.

Las personas frecuentemente niegan o bloquean los sentimientos dolorosos, pero no hay forma de evitar sentir el proceso de duelo. Es necesario, entender lo que se siente y hacer cosas que expresen externamente los sentimientos: Funerales, servicios de memoria, visitas al cementerio, comidas, soltar globos llenos de helio...estos rituales son significativas formas de expresar y tratar con la tristeza de un ser querido.

Es necesario además, en todos los casos, ayudar a la persona que sufre la pérdida de un ser querido, a evaluar la situación y sus sentimientos, pues reprimir todo lo que tiene dentro puede causar problemas psicológicos en el futuro.

$1 *$ Niña que murió de leucemia y dejó evidentes sus necesidades durante el desarrollo de su enfermedad a través de un diario el cual fue publicado.

Lo primero que hay que hacer para recibir una terapia de apoyo para sobrellevar la pérdida de un ser querido es, obviamente, encontrar el terapeuta indicado. Hay que escoger a un terapeuta que pueda llevarse bien con uno, pues la calidad de la relación es vital para el éxito de la terapia. El terapeuta debe estar dispuesto a contestar cualquier duda que se tenga, y es normal que uno sienta ansiedad antes de verlo por primera vez, pero él debe tener la habilidad de calmar.

Es necesario encontrar un terapeuta que esté dispuesto a escuchar cuidadosamente y explorar los aspectos del problema, no uno que ofrezca una solución rápida pues usualmente éstas son superficiales. Es importante no tener una relación personal o social con él antes de que se inicie la terapia, y se debe confiar en los instintos de uno para encontrar uno adecuado.

Independientemente de tener o no un terapeuta que pueda ayudar al paciente terminal es importante no olvidar que aunque este tipo de personas estén llegando al cierre de su ciclo vital, aun son personas y como tales tienen derechos, los cuales deben de ser respetados por 
los seres queridos, el personal de salud, el o los terapeutas y todos las personas allegadas al paciente, estos derechos son los siguientes.

\subsection{DERECHOS DEL ENFERMO TERMINAL}

De acuerdo a Jaramillo, (2001), el P.E.T, tiene varios derechos los cuales se mencionan a continuación:

1. Derecho a mantener hasta el final de sus días la misma dignidad y auto valor a los que ha tenido derecho en vida.

2. Derecho a obtener información veraz, franca y completa acerca de su diagnóstico, opciones de tratamiento y pronóstico. Según Behar (2003) es deseable informarle al paciente la verdad sobre su enfermedad, ya que la mentira es una traición que atenta contra la dignidad de la persona, genera recelo y desconfianza y evita una actitud realista y madura además resta dignidad al enfermo. Si se sabe la verdad sobre el diagnóstico será mas fácil trabajar con el paciente terminal para que este tenga una mayor aceptación y su ansiedad sea controlada.

3. Derecho a participar en las decisiones referentes a su cuidado y a aceptar o rehusar drogas, tratamientos o procedimientos.

4. Derecho a expresar sus deseos en lo referente a las circunstancias que rodearán su muerte, y a que estos sean respetados por familiares y médicos.

5. Derecho a elegir entre las opciones disponibles para morir y, conforme a ello, a que ni se le acelere ni se le posponga la muerte, lo cual incluye el derecho a no ser resucitado.

6. Derecho a conservar un sentimiento de esperanza, lo cual no equivale a que se le creen falsas expectativas.

7. Derecho a beneficiarse de las alternativas humanitarias existentes para su cuidado y a evitar la frialdad que con frecuencia acompaña la aplicación de la creciente tecnología en los lugares diseñados para casos agudos o críticos, y el hacinamiento que se da en algunos albergues para enfermos terminales.

8. Derecho a obtener alivio efectivo de su dolor y de sus síntomas, aún si los medicamentos o medidas requeridas para ello le redujeran el tiempo de vida restante.

9. Derecho a que le sean satisfechas integralmente sus necesidades, sin olvidar nunca que detrás de ese enfermo, hasta el último instante, hay un ser humano. 
10. Derecho a recibir apoyo psicológico para facilitar su adaptación a la fase terminal de su vida y a la inminencia de su muerte. Este puede provenir de sus familiares, médicos, enfermeras, cuando ello sea necesario y factible.

11. Derecho a elegir que su familia, como parte directamente afectada por su muerte, sea atendida, respetada y cuidada.

12. Derecho a su individualidad y privacidad

13. Derecho a ser acompañado en el momento de la muerte.

14. Derecho a recibir asistencia espiritual, siempre que lo solicite, y a que le sean respetadas sus creencias religiosas, cualesquiera que sean y sin tratar de cambiarlos.

15. Derecho a ser cuidado por personas sensibles, preparadas y concientes del difícil momento que atraviesa y de su obligación de ayudarlo en lo posible.

16. Derecho a disfrutar hasta el final de una vida con buena calidad, criterio este que debe prevalecer sobre la cantidad de vida.

17. Derecho a morir con dignidad.

18. Según Behar (2003), el paciente terminal también tiene derecho a la atención, al tiempo y a la capacidad de los médicos, sin importar que ya no puedan curarlo; no debe ser discriminado. El hecho de que un paciente se sienta atendido por los médicos, le puede ayudar a mantener una esperanza y a no pensar que todo termino, ya que esto puede generar un duelo anticipatorio en el P.E.T.

Una vez mencionados los derechos del P.E.T, es importante saber que también tienen varias necesidades que desgraciadamente no siempre son cubiertas, generalmente por falta de comunicación con el paciente, en el siguiente apartado se mencionan dichas necesidades, tanto las físicas como las psicológicas, así como algunos métodos para llegar a conocerlas, lo cual también ayudará al paciente a que tenga mejor calidad de vida al tener satisfechas dichas necesidades.

\subsection{NECESIDADES DEL ENFERMO TERMINAL}

Según Kübler Ross (1975), el paciente desahuciado tiene necesidades muy especiales que pueden cubrirse si se toma el tiempo para escuchar y averiguar cuales son.

Todo enfermo terminal, en su trayectoria hacia la muerte va presentando varias necesidades, entre las que destacan las siguientes:

a) Necesidad de seguridad: es importante que se haga todo lo posible para que el paciente no se sienta rechazado o abandonado. 
b) Necesidad de estar acompañado por aquellas personas que le son más afines, como sus seres queridos.

c) Necesidad de información concreta sobre la evolución de su enfermedad, el tiempo disponible, los trámites necesarios, etc.

d) Necesidad de resolver sus asuntos pendientes: Según Kübler-Ross (1975), lo que más angustia a los enfermos terminales son sus «asuntos pendientes», aquellas relaciones interpersonales no resueltas satisfactoriamente; la reconciliación con un pasado no aceptado que ahora, a las puertas de su muerte, no les deja en paz. La muerte ya no acepta más aplazamientos para afrontar los problemas realmente importantes que, quizás, hace años se esquivan.

e) Necesidad de ser escuchado, de comunicar sus dudas y miedos ya que conforme va avanzando la enfermedad se van presentando varios temores y es importante ayudarlos mediante asistencia psicológica a superarlos, los temores más frecuentes son los siguientes:

1. Temor a lo desconocido, al curso de la enfermedad

2. Al dolor físico y al sufrimiento

3. A la pérdida de partes del cuerpo y a la invalidez

4. A inspirar compasión

5. A perder el control de sí mismos y la autonomía en la toma de decisiones.

6. A dejar a su familia y amigos, es importante hacerlos sentir que no se les abandonará.

7. A la soledad por el abandono de los demás

8. A la pérdida de identidad propia

9. A morir privados de su dignidad. (Jaramillo, 2001).

Todos esos temores hacen que el paciente tenga ciertas necesidades debido a la gran tensión psíquica, de acuerdo a García (2002), existen 4 formas de reducir la tensión que la enfermedad produce, estas son:

a) Reconocer, aceptar y animar al paciente a expresar sus sentimientos: Dado que al paciente terminal se la aparta de su medio habitual y de sus hábitos cotidianos y que su vida depende en gran medida de terceros, se ve privado total o parcialmente de sus puntos de apoyo afectivo. Son frecuentes los sentimientos de desamparo, impotencia, soledad y de despersonalización, así como la alteración de la imagen corporal.

Las formas de expresar y por lo tanto, aliviar la frustración, la rabia, la hostilidad, el temor y la depresión que producen estos sentimientos, se ven muy limitados por el ambiente físico de las unidades de cuidados críticos (hospitales). 
El hecho de mantener una atmósfera de diálogo y aceptación anima al paciente a expresar sus sentimientos, y puede constituir una forma de superarlos. El diálogo sincero y abierto reduce la sensación de despersonalización y la ansiedad y evita el aislamiento y el retraimiento. Si se anima al paciente a expresar sus sentimientos, le será más fácil darse cuenta del porqué de esos sentimientos y de ciertas conductas que pueden parecer anómalas o equivocadas. Es conveniente que tanto el personal de salud, como cualquier otro miembro del equipo asistencial, están preparados para aceptar lo que el paciente dice, independientemente de la carga afectiva que posea lo expresado.

Hay pacientes que por sus condiciones no pueden expresar libremente sus sentimientos, por esta razón son especialmente vulnerables a las tensiones psicológicas. Es necesario que la familia y el personal de salud no caigan en la tendencia natural de comunicarse menos con los que tienen menor capacidad para hablar. Una forma de reducir la sensación de aislamiento es ofrecer un lápiz y un papel al paciente y mantenerlos siempre a su alcance para que este pueda de alguna manera expresar sus temores, sus miedos, etc., ofreciéndole ayuda cada vez que sea necesario. No obstante estos métodos no son adecuados para expresar sentimientos personales o preocupaciones complejas.

b) Informar, aclarar errores de interpretación en cuanto al estado físico, objetivo del tratamiento y medidas adoptadas: Dado que la conducta del paciente frente a su enfermedad y al medio que lo rodea está condicionada por la percepción del estrés y no por la situación en sí es fundamental que tanto éste como su familia reciban la información adecuada y explicaciones sencillas. En ausencia de estas explicaciones, el ambiente de los hospitales se presenta como un lugar misterioso y hostil. El sentimiento de vulnerabilidad del paciente se ve exacerbado por el alto grado de complejidad técnica que lo rodea.

Mucho de lo que el paciente sabe acerca de su enfermedad depende de lo que el equipo sanitario le enseñe, tanto directa como indirectamente. La enseñanza de paciente en estado crítico requiere objetivos a corto plazo. El dolor, la debilidad, la ansiedad y la confusión transitoria constituyen algunos de los obstáculos que experimentan estos pacientes en su proceso de aprendizaje.

A pesar de estos obstáculos, los pacientes y sus familiares necesitan explicaciones repetidas y sencillas de todos los procesos y del propósito de cada intervención, así como una introducción a los planes de rehabilitación y de mantenimiento de la salud. Es posible que al principio los pacientes no comprendan o no crean aquello que se les dice, o que la ansiedad y la negación les impida recordarlo.

Es probable que haya que repetir y reinterpretar el diagnóstico, el pronóstico, los objetivos del tratamiento, los procedimientos y las expectativas del paciente y su familia continuamente durante toda la estancia dentro del hospital.

El paciente y su familia podrán percibir la situación con mayor claridad y hacer planes realistas si se les mantiene informados y al día en cuanto a la evolución del paciente y las 
modificaciones de los planes asistenciales, además, motiva la cooperación porque los convierte en miembros del equipo que cuida al enfermo terminal.

c) Estimular y respaldar la participación del paciente y su familia en la asistencia y la toma de decisiones: Cuando el paciente y su familia conocen bien el objetivo del tratamiento y comprenden el diagnóstico del paciente, su estado actual y el pronóstico, se les puede hacer participar en muchos aspectos de la planificación asistencial y son capaces de tomar decisiones coherentes con el tratamiento.

La participación de individuos en los que el paciente tiene gran confianza, supone un alivio de su sentimiento de impotencia, frustración y ansiedad. Además, cuando estas personas de gran importancia afectiva, ya sean familiares o amigos, comprenden y colaboran con los objetivos del tratamiento y participan en el cuidado del paciente, están mejor capacitados para continuar y ampliar esta conducta cuando el paciente abandona las unidades de cuidados críticos y el hospital, si es que esto llega a suceder. Aún cuando el paciente esté en coma, las visitas de personas claves desde el punto de vista afectivo, que le hablen y toque, puede tener efectos positivos, aunque difíciles de objetivar y ayudar a disminuir la sensación de desamparo de los familiares. Los pacientes con el sensorio intacto pueden participar directamente en el establecimiento de objetivos terapéuticos y en la planificación asistencial. Es importante de que al paciente se le trate como un individuo capaz de tomar ciertas decisiones, ya que esto mejorará la autoestima.

d) Favorecer y conservar un entorno sensorial controlado: El ambiente en los hospitales es un factor creador de grandes tensiones, con el que tanto el paciente como la familia deben enfrentarse. Hay que añadir que los pacientes que reciben narcóticos y sedantes, los extremadamente ansiosos, los que sufren varias afecciones debilitantes concurrentes, los que padecen trastornos respiratorios y metabólicos, los que sufren de insomnio y los ancianos, suelen exhibir alteraciones del pensamiento y distorsión de la percepción. Estos individuos necesitan que se les conecte con la realidad en forma continua. Aunque algunos factores ambientales no se pueden modificar, hay acciones que el personal médico puede llevar a cabo con el fin de crear un ambiente sensorial adecuado.

En conclusión los enfermos terminales experimentan muchos temores cuando se acerca el momento de su muerte, por eso es importante el estar en relación activa con una o varias personas que los escuchen, que reciban sus confidencias, que compartan con ellos, para que de esta manera tengan alivio psicológico.

El apoyo psicológico que pueden recibir este tipo de pacientes, será explicado posteriormente en el capítulo tres.

Actualmente existen cierto tipo de cuidados especiales para este tipo de enfermos, dichos cuidados se les llama paliativos y pueden ser muy útiles para ayudar a satisfacer ciertas necesidades del P.E.T, a continuación se explica de manera mas amplia en que consisten este tipo de cuidados. 


\subsection{CUIDADOS PALIATIVOS}

"El mejor servicio que un médico puede prestar a un enfermo es ser una persona amable, atenta, cariñosa y sensible". Kübler Ross (1975).

Paliar es un término derivado del latín paliare que significa tapar, encubrir, disimular.

Se puede definir la medicina paliativa como: la rama de la medicina que se encarga de disimular, mitigar, y de moderar el rigor o la violencia de ciertos procesos médicos.

Los cuidados paliativos son aquellos que buscan procurar bienestar al enfermo.

Es un programa interdisciplinario que procura controlar el dolor, los síntomas y necesidades físicas que presenta el enfermo terminal.

Este tipo de cuidados incluye principios y técnicas diferentes a las del cuidado medico tradicional.

Se basa principalmente en mejorar la calidad de vida del paciente, no se trata de prolongar la vida, ni de erradicar la enfermedad sino de darle al paciente una atención especial para que viva sus últimos días con la mayor calidad posible, los cuidados paliativos tienen como propósito dar apoyo y cuidado a personas desahuciadas, permitiéndoles vivir de una manera mas confortable posible.

Esta filosofía del cuidado integral al paciente terminal, tuvo su origen en Inglaterra, en el año de 1967 con la Doctora Cicely Saunders. (Jaramillo, 2001).

Es desde año cuando se empezó a expandir por todo el mundo, como una alternativa que respeta la dignidad humana.

La medicina paliativa es una concepción muy antigua y complementaria de la medicina curativa y constituye una terapia de soporte muy importante y no solamente es para usarse en forma exclusiva con los enfermos en fase terminal. Los cuidados paliativos con los enfermos en fase terminal representan un aspecto dentro del concepto de medicina paliativa, que abarca el tratamiento del dolor y otros factores, los cuales deben tenerse en cuenta desde el momento del diagnostico y comienzo del tratamiento.

Dentro de la medicina paliativa el objeto de estudio es el enfermo y el respeto de su dignidad durante la enfermedad, el enfermo no es un número de cama en un gran hospital ni uno más en la serie de ensayos clínicos.

La dignidad humana se fundamenta básicamente en la libertad: la capacidad de la voluntad de hacer o no hacer un acto, de cumplir o dejar de cumplir nuestras metas, es la capacidad de determinar la dirección o el "sentido", de toda nuestra existencia. 
Es muy importante señalar una vez mas que los equipos dedicados a atender a los enfermos en fase terminal deben ser multidisciplinarios, es decir se tiene que integrar tanto médicos, enfermeras, trabajadores sociales, psicólogos, tanatólogos y guías espirituales. Uno de los aspectos más importantes de la medicina paliativa es la intercomunicación entre los integrantes del equipo multidisciplinario.

Este tipo de cuidados se utiliza bajo las siguientes circunstancias:

i. Cuando el tratamiento tradicional ya no es efectivo para curar al paciente

ii. Cuando debido a la gravedad de la enfermedad, el tratamiento es agresivo y en lugar de ayudar, perjudica más al paciente.

iii. Cuando el paciente así lo decida, o en el caso de los niños cuando la familia se de cuenta de que la enfermedad es incurable y ya no hay nada mejor que hacer.

Los cuidados paliativos son dados por un grupo que consta de un médico, enfermeras, y un psicólogo con entrenamiento en Tanatología, este tipo de apoyo incluye a la familia, inclusive los niños, en el cuidado del enfermo.

Este tipo de cuidados generalmente se dan en un pabellón destinado a los enfermos terminales, o en la casa del paciente, y solo a pacientes con no más de 6 meses de vida (hasta donde sea posible predecirlo.) (Jaramillo, 2001).

Todos los participantes en los cuidados paliativos, mismos que se mencionaron anteriormente, se comprometen a no abandonar el caso bajo ninguna circunstancia, además de tener empatía y tolerancia a la frustración.

También forma parte del programa la asistencia a la familia, después de que el paciente muera ya que la familia pasa por un doble duelo, el apoyo que obtienen los familiares después de la muerte del paciente es psicológico y/o tanatológico.

Los cuidados paliativos pueden darse en el hospital, en el hogar del paciente o en lugares especializados en el cuidado del paciente terminal, estos lugares son los Hospicios, los cuales se definirán a continuación

\subsection{HOSPICIOS}

Hospicio proviene de la palabra latina Hospes, que significa huésped y con ella se designaba la costumbre romana y griega de dar apoyo a los viajeros y ofrecerles regalos.

Según Behar (2003), la primera institución que utilizó el término hospicio, en el sentido especial de cuidar a los moribundos, fue fundada en 1842 en Francia.

En 1906 se inauguró en Londres un Hospicio para personas con Tuberculosis y enfermos terminales, desde este momento el término Hospicio se convirtió en sinónimo de cuidado a pacientes terminales. 
Desde la segunda mitad del siglo pasado existe un reducido número de instituciones dedicadas al cuidado de los moribundos, fundada en su mayoría por enfermeras religiosas. Estas instituciones ofrecían asistencia a enfermos terminales que carecían de familia que los cuidara, y fueron fundadas debido al gran número de personas necesitadas que morían solas, y con frecuencia, aun en las calles. (Sherr, 1992).

La principal finalidad del hospicio es tratar la enfermedad en el contexto del paciente, es decir tomando en cuenta a su familia y a las personas que lo cuidan. La intención es llevar al máximo la calidad de la vida que le resta al paciente, mediante los cuidados paliativos que se mencionaron anteriormente.

Dado que un hospicio es un concepto y no una estructura permanente, puede tener lugar empleando una gran variedad de modelos de asistencia, en la actualidad existen dos: 1. Unidad especializadas para internos, 2. Equipos de apoyo domiciliario, (hospicio en casa).

Unidades especializadas para internos:

Este es el modelo que mejor se ajusta al concepto popular de hospicio. La mayoría de las veces son pequeñas unidades independientes, con cuidado y atención individualizada. 10 a 25 camas, consta de un gran grupo de enfermeras, ya que los pacientes terminales tienen una gran dependencia y necesidades físicas que solo enfermeras de tiempo completo pueden atender dichas necesidades.

En estas unidades por lo general existe un gran numero de voluntarios encargados de diversas labores, entre ellas: asistencia en el cuidado nocturno, labores de recepción, lavado de ropa, clases de arte o manualidades para los pacientes, esto último es beneficioso tanto para la institución ya que los artículos pueden ponerse a la venta, como para el paciente ya que brinda la oportunidad de dar algo a cambio de los cuidados que están recibiendo.

Aunque estos hospicios funcionan de manera independiente, muchos se han afiliado a algunos equipos de apoyo domiciliario.

Equipos de apoyo domiciliario, (hospicio en casa):

Consiste en el apoyo de una enfermera especializada la cual realiza las mismas labores que en el hospital pero en el hogar del paciente.

Esta enfermera puede de tiempo completo en el hogar del paciente o encargarse de otros pacientes que también atienda en el domicilio.

Es la enfermera la encargada de establecer vínculos con médicos, consejeros espirituales, etc. que necesite el paciente o la familia.

En el siguiente capítulo se mencionarán algunas alternativas terapéuticas para ayudar a que el paciente tenga mayor calidad de vida. Socialmente calidad de vida se refiere a la capacidad adquisitiva que permita vivir con las necesidades básicas cubiertas además de disfrutar de una buena salud física - psíquica y de una relación social satisfactoria. 
De acuerdo a Zuleta (2004), la calidad de vida implica necesariamente el apoyo social y familiar a las personas que desean continuar viviendo en la comunidad, siendo cuidadas en familia, para que puedan seguir haciéndolo, al tiempo que siguen desarrollándose todas sus potencialidades hasta el último momento.

La calidad de vida implica necesariamente el apoyo social y familiar a las personas, es necesario que los pacientes se sientan apoyados por sus seres queridos, para que un paciente tenga una mejor calidad de vida hay que dejarlos que desarrollen todas sus potencialidades hasta el último momento.

Para poder ayudar al paciente es necesario que se le de apoyo no solo afectivo, familiar, espiritual y médico, sino también psicológico y/o tanatológico y precisamente de esta parte trata el siguiente capítulo.

Una vez teniendo definido lo que es el paciente terminal, cuales son sus derechos y necesidades y la forma en como los podemos ayudar a tener satisfechas sus necesidades físicas mediante los cuidados paliativos se realicen o no en un hospicio es importante conocer de que manera se le puede ayudar a detectar y satisfacer sus necesidades psicológicas mediante el apoyo psicológico con enfoque humanista, terapia ocupacional y el acompañamiento y apoyo tanatológico, de esto precisamente es de lo que trata el siguiente capitulo. 


\section{CAPITULO 3:}

\section{APOYO PSICOLÓgICO Y TANATOLÓGICO AL PACIENTE TERMINAL PARA LA ELABORACIÓN DEL DUELO.}

El siguiente capítulo trata sobre los enfoques de apoyo al paciente terminal, tanto el psicológico como el tanatológico para ayudar al enfermo terminal a tener una mejor calidad de vida, entendiendo por esta como "la suma de circunstancias susceptibles de ser modificadas y que permiten el desarrollo de algunas aspiraciones del individuo". (Behar, 2003, p.46).

\subsection{QUÉ ES LA TANATOLOGÍA}

Tanatología viene de las raíces griegas: Tanatos: muerte y logos: estudio

Es la ciencia encargada del estudio del proceso de duelo por la muerte de un ser querido y los fenómenos asociados a ellas.

A pesar de que todas las sociedades han especulado sobre la muerte, su estudio sistemático es reciente sobre todo en la cultura occidental donde este tema resulta difícil de tratar debido al miedo que ocasiona este tema.

Mucha gente todavía piensa que el estudio de la muerte es un tema delicado, pero los tanatólogos consideran que su trabajo puede beneficiar a todos, ya que la comprensión del proceso de la muerte puede hacer que esta experiencia sea menos alienante y temida.

De acuerdo a Sánchez (2005), la Tanatología aborda el fenómeno de la muerte desde varias perspectivas: humanista, religiosa, social y familiar, psicológica, de lo que significa morir, la finalidad de esta es eliminar o disminuir el miedo a la muerte, mejorar la calidad de vida, y a esto considero importante añadirle que también se dedica a detectar las necesidades del paciente terminal para que tenga una mejor calidad de vida.

En esta investigación se trató de que se cubrieran todas estas perspectivas, ya se revisó el religioso, social y en el siguiente apartado se verá el psicológico y humanista. 


\subsection{APOYO TANATOLÓGICO AL ENFERMO TERMINAL.}

Lo más importante es nunca mentirle al paciente sobre la gravedad de su enfermedad, porque tienen conciencia de su cuerpo y se da cuenta de que algo anda mal, a continuación se presenta un fragmento del cuento de Ivan Illich de Tolstoi el cual muestra claramente como es necesario siempre hablarle con la verdad a los enfermos:

Le atormentaba esta mentira, le atormentaba el hecho de que no quisieran reconocer lo que todos sabían y sabía el mismo, sino que quisieran mentirle acerca de su espantosa situación, obligándole a tomar él mismo parte en la mentira. La mentira, esta mentira de que era objeto en vísperas de su muerte, una mentira que debía reducir el acto solemne y terrible de su muerte al nivel de las visitas, las cortinas, el esturión de la comida... era algo atroz para Ivan Ilich. Y, cosa rara, en muchas ocasiones cuando realizaban con él sus maniobras, estaba apunto de decirles: "No mintáis; sabeis, y yo se, que me estoy muriendo; dejad de mentir al menos"

Tolstoi .(1975)

No hablar de la muerte con un paciente terminal es como no hablar del parto con una mujer embarazada. Ambos forzosamente tendrán que descubrirlo.

\section{ANONIMO}

Otro punto importante es ayudar al paciente en sus temores, ya que el enfermo terminal en la trayectoria hacia la muerte inevitable, los enfermos enfrentan múltiples temores que es muy importante legitimar y resolver, en lo posible, dentro de la asistencia psicológica. Los más frecuentes son:

- A lo desconocido

- Al curso de la enfermedad

- Al dolor físico y al sufrimiento

- A la perdida de partes del cuerpo

- A inspirar compasión

- A dejar a su familia y amigos

- A que lo abandonen

- A morir privados de su dignidad

Los enfermos terminales experimentan temores cuando se acerca el momento de la muerte, sin embargo al estar en relación activa con una o más personas, que compartan 
con ellos sus sentimientos, personas en las que los pacientes confíen, representa un alivio psicológico.

En muchos casos los pacientes sienten "temor de compartir sus temores" con sus familiares, pues no quieren inquietarlos, preocuparlos o causarles más sufrimiento, lo cual representa algo así como una condena a sufrir en silencio, cuyo resultado es una notoria y dolorosa reducción en la comunicación, con la consiguiente sensación de aislamiento. (Jaramillo,1988).

El apoyo tanatológico tiene varios niveles los cuales son los siguientes:

\subsubsection{NIVELES DE INTERVENCIÓN TANATOLÓGICA}

De acuerdo a Sánchez (2005), los niveles de intervención tanatológica son los siguientes:

APOYO TANATOLÓGICO: Es la primera etapa, sabemos que se puede desencadenar un problema de duelo pero no se habla del tema, en esta fase solo se apoya a determinadas necesidades del paciente, mas de tipo físico, también se escucha a los pacientes, no hay continuidad.

ACOMPAÑAMIENTO TANATOLÓGICO: En esta fase solo se busca contener y escuchar al paciente, no se busca cambiar la actitud del paciente, solo se utiliza con pacientes terminales, se busca empalizar con el y que se sienta apoyado por alguien ajeno a sus seres queridos. El acompañamiento se realiza en máximo 8 sesiones, si son más ya se considera terapia.

CONSEJERÍA TANATOLÓGICA: En esta tercera fase se trabaja con los dolientes y se aplica con los familiares y seres queridos de la persona que murió.

En la presente investigación se trabajara únicamente con las 2 primeras fases, se brindara apoyo tanatológico cuando el paciente requiera algo como por ejemplo que se le ayude a comer, que necesite que se le hable a algún médico, etc., y también se les dará acompañamiento ya que se trabajara con ellos durante 6 sesiones y se buscara contener a los pacientes y escucharlos con la finalidad de detectar sus necesidades físicas y psicológicas, por lo tanto no se busca que cambie de una fase a otra en el proceso de duelo ya que con el solo hecho de dar contención se le ayuda mucho al paciente.

No solo el apoyo y acompañamiento tanatológico son útiles para el P.E.T, también hay otras herramientas con las que se le puede ayudar y estas son la psicológica con enfoque humanista y la terapia ocupacional, las cuales se explican a continuación.

\subsection{ENFOQUES TERAPÉUTICOS COMO APOYO EN EL PROCESO DE DUELO}

En el apoyo psicológico ante la cercanía de la muerte es necesario construir un espacio de confianza, en donde se rompan las barreras de la incomunicación para facilitarle al enfermo el hablar y expresar sus temores, miedos y preocupaciones. 
Desde mi punto de vista considero que es muy importante la actitud que tome el psicólogo con el paciente ya que esta debe de ser una actitud abierta, acogedora, sin ningún elemento subjetivo ni autoritario, y debe de ser, el psicólogo debe de ser capaz de mentalmente ponerse en la posición del enfermo (empatía), pero sin fusionarse con él, pienso que esta actitud resulta muy favorable para que el paciente se entregue más fácilmente a la comunicación, la ventilación afectiva y la cooperación con el psicólogo.

Antes de pensar en dar apoyo psicológico a una persona con enfermedad terminal es necesario considerar los siguientes puntos:

- Es importante ver el contexto: puede ser en instituciones como los hospitales y los hospicios o en la casa del paciente.

- Si la terapia se va a dar en alguna institución es importante estar bien informado sobre el funcionamiento del hospital o del hospicio.

- Es importante estar informado sobre el estado del paciente y estar abiertos a que no siempre será posible establecer un horario de terapia ya que este puede encontrarse indispuesto.

- Es importante que el terapeuta entienda que no siempre el paciente va a encontrarse de buen humor, y que inclusive puede llegar a ser poco cooperativo, grosero o rebelde.

- Es importante considerar que no se cuenta con mucho tiempo por lo que las metas que se plantean en la terapia deben de ser a corto plazo.

- Finalmente y el que considero más importante es que el psicólogo que apoye a este tipo de personas deben de tener elaborados sus propios duelos.

Independientemente del tipo de apoyo que se le aplique al enfermo terminal, según Jaramillo (2001), el terapeuta debe de contar con la capacidad de no asustarse ente los contenidos erráticos y demoledores del enfermo, de responder con empatía a su necesidad de ser acompañado, escuchado y comprendido con respeto.

Según Yalom, (1984), los pacientes terminales durante el proceso de su enfermedad tienen sorprendentes modificaciones y cambios internos, que se pueden atribuir a un desarrollo personal:

- Sentido de liberación: la capacidad de elegir solo lo que se desea hacer.

- Sentido realzado de la vida en el presente inmediato, en lugar de posponerla para cuando uno se retire o para algún otro momento futuro.

- Profundo aprecio por los hechos elementales de la existencia: el cambio de las estaciones, el viento, la última Navidad etc... 
- Comunicación con las personas amadas más profunda que la mantenida antes de la crisis.

- Menos temores interpersonales, menos miedo al rechazo, mayor predisposición a arriesgarse que antes de la crisis.

Por otra parte es necesario considerar que las personas que se dedican a dar algún tipo de apoyo a personas con enfermedad terminal deben tener las siguientes características según García (2002):

Analizar sus propios sentimientos en relación a la muerte

Debe de ser una persona que sepa escuchar para poder valorar las necesidades del paciente y la familia.

Estar siempre disponible; estar presente tanto física como emocionalmente.

El terapeuta debe de mantenerse constantemente informado sobre el estado de su paciente.

Debe de ser una persona capaza de respetar la relación paciente-familia, así como sus costumbres.

No debe de emitir juicios de valor

Ya teniendo claro cuales son las características que debe de tener el terapeuta que se dedica a trabajar con personas con alguna enfermedad terminal, se mencionaran los tipos de terapia, empezando por la ocupacional

\subsubsection{TERAPIA OCUPACIONAL}

La terapia ocupacional comienza en el siglo XIX y comienzos del siglo XX. La ocupación ha tenido un papel central en la existencia humana, probablemente, desde el comienzo de los tiempos.

Según Mila (2003), el uso terapéutico de la actividad y del movimiento, ha sido apreciado desde los inicios de las civilizaciones.

El juego, el cuento y el dibujo, son medios en donde la imaginación libre, no controlada por la lógica de la razón, permiten resolver sus conflictos internos, elaborar sus duelos y adaptarse a la vida.

Es muy importante que se mantenga al paciente terminal ocupado; esto puede ayudarlo a alejar la atención hacia su discapacidad o su enfermedad. Para lograr esto es importante conocer los gustos del paciente y sus pasatiempos; según Yalom (1984), los pasatiempos se pueden llegar a convertir en una ocupación que llene el vacío y hace que la vida transcurra con el menor dolor posible. 


\subsubsection{Eldibujo}

El dibujo refleja la personalidad del paciente, su vida emocional, el conocimiento y la comprensión que tiene de la realidad.

Al igual que el juego es uno de los medios por el cual el paciente se expresa con mayor libertad, refleja en él sus intereses y conflictos, comunica sus emociones y creencias, así como la percepción que tiene de sí mismo y de los demás.

La espontaneidad y facilidad con que crea imágenes y lo que estas nos dicen es una fuente inagotable de información para conocer su mundo interior.

Entre las características del dibujo están el realismo, la expresión y la comunicación. El paciente dibuja la realidad que le es significativa como la conoce.

Por medio del dibujo expresa lo que piensa y siente, es una salida a los productos de su imaginación, comunica su mundo interior, y los familiares deben de ser sensibles para poder interpretar lo que el paciente nos quiere transmitir, si el familiar no es capaz de entenderlo que el paciente nos quiere decir, podrán recurrir al apoyo de un psicólogo para saber el mensaje oculto del dibujo.

En el dibujo del paciente que elabora un duelo, lo que interesa es el mensaje que transmite, no lo bien hecho que pueda estar. El paciente traslada su estado de ánimo al papel y lo expresa mediante lenguaje simbólico.

\subsubsection{Eljuego}

El juego es una actividad generadora de placer que no se realiza con una finalidad exterior a ella sino por si misma. ( Rüssel, 1985).

Esta técnica se utiliza más en niños que en adultos con enfermedad crónica y / o terminal.

Según Petrillo y cols. (1972), el juego es un fenómeno natural que conduce al aprendizaje; es imaginativo, pero al mismo tiempo se relaciona con la realidad.

Por eso es importante incluir el juego dentro de la terapia ocupacional ya que refleja la realidad por la que esta pasando el enfermo terminal y esto nos puede ayudar para detectar las necesidades del P.E.T.

A través del juego se reflejan miedos, fantasías, sentimientos y conflictos.

Características del juego:

-Es una actividad libre, supone la capacidad inventiva del jugador, no prevé resultados. 
-Es ficticia, la conciencia específica de la realidad es seguida de irrealidad en relación a la vida cotidiana.

-Placentera, siempre es agradable a quién la realiza

Es importante que el paciente pueda vencer la realidad por medio del juego, pero es aún más importante para su desarrollo la libertad de transformar un acontecimiento en el que es sujeto pasivo en otro acontecimiento en el que sea el controlador activo.

En los juegos los pacientes escenifican, lo que existe en su mundo interior, sus miedos y sufrimientos se expresan de una manera espontánea y controlada a la vez por ellos mismos y esto le permite asimilar y aceptar poco a poco su realidad.

Un tipo de juego que puede ser utilizado con el niño terminal y con sus hermanos es el juego simbólico compensatorio, ya que por medio de la alternancia de la realidad con la fantasía, el niño resuelve una serie de conflictos interiores y aprende a adaptarse a la vida y a las situaciones que están viviendo actualmente. Por eso es necesario dejarlo jugar lo mas que pueda, no reprimir esa forma de expresión, en el caso de los hermanos que están perdiendo a un hermano o que ya lo perdieron y están en proceso de duelo hay que dejarlos jugar ya que solo así podrán ir entendiendo la situación, es normal que un niño juegue, no hay que reprimirlo.

La risa y el juego son para el paciente tan necesarios como el llanto en la resolución de un duelo, y los juegos que pueden parecer a los adultos totalmente inadecuados en ciertos momentos, para el niño son totalmente normales, además son una vía normal para aceptar la realidad de la muerte o cualquier otra pérdida significativa, en el caso del paciente terminal es la pérdida de la salud.

\section{$\underline{\text { 3.3.1.3Elcuento }}$}

El cuento a diferencia del dibujo y el juego, presenta una fantasía ya elaborada; conforme el juego se va desarrollando el paciente va expresando los conflictos que le causa el hecho de saber que va a morir.

El cuento como herramienta proyectiva es utilizada con mayor frecuencia en niños, aunque también se use en adultos.

La terapia ocupacional puede ser muy útil para los pacientes ya que en la mayoría de las ocasiones estos presentan sentimientos de inutilidad y el sentir que todavía pueden realizar ciertas actividades puede ayudarlos a su autoestima y a mejorar su calidad de vida ya que sus sentimientos de minusvalía disminuyen, desgraciadamente no siempre se les puede aplicar este tipo de terapia ya que los P.E.T muchas veces debido a su enfermedad, su estado 
físico los imposibilita a realizar este tipo de actividades, en este caso es recomendable aplicar otro tipo de apoyo como puede ser el enfoque humanista, el cual es explicado en el siguiente apartado.

\subsubsection{TERAPIA HUMANISTA}

\subsubsection{AntecedentesdelHumanismo}

Las tres grandes escuelas de pensamiento en la psicoterapia han sido el psicoanálisis, la terapia conductista y la tercera fuerza llamada psicología humanista. Cada una de ellas ha logrado a su manera ayudar a la gente con problemas.

La psicología humanista surgió en parte como una rebelión tajante hacia el psicoanálisis y el conductismo.

Según Kopp (1971), a la tercera fuerza se le denomina "movimiento del potencial humano", y fue creado por personas jóvenes cansadas del psicoanálisis y el conductismo.

Tres de los líderes más importantes del movimiento son: Abraham Maslow, Carl Rogers y Fritz Perls.

Abraham Maslow fue uno de los primeros psicólogos en notar que era un error estudiar únicamente a gente enferma, infelicidades y situaciones problemáticas, y que el campo de la psicología solo se preocupaba por la curación de las mismas.

Maslow pensaba que los psicólogos se habían dedicado solo a los sufrimientos y no a las alegrías, al crecimiento y a la trascendencia, es por esto que optó por estudiar la cara creativa y a favor de la vida del hombre, se interesó principalmente por la persona como un ser singular y único.

De acuerdo a Kopp (1971), Maslow sintetizó su visión de salud psicológica en su concepto de autorrealización, este término fue utilizado por él en los años 50’s.

Por su parte, Rogers contribuyó mucho con la teoría humanista; su mayor contribución es la psicoterapia centrada en el cliente. A Rogers le disgustaba que el terapeuta estuviera definido como distante del cliente, como la autoridad experta que hace interpretaciones. Veía al terapeuta y al cliente como iguales. Para él la actitud del analista debía de ser abierta, permisiva y respetuosa, su orientación era fenomenológica en el sentido que debía abrirse al mundo tal como lo experimentaba el paciente. 
Rogers buscaba que el terapeuta fuera no directivo y que se tratara al paciente con una consideración positiva incondicional y respetará los sentimientos del cliente, sin hacer juicios ni interpretaciones.

Kopp (1971), cita las propias palabras de Rogers, las cuales dan una idea de lo que significa ser un terapeuta:

Si puedo crear una relación caracterizada por mi parte por:

Una autenticidad y transparencia en las que yo soy mis sentimientos verdaderos;

por una cálida aceptación y aprecio de la otra persona como individuo;

Por una sensible capacidad de verle a él y a su mundo tal y como él los ve.

Entonces, el otro individuo en la relación, experimentará y entenderá aspectos de si mismo que previamente había reprimido;

Se encontrará mejor integrado, más capaz de funcionar eficazmente;

Se parecerá más a la persona que le gustaría ser; se volverá más dueño de su destino y tendrá más confianza en sí mismo; será más persona; más única y más autoexpresiva; comprenderá y aceptará más a los demás: podrá lidiar con los problemas de la vida de forma más adecuada y más cómoda. (P.67)

Para poder llegar a la comprensión de esta teoría se deben conocer primero los conceptos en la cual están los argumentos de la existencia de esta escuela:

Congruencia: Rogers (1962), menciona que la congruencia del terapeuta es la capacidad de ser una persona genuina e integrada dentro de los confines de la relación, debe de mostrarse honesto y sin máscaras, y permanecer abierto a expresar los sentimientos y actitudes que fluyan en él.

Por otra parte Muñoz, (1990), explica que es necesario que el terapeuta sea congruente y que niegue y reprima lo menos posible la experiencia que tiene con el cliente, es decir que no sea defensivo.

Ser congruente es aceptar y vivir los sentimientos y ser capaz de comunicarlos en el momento apropiado.

Rogers (1962), menciona que mientras más congruente sea al terapeuta, será más probable lograr un cambio en la personalidad del cliente.

Muñoz (1990), dice que una actitud congruente por parte del terapeuta modelará hacia el cliente la capacidad de aceptar cada vez más su experiencia como propia, sin tener que negarla.

En conclusión una persona congruente es alguien que acabará sintiéndose a gusto con su persona, percibiéndose a si mismo de manera diferente, con sus sentimientos, pensamientos y emociones, y no la que alguna vez se le halla sido impuesto por otras personas ya sea directa como indirectamente. 
Es importante acercarse a los pacientes y tratar de ser congruentes tanto en lo que se dice como en lo que se piensa y en lo que se actúa.

Consideración positiva incondicional: De acuerdo a Rogers (1978), menciona que cuando el terapeuta se encuentra en si mismo experienciando una aceptación cálida de cada aspecto de la experiencia del paciente como parte de éste, esta experienciando una consideración positiva incondicional; dentro de esta actitud no existen condiciones de aceptación. La consideración positiva incondicional implica un interés por la persona pero no de forma posesiva, sino tener un interés por la persona como individuo aparte, con permiso de tener sus propios sentimientos y vivencias.

De acuerdo a Meza y Colunga (1997), la condición positiva incondicional no implica que al terapeuta deban de gustarle todas las conductas, sentimientos y actitudes de la persona en todo momento, implica más bien, que detrás de su gusto o disgusto personal, este dispuesto a considerar al otro de manera positiva, comprendiéndolo profundamente.

Por ejemplo puede ocurrir que al trabajar con un P.E.T. que tenga una religión diferente a la del terapeuta puede ocurrir que este último lo rechace o trate de cambiar la ideología del paciente por eso es importante tener una condición positiva incondicional y aceptar al paciente sea cual sea su religión, ideologías, forma de ser, etc. Y no juzgarlos.

Empatía: Esta es la tercera condición que propone Rogers para la relación terapéutica.

De acuerdo a Rogers (1962), la empatía implica percibir el mundo interno de significados privados y personales del otro, como si fueran propios, pero sin nunca perder la cualidad de "Como si", lo cual el autor define como una especie de vivir temporal a través de los ojos y el alma del otro... sin juicios o valoraciones, simplemente un fluir en el encuentro de manera tal, que es posible percibir sentimientos y significados que quizás, el otro apenas alcanza a contactar.

Según Yalom (2002), la terapia se potencia si el terapeuta ingresa con precisión en el mundo del paciente; una empatía exacta es sumamente importante en la esfera del presente inmediato, es decir el aquí y el ahora. El aquí y el ahora se refiere a los acontecimientos inmediatos, a lo que esta ocurriendo aquí (en el espacio particular entre el paciente y el terapeuta), en los minutos de esta sesión inmediata, el aquí y el ahora se deben usar en cada sesión.

Es importante trabajar en el aquí y el ahora sobretodo al trabajar con pacientes terminales es importante enfocarse en el aquí y el ahora ya que no hay tiempo que perder, por eso no hay que enfocarse en asuntos pasados o en planes futuros ya que no se sabe con cuanto tiempo cuanta el P.E.T.

De acuerdo a Unikel (2001), la empatía es percibir al cliente tal como se percibe a si mismo y a su entorno, y de captar la realidad tal y como el la ve. Es tener la experiencia junto con él, de sus pensamientos, sentimientos y sensaciones, por contradictorios que sean y comprender de esta manera su mundo de significados y valores personales. 
Muñoz (1990), define la empatía como el ponerse verdaderamente en el lugar del otro y ver el mundo como el lo ve. También considera que la empatía es entender y captar la significación personal de la experiencia, más que responder al contenido intelectual de las palabras. Con el encuentro empático, la persona se siente escuchada, acompañada y comprendida, la empatía provoca la sensación de ser profundamente comprendido.

Para poder ser realmente empáticos es necesario que el terapeuta omita cualquier juicio de valor ya que se puede obstaculizar la relación terapéutica.

En conclusión la empatía es cuando el terapeuta se dedica por entero a escuchar, comprender los problemas del cliente (incluso aquellos de los que este puede no ser consciente), clasificarlos y comunicarle este conocimiento para que luego se pueda escuchar a si mismo y expresar sentimientos y pensamientos bloqueados anteriormente; en este caso la empatía es el poder sintonizarte con las necesidades y el sufrimiento de los demás.

Es importante mencionar que en esta investigación no se brindó terapia humanista, solo se apoyo a los pacientes con enfermedad terminal mediante un enfoque de orientación humanista buscando la empatia con ellos, tendiendo consideración positiva incondicional y siendo congruentes, todo esto mediante la observación fenomenológica que es lo que se explicará a continuación.

\subsubsection{Observación Fenomenológica.}

El término fenomenología proviene del vocablo griego phainomenon, que significa apariencia, lo que sale a la luz, es decir lo que se muestra o lo que aparece.

De acuerdo a Martínez (2004); el término fenómeno se refiere a aquello del mundo tal y como lo experimentamos.

Según Unikel (2001), el método fenomenológico es uno de los varios métodos llamados cualitativos.

Las raíces de la fenomenología pueden situarse en Edmund Husserl en los primeros años del siglo XX. Actualmente la fenomenología se centra en el estudio de lo particular en cada individuo y en la profundización de su subjetividad, es decir, en su modo específico de seren- el-mundo.

La fenomenología busca conocer los significados que los individuos dan a su experiencia. Es una invitación a ver las cosas desde el punto de vista de otras personas y describirlas; en este caso se busca describir como el P.E.T. percibe su situación al estar cerca de la muerte y que describa sus necesidades físicas y psicológicas. 
De acuerdo a Gutiérrez (1990), la fenomenología solamente pretende estudiar aquello que se presenta con evidencia, desecha el raciocinio lógico. Describir lo que aparece es justamente el sentido de la fenomenología.

Unikel (2001), dice que la descripción fenomenológica debe de ser neutra, es decir hay que escuchar lo que dice el paciente, sin asociarlo con creencias propias del investigador.

Según Martínez (1999), la investigación fenomenológica se realiza de la siguiente forma:

1. Es el estudio de la experiencia de vida de la persona, captada y descrita tal cual, sin juzgarla, etiquetarla ni darle categorías. Es contemplarla con libertad, sin la autolimitación de teorías, creencias que prejuicien y / o dirijan la observación.

2. Es el estudio de lo que es significativo para esa persona.

3. Es la exploración del significado que tiene para la persona su ser- en- el- mundo, su ser hombre, mujer, etc., en el conjunto de su mundo de vida, de su entorno social, económico, familiar, social, etc.

4. Es la búsqueda de todas las perspectivas posibles para detectar y observar la experiencia de la persona. Se trata de obtener la mayor cantidad de información desde las diversas perspectivas desde donde se puede ver la experiencia.

5. Es sacar a la luz los significados profundos que están sumergidos bajo los datos superficiales y obvios.

De acuerdo a Martínez (1999), hay ciertas reglas para poder tener una buena actitud fenomenológica y esas son las siguientes:

a) Ver todo lo dado, tratar de captar lo más posible de lo que se presenta ante el terapeuta. Tener cuidado de no solo ver lo que interesa o confirmar nuestras propias ideas, sino estar abierto a captar lo más posible.

b) Observar la gran variedad y complejidad de sus partes, estar abierto a la complejidad, no reducir lo complejo a lo simple para entender.

Unikel (2001), agrega las siguientes:

Es necesario que el observador tenga la capacidad de percatarse lo que ocurre en su campo, es decir en su organismo / ambiente, dentro y fuera de sus fronteras de contacto, se trata de que el observador sea capaz de percatarse de su marco de referencia, para no mezclarlo con el marco de referencia de su cliente.

El observador debe de tener la capacidad de escuchar para captar no solo la información explícita sino para percibir también la implícita; para esto es necesario poner atención a lo digital es decir a las palabras y su estructura, a lo analógico: el tono de voz, etc. Y a la relación entre lo digital y lo analógico: el contacto con la experiencia, es decir la relación entre las palabras y sus significados.

Según Cayrol (1984), el terapeuta debe buscar el verdadero significado de las palabras para comprender plenamente las experiencias a que corresponden ya que muchas veces las 
palabras utilizadas por el paciente no corresponden con las experiencias, (se ve si el paciente es congruente).

Las reacciones del investigador requieren ser concientizadas en orden para poder ponerlas entre paréntesis.

De acuerdo a Martínez (2004), la fenomenología trata de encontrar lo que es igual entre los iguales, la fenomenología busca semejanzas, en esta investigación se buscara detectar las necesidades psicológicas y físicas entre pacientes terminales, aunque será difícil encontrar todas las necesidades del los pacientes ya que de acuerdo a los fenomenólogos no es posible para el ser humano el encontrar la última realidad de cualquier objeto.

Según Mártinez (2004), el método fenomenológico se basa en seguir los siguientes pasos:

1. Epoche: se basa principalmente en dejar a lado todas las concepciones iniciales y prejuicios sobre las cosas o la realidad, es dejar atrás al menos de manera temporal todos los conocimientos que tenemos sobre el fenómeno, es decir hay que poner entre paréntesis esos conocimientos para poder permanecer abiertos a la experiencia inmediata.

2. La descripción: Se trata de describir el fenómeno tal cual ocurrió sin hacer interpretaciones o traducciones. Toda descripción tiene ciertos elementos explicatorios, los cuales se tienen que hacer tal cual ocurrieron los hechos.

3. La horizontalización: Se basa principalmente en no darle mas importancia a un fenómeno que a otro, no se deben jerarquizar los hechos ya que ninguna de las piezas puede recibir una importancia mayor que las otras.

Concluyendo, la Teoría Humanista se diferencia de las otras perspectivas por el hecho de utilizar como método a la introspección como revisión interna; el método experiencial y el fenomenológico por medio de terapia. Pasa a ser una teoría preocupada de la persona como un ser individual destacando lo positivo de este. La terapia humanista busca la autorrealización de las personas es decir el desarrollo de sus potencialidades, además es importante mencionar que este tipo de enfoque se puede utilizar como base en el apoyo a pacientes terminales, independientemente de que se le aplique terapia ocupacional, apoyo o acompañamiento tanatológico o no.

Todos los tipos de terapia anteriormente mencionados tienen como objetivo:

Ayudar a que el paciente con enfermedad terminal siga productivo y lograr que tenga una mejor calidad de vida.

Dar apoyo tanatológico al paciente terminal así como acompañamiento en caso de que lo requiera.

Lograr que el paciente exprese temores, miedos, sentimientos y dudas para ayudarlo a satisfacer sus necesidades.

Apoyar al paciente para que este pueda disminuir su ansiedad y/o sus temores. 
En conclusión todo esto se puede lograr siempre y cuando el terapeuta se acerque al paciente de tal forma que se pueda establecer una empatía, logrando esto se puede aplicar tanto la entrevista como el apoyo y/o acompañamiento tanatológico, basado siempre en las 3 condiciones de la terapia humanista las cuales son congruencia, empatía y condición positiva incondicional, todo esto para poder detectar las necesidades del P.E.T y ayudarlo a satisfacerlas para que este tenga una mejor calidad de vida.

\section{CAPITULO 4: MÉTODO}

\subsection{OBJETIVOS}

4.1.1 Objetivo General: Detectar las necesidades psicológicas y físicas del paciente terminal.

4.1.2 Objetivo Particular: Aplicar apoyo psicológico y tanatológico a pacientes terminales para mejorar la calidad de vida.

\subsection{PLANTEAMIENTO DEL PROBLEMA}

\subsubsection{Problematización:}

Las enfermedades terminales son un problema social ya que afectan tanto al paciente como a las personas que lo rodean, por lo tanto es necesario contar con el apoyo psicológico y tanatológico para poder satisfacer las necesidades del paciente y así poderlo ayudar a elaborar el proceso de duelo y mejorar su calidad de vida.

\subsubsection{Preguntadeinvestigación:}

¿Cuáles son las necesidades del P.E.T y de que manera le puede ayudar el apoyo psicológico con enfoque humanista y tanatológico a satisfacer dichas necesidades?

\section{3 EJES TEMÁTICOS:}

1. Percepción de la propia muerte: Según Vincent. (1980), la muerte se puede definir desde 3 puntos de vista:

A) Muerte aparente: especie de síncope prolongado, insensibilidad, desaparición del tono muscular, paro respiratorio y debilitamiento de la actividad cardiaca y circulatoria, en donde el sujeto puede volver a la vida de 2 maneras, la primera es de forma espontánea y voluntaria y la segunda es como consecuencia de las medidas de reanimación. 
B) Muerte clínica: cesa la actividad circulatoria y respiratoria, sin embargo el retorno a la vida es posible salvo cuando la irrigación sanguínea falta al cerebro por mas de 5 a 8 minutos.

C) Muerte absoluta: Es la muerte cerebral, aquí ya es irreversible, también se le conoce como vida vegetativa, el daño es en el tronco encefálico, este momento es ideal para la donación de órganos porque estos siguen manteniéndose vivos.

\section{Necesidades del P.E.T:}

Todo enfermo terminal en su trayectoria hacia la muerte va presentando varias necesidades, las más frecuentes y observadas en esta investigación son las siguientes:

a) El paciente con enfermedad terminal tiene temor a lo desconocido, al curso que pueda tomar su enfermedad, por lo que tienen necesidad de saber que es lo que les va a pasar.

b) Necesidad de evitar o controlar el dolor físico y el sufrimiento

c) Necesidad de compañía

d) Necesidad de sentirse comprendidos por sus familiares y seres queridos.

e) Necesidad de expresar sus miedos, temores, sentimientos, dudas, etc.

f) Necesidad de autonomía y de tener el control de la situación para no sentirse inútil.

g) Necesidad de vivir lo más dignamente posible.

\subsection{PLANEACIÓN DE LA INVESTIGACIÓN:}

Estudio de casos intrínseco. De acuerdo a Bonilla. y García. (2002), este tipo de estudio se caracteriza porque presta especial atención a cuestiones que específicamente pueden ser conocidas a través del estudio de casos, en esta investigación serán 3, con personas que tengan alguna enfermedad terminal.

Será intrínseco porque el problema a investigar se puede presentar en otras personas que estén en la misma situación (una enfermedad terminal), y necesidad de satisfacer sus necesidades físicas y psicológicas.

Tipo de estudio: La investigación será de tipo cualitativo ya que se pretende describir las necesidades que presenta una persona con enfermedad terminal, utilizando como recurso la entrevista profunda, de la cual se obtendrán datos que serán registrados.

Nivel de investigación: Descriptivo, ya que se pretende identificar ciertas características de nuestro objeto de estudio, en este caso las necesidades psicológicas y físicas del paciente terminal así como su desarrollo en el transcurso de la enfermedad. Se utilizará un grupo determinado es decir personas con alguna enfermedad terminal. 


\subsection{INFORMANTES CLAVE}

Se requieren 3 personas con enfermedad terminal que se encuentren en alguna etapa de duelo, sin importar edad, sexo, tipología o causa de la enfermedad.

\subsubsection{Seleccióndelosinformantes clave}

Serán personas con alguna enfermedad terminal, ya que ante la pérdida de la salud, estos comienzan a elaborar el duelo y a tener ciertas necesidades que no siempre son cubiertas y, por lo tanto, el duelo tarda más tiempo en resolverse o inclusive podría nunca hacerlo.

\subsection{TÉCNICAS DE RECOLECCIÓN DE INFORMACIÓN}

Para recolectar los datos necesarios para detectar las necesidades del paciente terminal se utilizará como herramienta la entrevista profunda y se realizaran en total 6 con cada uno de los pacientes.

De acuerdo a Bonilla. y García. (2002), la entrevista sirve para obtener información con relación a un objetivo, en este caso, la entrevista servirá para detectar las necesidades del paciente terminal y de esta forma ayudarle mediante el apoyo psicológico con enfoque humanista y el apoyo y acompañamiento tanatológico.

Se realizaron 6 entrevistas con cada paciente, esto tuvo como objetivo el recolectar la mayor cantidad de información posible. Como se trató de personas con enfermedad terminal muchas veces no tenían ni la disposición, ni el tiempo, ni las ganas para tener entrevistas largas, por lo mismo se consideró pertinente que fueran 6 ya que en caso de que el paciente no quisiera hablar mucho o no pudiera hacerlo debido a su estado de salud o a las constantes interrupciones por parte del personal de salud se fue complementando la información durante las 6 sesiones y no se le presionó a brindar todos los datos necesarios en dos o y tres sesiones.

Las entrevistas tuvieron como finalidad el obtener la información necesaria mediante un proceso de comunicación directa con el paciente en relación a las necesidades que tiene la P.E.T, durante el transcurso de su enfermedad.

Cada entrevista se realizó de manera individual, y tuvo una duración aproximada de $1 \mathrm{hr}$. a 2 hrs. como máximo; las entrevistas se realizaron dentro del Hospital Darío Fernández Fierro del I.S.S.S.T.E, en el propio cuarto de la P.E.T., se buscó que el paciente se encontrara en cuarto aislado para tener un ambiente mas privado y con mayor confidencialidad.

La entrevista fue semiestructurada ya que se tuvo una guía temática en la cual se apoyo dicha entrevista para obtener los datos deseados, las preguntas fueron abiertas para 
obtener respuestas más emocionales que racionales, ya que lo que interesa en esta investigación es el detectar las necesidades del enfermo terminal y saber como se siente.

Las preguntas de la entrevista profunda fueron dirigidas principalmente para detectar cuáles son las necesidades principales del enfermo terminal, tanto las psicológicas que son las que interesan en esta investigación y las físicas ya que el personal medico del hospital, se interesó tanto en esta investigación que pidió se detectaran las necesidades físicas del paciente terminal para brindarle un mejor servicio.

\subsection{INSTRUMENTO}

Para complementar los datos obtenidos con la técnica de la entrevista profunda se utilizó un instrumento diseñado por el personal médico del Hospital en donde se realizó la presenta investigación, este instrumento tiene como finalidad el detectar las necesidades tanto físicas como psicológicas, estas últimas son las que interesan en esta investigación, mientras que las físicas interesan al personal de salud.

Este instrumento consiste en 25 preguntas con 2 alternativas de respuesta, las cueles son SI o NO, las preguntas se basan principalmente en detectar necesidades del paciente tanto a nivel físico como psicológico, y también busca el saber como se siente dentro del hospital y de que manera se le puede dar un mejor servicio.

Una vez aplicado el instrumento, se redactaron y describieron los datos obtenidos, complementándolos con los datos obtenidos con la técnica de la entrevista profunda.

\subsection{CATEGORÍAS DE ANÁLISIS:}

En la entrevista con los pacientes se buscó obtener la siguiente información:

En primer lugar interesa saber si el paciente esta conciente o no de la gravedad de su enfermedad.

Una vez que se sabe si hay conciencia de enfermedad es necesario conocer lo que piensa y siente al paciente con respecto a su enfermedad.

También es importante saber si el paciente sabe que va a morir y que piensa sobre el tema de la muerte.

Se requiere saber si el paciente comparte con sus seres queridos y / o familiares sus sentimientos, pensamientos y miedos.

Hay que hacer una revisión general sobre la propia vida del paciente, ya que en ocasiones tienen conflictos desde el pasado que no los dejan estar tranquilos y es importante saber donde se originan para poder brindar un mejor apoyo.

También es necesario saber como son sus relaciones interpersonales con sus amigos, seres queridos y la familia.

Es importante preguntarle al paciente que es lo que necesita, que le falta para tener una mejor calidad de vida. 
Saber cómo se siente el paciente dentro del hospital, cómo lo tratan, qué le gusta y qué le disgusta.

Saber qué espera el paciente de su familia, que hacen sus familiares por él.

Lo anterior es la guía temática de la entrevista que se aplicó a cada paciente, sin embargo el orden no siempre fue respetado ya que dependió del curso que tomó la entrevista la cual fue semidirigida, es decir tuvo como fin el detectar las necesidades del paciente, pero este tuvo la libertad de expresar y decir lo que sintió en el momento de la entrevista.

\subsection{PROCEDIMIENTO}

1. Se seleccionaron a 3 pacientes con enfermedad terminal, sin importar sexo, tipología y causa de enfermedad, se utilizó el censo del hospital para detectar a los pacientes que tengan alguna enfermedad terminal, ya teniendo seleccionados a los pacientes se revisó el expediente médico para ver cuanto tiempo permanecerán en el hospital, si van a estar internados entre 2 y 3 semanas, se verá si el paciente acepta el apoyo psicológico y tanatológico. La finalidad de tener acceso a los expedientes de los pacientes también sirvió para corroborar datos dados por los pacientes, así como para completar los que no podían ser proporcionados por ellos.

2. Si el paciente aceptó el apoyo se comenzó con las entrevistas, tratando de lograr que desde la primera se estableciera un buen rapport.

3. Las entrevistas no siempre fueron realizadas en sesiones seguidas ya que de esto dependió el estado de ánimo del paciente, que no tuviera algún estudio programado o que su estado de salud imposibilitara que se llevara a cabo la sesión.

4. Durante alguna de las 6 sesiones de entrevistas se aplicó el instrumento proporcionado por el Hospital, mismo que detecta las necesidades físicas y psicológicas del paciente.

5. Los resultados del instrumento fueron supervisados por el Coordinador de Medicina Interna del Hospital, mismo que pudo atención a las necesidades físicas de los pacientes y trató de ayudar junto con el resto del personal de salud a satisfacer dichas necesidades, por otra parte las necesidades psicológicas son las que se trataron de satisfacer mediante el apoyo psicológico con enfoque humanista y apoyo y/o acompañamiento tanatológico.

6. Una vez detectadas las necesidades se buscó ayudar al paciente mediante un apoyo psicológico con enfoque humanista, basado en respeto, congruencia, condición positiva incondicional y empatía, y en caso de ser necesario y que el paciente así lo pidiera se brindó terapia ocupacional y apoyo tanatológico. Este tipo de apoyo también fue supervisado por el Coordinador de medicina Interna. 


\section{RESULTADOS Y ANÁLISIS CUALITATIVO DE LOS RESULTADOS:}

Muchas personas de diferentes clases sociales acuden al Hospital Darío Fernández Fierro del I.S.S.S.T.E específicamente al área de Medicina Interna por la necesidad de encontrar una cura a su enfermedad que en la mayoría de los casos suele ser de carácter terminal o simplemente lo único que se logra encontrar es un tratamiento paliativo para mantener al enfermo y logre de alguna manera vivir con ella; dentro de este hospital la mayoría de los pacientes son de clase social baja por lo que muchos mueren por falta de recursos, y el resto porque su enfermedad ya esta muy avanzada, este último punto limitó hasta cierto punto seleccionar una muestra más grande por tal razón el presente estudio se realizó con una muestra constituida por 3 pacientes.

La muestra debió ser reducida por las variantes en los tratamientos del total de pacientes internos, ya que la mayoría no se encuentran dentro del hospital más de una semana, otros solamente van a consulta externa y muchos otros lamentablemente murieron.

Se seleccionó a aquellos pacientes que estarían entre dos y tres semanas en el hospital, ya que no siempre se pudo realizar las seis entrevistas seguidas.

Se entrevistó a los pacientes y, en algunos casos, para completar la información sobre su estado de salud se preguntó al personal de enfermería y médicos para conocer los casos, tratamientos y evoluciones de los pacientes; se estableció empatía con los pacientes para aplicar entrevistas y así obtener la información requerida para la investigación. Para lograr la obtención de los datos de una manera verídica se utilizó un cuaderno de notas en donde se escribió lo más sobresaliente de las entrevistas.

Se trabajó con ellos en un proceso psicológico y tanatológico, bajo la observación fenomenológica tomando en cuenta los principios fundamentales del enfoque humanista, los cuales son: congruencia, consideración positiva incondicional y empatía, para poder detectar las necesidades del paciente.

Las sesiones se trabajaron con algunos pacientes de manera continua, con otros se requirió de varias semanas, en total fueron seis sesiones con cada uno, las primeras sirvieron para conocer las actitudes del paciente y luego se les apoyó con las etapas de duelo que fueron presentando. Para complementar la información se aplicó un instrumento no - validado que contiene preguntas para detectar las necesidades del paciente, este instrumento fue realizado por algunos médicos los cuales interesados en este trabajo, proporcionaron una serie de preguntas a los que ni ellos mismos tenían respuesta, por lo que pidieron que se realizara este instrumento. 
Este instrumento esta constituido por 25 preguntas en donde se ven las necesidades del paciente tanto de tipo físico,( las cuales son cubiertas por los médicos y el personal de salud), como las de tipo psicológico que son con las que se trabajó en esta investigación.

Para la presentación de resultados se realizó un análisis cualitativo comparativo de cada caso. En ellos está inmersa la explicación correspondiente acerca de la evolución de cada uno, así como en qué momento o a qué etapa de duelo lograron llegar.

En la narración de los casos se intercalan las reacciones personales de la investigadora para mostrar el proceso interno de la misma y con ello ser congruente con la metodología.

\section{PRESENTACIÓN Y ANÁLISIS DE LOS RESULTADOS.}

Esta investigación fue motivada a partir de la experiencia previa que se obtuvo durante la práctica supervisada en el año 2004 en el Hospital Darío Fernández Fierro, I.S.S.S.T.E, durante los estudios de un diplomado en Tanatología en el Instituto Mexicano de Tanatología, en el cual se tuvo contacto directo con más de 20 pacientes que se atendieron, en especial uno de ellos que en la última fase de su enfermedad que se diagnosticó como terminal dejó la semilla para que se iniciara el presente estudio.

Esta investigación inició a mediados del 2004 y se ha trabajado con más de 60 pacientes, sin embargo solo algunos permanecieron en el hospital el tiempo necesario para poder realizar el estudio.

Con cada uno de los pacientes se estableció rapportt, definido por Díaz Portillo (2002) como una relación cordial, afectuosa, de confianza, de aprecio y respeto mutuo desde el principio de la primera entrevista, y se recolectó información mediante seis entrevistas para hacer una revisión de vida del paciente, hacer la detección de las necesidades y se les dio apoyo psicológico con enfoque humanista, así como apoyo tanatológico.

La información recolectada sirvió para conocer a cada paciente y su problemática emocional. No se trabajó de la misma manera con cada uno de ellos ya que no presentaban la misma sintomatología aunque todos coincidían en que se sentían muy ansiosos por su futuro inmediato. De esta forma se logró organizar las seis sesiones en las cuales fueron avanzando según las condiciones físicas y emocionales se los permitieron.

A continuación se dan a conocer los tres casos de personas con enfermedad terminal.

La finalidad de las viñetas es conocer la forma en que evolucionaron las personas de la investigación durante el tratamiento, y poder ubicar la etapa a la cual lograron llegar del proceso de duelo. Así mismo ver como se llevó a cabo el apoyo psicológico con enfoque humanista y tanatológico. 


\section{PACIENTE \#1:}

\section{Sesión \# 1}

\section{Fecha: 7 de Febrero- 2005}

J.L.R. de sexo masculino de 62 años de edad, nació el 10 de Marzo de 1942, de estatura aproximada de $1.65 \mathrm{~m}$ y de un peso aproximado de $50 \mathrm{Kg}$., tiene cabello corto negro, lacio, entrecano, y peinado, ceja muy delgada y poco poblada, ojos pequeños color café, labios delgados, tez morena clara, nariz recta y pequeña, uñas limpias y cortas, se encontraba aliñado y limpio ya que se acababa de bañar. Usaba lentes ya que tiene vista cansada.

De religión cristiana, el paciente comentó que tiene la esperanza de que después de la muerte va a tener la vida eterna y que por esa razón no le teme a la muerte.

Se encuentra ubicado en tiempo y espacio. Su lenguaje fue muy claro y con fluidez verbal.

J.L.R se encontraba muy serio y poco cooperador y se definió así mismo como una persona que nunca se ríe, la verdad este comentario no me agrado y en ese momento pensé en cambiar de paciente ya que en un principio el paciente no me cayó bien, pero con el transcurso de la entrevista fui logrando tener una mayor consideración positiva incondicional con él.

Ingresó al hospital el 4 de febrero debido a una Bicitopenia, es decir el paciente tiene bajos 2 de los elementos de la sangre, en este caso las plaquetas y los glóbulos rojos por lo que padece Anemia, esto es causado por su Plenomegalia lo cual es un problema del bazo, este se encuentra inflamado y absorbe excesivamente los glóbulos rojos y las plaquetas, por esta razón el paciente constantemente es sometido a transfusiones sanguíneas, hasta ahora lleva 3 transfusiones y aún le faltan 2 .

Esta consciente de que su enfermedad es grave y que puede tener varias complicaciones que pueden llevarlo inclusive hasta la muerte.

En esta primera sesión J.L.R se encontraba en el cuarto aislado de la sección de medicina interna ya que debido a su estado de salud era conveniente que se le aislara, debido a que se encontraba bajo de defensas y podía contagiarse de varias enfermedades fácilmente. 
Se encontraba con su esposa una mujer de 58 años de edad, de estatura aproximada de 1.60 y peso aproximado de $80 \mathrm{Kg}$., con ojos café, ceja poblada, nariz chata, tez morena, cabello negro, entrecano, ondulado, recogido en una cola de caballo, usaba lentes ya que padece vista cansada al igual que su esposo; el paciente tiene 9 hijos.

La primera es una mujer llamada Estrella de 40 años de edad, enfermera y casada; el segundo es un varón llamado Víctor de 38 años, casado e ingeniero en computación, la tercera es una mujer llamada Paula de 36 años, profesora de ingles, casada; el cuarto es un varón llamado Ángel de 34 años, casado y es herrero; el quinto es un varón llamado Felipe de 32 años, casado y es mariachi, no tiene carrera; la sexta es una mujer llamada Concepción de 30 años, casada y es Farmacéutica; el séptimo es un varón llamado Pablo de 28 años, soltero y vive con sus padres, no tiene carrera, terminó solo hasta la preparatoria; la octava es una mujer llamada Elisa de 26 años, educadora , casada y finalmente el último de sus hijos es un varón llamado Juan Carlos de 24 años de edad, casado y terminó hasta la secundaria.

El paciente centró toda su plática en sus hijos, comentó que sus hijos consentidos son Víctor el cual es el más alto y fuerte de la familia, según el paciente, y Estrella la cual tiene gemelas y según él es la hija que más se preocupa por él.

J.L.R, comenta que ya quiere salir del hospital ya que el 10 de marzo es su cumpleaños y quiere festejarlo con toda su familia. También quiere estar bien para poder festejar el cumpleaños de sus nietas las gemelas es decir de las hijas de Estrella las cuales cumplen 15 años el 2 de Abril.

Regresando a sus hijos, mencionó que no todos sus hijos quisieron estudiar, que uno de sus hijos es ingeniero, el otro es mariachi, de sus hijas, Estrella es enfermera, en un principio quería ser bióloga marina pero, como la carrera la tienen fuera del D.F, y era muy costoso no le pudieron pagar la carrera. Después de esto, la hija del paciente ya no quería estudiar, pero tanto el paciente como sus esposa la convencieron de que estudiara otra cosa y se decidió por la carrera de enfermería, actualmente es jefa de enfermeras en un hospital público, por otra parte su hija mas chica es maestra de inglés en una escuela pública.

El paciente asegura sentirse orgulloso de todos sus hijos ya que a todos son personas de provecho y ninguno tiene adicciones. Recordó que en su pueblo (San Andrés), toda la gente lo envidiaba por ser tan buen padre, porque él jugaba con sus hijos, estaba siempre con ellos y siempre trató de mantener a la familia unida, por estas razones el siente que no falló como padre a pesar de que algunos de sus hijos no quisieron estudiar una carrera. 
$\mathrm{Al}$ recordar esto el paciente empezó a llorar, al preguntarle porque lloraba comentó que era de alegría y que le causaba mucha emoción recordar esos momentos, cuando sus hijos eran pequeños.

Se estableció un buen Rapportt ya que con el transcurso de la entrevista se empezó a mostrar cooperador; comentó que casi siempre es muy cortante con la gente que acaba de conocer y que se define como una persona desconfiada, pero pidió tener más sesiones ya que le había gustado platicar.

En esta sesión J.L.R no quiso realizar ningún tipo de terapia ocupacional ya que se encontraba cansado.

Al preguntarle como se sentía, comentó que se siente triste porque el siempre había sido una persona muy activa y que actualmente se cansaba con facilidad y que no podía realizar muchos esfuerzos físicos.

Los síntomas emocionales que más predominaron durante esta sesión fueron: tristeza ya que se siente incapaz de realizar las actividades que solía hacer como las de albañilería, por otro lado ansiedad por los cambios que los tratamientos médicos le ocasionan, tales como mareos, nauseas, siente que no es el cuando le suministran sedantes. Fue muy claro al decir lo que especulaba sobre su enfermedad por lo que ha tratado de arreglar sus problemas tanto familiares, como económicos y legales, ya que no quiere dejarle problemas a sus esposa ni a sus hijos cuando muera.

\section{Sesión \#2}

\section{Fechas: 8 de febrero -2005 .}

El paciente se encontraba limpio y aliñado, rasurado y peinado, se le veía la expresión de cansancio ya que no durmió debido a la temperatura que tuvo durante la noche, le cuesta trabajo moverse ya que aún no le suministraban los sedantes y le dolía toda el área abdominal debido a la inflamación del bazo.

La noche la pasó con su hijo mayor. Y ahora se encontraba acompañado de su esposa.

A pesar de verse cansado el paciente tenía mejor humor, estaba risueño e insistía en contarme anécdotas que el describía como "chistosas", y me pidió que estas anécdotas las pusiera en mi tesis, por lo que se incluyen aunque no parezcan relevantes a la presente investigación.

En esta sesión comenzó hablando sobre como había conocido a su esposa, ella es de un pueblo llamado San Andrés que se ubica en el estado de Morelos, el paciente vivía en el D.F, a los 6 años de edad él y su familia se fueron a vivir a San Andrés y la conoció, eran vecinos y de niños se la pasaban jugando, al crecer él se empezó a interesar en ella 
y logró conquistarla a pesar de que el padre de ella se oponía, describe a su suegro como un "ogro".

Una de las anécdotas que recordó fue cuando su esposa se embarazó de su primer hija, fueron a la feria del pueblo en Tepepan y ella siempre había tenido ganas desde niña de subirse a la rueda de la fortuna y el paciente decidió subirse con su esposa, cuando bajaron del juego dice que toda la gente le empezó a gritar de groserías y las mujeres lo agarraron a golpes ya que había arriesgado la salud de su esposa y de su bebé, él comenta que nunca le ha gustado que le digan lo que tiene que hacer, se considera una persona centrada capaz de tomar sus propias decisiones, dice que cada vez que la gente le dice lo que debe de hacer el reacciona de manera agresiva.

También comentó que él se dedicaba a la albañilería, y a la crianza de borregos, conejos y pollos. Su esposa desde pequeña se dedicó a la siembra y siempre apoyó a la economía familiar ya que no le gustaba sentirse inútil ni mantenida.

Asegura sentirse orgulloso ya que se casó con una mujer trabajadora y virgen, que no estaba vivida y que no le llevaba ventaja en lo sexual.

A pesar de que el paciente se encontraba de mejor humor, al recordar cuando antes salía a caminar con su esposa en el pueblo de San Andrés que es donde actualmente siguen viviendo, le cambió su estado de ánimo y empezó a ponerse triste ya que ahora se siente incapaz de salir de paseo con su esposa debido a su enfermedad ya que se cansa mucho.

Recordó que una ocasión tuvo una caída muy fuerte, y cayó de lado, los médicos le han dicho que posiblemente esa caída le originó la inflamación del bazo, y que al no tratarse se le complicó.

La sesión se vio interrumpida por la visita del médico de guardia, el cual le dijo que solo estaban en espera de su médico tratante para que le dieran indicaciones y ver cuando le iban a hacer la otra transfusión.

Después de la visita médica entró el personal de enfermería para suministrarle unos sedantes para disminuir el dolor que tenía el paciente debido a la inflamación del bazo, también le sacaron sangre para llevarla a analizar y ver como están las plaquetas y los glóbulos rojos, y ver su evolución después de las transfusiones, debido a los sedantes empezó a tener sueño, a pesar de eso trató de seguir platicando pero ya se le veía cansado, así que se consideró pertinente dar por terminada la sesión para que pudiera descansar.

\section{Sesión \#3:}

\section{Fecha: 9- Febrero- 2005}

El paciente se encontraba aliñado, bañado y peinado, con la bata blanca del hospital y debajo de ella una pijama a cuadros color azul, se encontraba con aspecto tranquilo, 
comentó que ahora si había podido dormir bien ya que no tuvo temperatura. Estaba acompañado de su esposa.

Comentó que en la mañana había recibido la visita médica y en esta ocasión si había ido su médico tratante el cual le dijo que probablemente el viernes lo daban de alta.

El paciente se esfuerza en agradar y en dar información útil, busca ayudar con la investigación, esto se ve en que constantemente me pregunta si la información que me da me sirve o no para esta investigación.

En esta ocasión se le vio más animado, se encontraba leyendo una revista, comentó que se sentía de mejor humor ya que los mareos y la temperatura habían desaparecido y que ya podía leer y hacer más cosas.

Dijo que el día de ayer sentía que su cerebro no funcionaba bien, dijo que se le olvidaba lo que tenía que hacer, y que si se paraba para hacer algo a los pocos minutos se le olvidaba lo que iba a hacer, los médicos dijeron que esto era normal debido a las altas temperaturas y a los efectos de los sedantes que le suministran para calmar el dolor que le causa la inflamación del bazo.

En esta sesión J.L.R se enfocó principalmente al tema de su familia, y me pidió que esta historia también la incluyera en mi investigación, comentó que tanto su abuelo paterno, como su padre habían construido sus casas ellos mismos, dice que esto es una tradición, comentaba que el no pudo construir su casa antes de casarse que es lo que se acostumbra en su familia, él tuvo que ahorrar y no fue sino hasta su jubilación cuando empezaron a comprar material para construir la vivienda, la cual la construyeron entre él y su esposa, su casa esta construida en el pueblo de San Andrés en Morelos, en un terreno de $550 \mathrm{~m} 2$, es de 3 niveles y han tardado en construirla alrededor de 5 años debido a la situación económica.

Actualmente en su casa tienen árboles de chabacano, durazno y ciruelas, las cuales venden para tener un ingreso extra y poder terminar la construcción.

Otra de las razones por las que no había podido construir su casa es porque ayudó a cada uno de sus hijos a que hicieran la suya, por esta razón todos sus hijos tienen casa, excepto uno que aun vive con ellos, dice que desgraciadamente sus hijos se acostumbraron a que todo se les diera y que ahora se enojan cuando no se les da más dinero.

El padre del paciente era de Querétaro, trabajaba en un rancho, fue militar y cuando se fue del D.F a San Andrés conoció a la madre de J.L.R, la cual huyó de su casa ya que siempre trabajó y su madre le quitaba el dinero, por esa razón la madre del paciente decidió salirse de la casa y trabajar como sirvienta.

J.L.R, no recuerda muchas cosas de su padre ya que dijo que casi no lo veía porque se la pasaba fuera de la casa trabajando en el rancho, pero recuerda a su padre como una persona agradable y con sentido del humor.

Los padres del paciente no se casaron, vivieron en unión libre y dice que esto le avergüenza porque habla mal que una mujer viva con un hombre sin estar casados. 
Tiene 3 hermanos, la primera es mujer, el segundo es hombre, después es él y finalmente otra mujer, la relación con sus hermanos actualmente es buena, comentó que hace tiempo tuvo problemas con su hermana mayor ya que Ésta no aceptaba a su esposa.

También tuvo problemas con su hermana menor la cual vive en Tlaxcala, ella tampoco aceptaba a la esposa del paciente, dice que en una ocasión que fueron a Tlaxcala a visitarla jamás los invitó a su casa e hizo que se fueran a un hotel, el paciente comenta que se sintió rechazado y asegura que esa experiencia le endureció el corazón y decidió no volverla a buscar, comenta que le guardó rencor por mucho tiempo.

Actualmente a raíz de su enfermedad decidió hablar con sus hermanas y asegura llevar una buena relación con ellas, comenta que ya están grandes como para guardar rencores y más si son hermanos, la esposa del paciente también lleva una buena relación con sus cuñadas.

La sesión se tuvo que dar por terminada debido a que entró el personal médico para someterlo a su cuarta transfusión.

\section{Sesión \#4:}

\section{Fecha: 10 Febrero- 2005}

El paciente se encontraba sentado en la cama con su bata de hospital y debajo de ella una pijama, estaba bañado, aliñado y peinado. Nuevamente se encontraba acompañado de su esposa y se encontraban escuchando música.

Se encontraba muy sonriente, de buen humor, cooperador y nuevamente dispuesto ayudar con la investigación, proporcionando información.

El día de hoy no se encontraba cansado, ni con temperatura ni bajo efectos de los sedantes, por lo que en esta ocasión aceptó que se le aplicara terapia ocupacional, lo que aceptó hacer fue sopa de letras y crucigramas ya que según lo dicho por el paciente es lo que acostumbra hacer diario en sus ratos libres y que quería aprovechar que ya no se mareaba y que podría retomar estas actividades, en estas actividades duró aproximadamente $30 \mathrm{~min}$. y gritaba y se emocionaba cuando lograba terminarlos.

La sesión se vio interrumpida con la visita médica, al salir los médicos se retomé la sesión y ahora el paciente se encontraba con otra expresión se le veía preocupado, le pregunte que le pasaba y en efecto el pacientes comentó que estaba preocupado ya que el médico le dijo que se le había detectado neumonía nosocomial, es decir una neumonía que había sido adquirida dentro del hospital debido a la baja de defensas que tiene.

J.L.R desconocía que podía padecer neumonía el pensaba que solo tenía tos, pero con los resultados de las radiografías tomadas en la noche anterior, el diagnóstico de neumonía 
fue confirmado por lo que el paciente permanecerá en el hospital hasta que ceda la infección.

En cuanto a su problema de bazo le dijeron los médicos que ya había disminuido la inflamación, y en cuanto a su Bicitopenia (anemia) por baja de glóbulos rojos y plaquetas, solo estaban esperando a los donantes para hacerle la siguiente transfusión.

El día de hoy se le aplicó el instrumento de necesidades, y los resultados fueron los siguientes, el paciente siente que no se le dio un trato humano en el hospital, afirma que el personal de enfermería nunca lo lastimó y que siempre que necesita algo hay una enfermera cerca, tanto los médicos residentes como el médico tratante le parece que son personas éticas y profesionales que siempre le hablan con la verdad y en términos que entiende

El paciente esta conciente de la enfermedad que padece y de sus posibles consecuencias, el diagnóstico lo sabe también su familia y seres queridos con los que comparte abiertamente sus miedos, pensamientos y sentimientos, le gusta sentirse acompañado y querido, J.L.R, afirma no tener asuntos pendientes ya que arregló sus diferencias con sus hermanas, no tiene problemas con la esposa ni con sus hijos y asegura ya tener listo su testamento y los asuntos legales.

Actualmente no tiene sentimientos de soledad, de tristeza o de ira, aunque acepta haberlos tenido, pero comentó que con las sesiones que hemos tenido ha podido manejarlos mejor sin embargo, sigue sintiéndose incapaz de realizar las mismas actividades que antes realizaba ya que se cansa con mucha facilidad.

Comenta que no le tiene miedo a la muerte ni a lo que pueda pasarle, aunque expresó que algo que si le da miedo es el dolor.

J.L.R, se siente bien de poder compartir sus sentimientos, miedos y pensamientos con una persona ajena a la familia, por lo que pidió que el día de mañana hubiera otra sesión y que le gustaría realizar alguna otra actividad para no aburrirse, comentó que no había querido hacer nada debido a que se sentía muy cansado.

A los pocos minutos de la aplicación del Instrumento, la sesión terminó debido a que iba a desayunar y de ahí se le iba a llevar al laboratorio para que le tomaran una muestra de sangre para ver como iba evolucionando su Bicitopenia, y ver cuantas transfusiones más iba a requerir. 


\section{Sesión \#5}

\section{Fecha: 11 de Febrero -2005}

El paciente se encontraba bañado, aliñado y peinado, se le veía serio, callado y pensativo, tenía tos debido a la neumonía, se encontraba acompañado nuevamente con su esposa.

J.L.R ya no tuvo temperatura, ya no tiene mareos, la inflamación del bazo disminuyó, la bicitopenia esta controlada y lo único que lo mantiene en el hospital es la neumonía.

En la mañana había recibido su última transfusión, en total fueron 5, por lo tanto fueron 5 donantes, 3 de ellos sus hijos los cuales después de la transfusión tuvieron una pequeña baja de defensas por lo que les dio gripe y debido a que el paciente tiene neumonía no pueden visitarlo hasta que se recuperen de la gripa.

También en la mañana se le sacó otra dosis de sangre para checar como iban sus glóbulos rojos y sus plaquetas y al parecer ya sus células están restableciéndose.

Comentó que se sentía cansado pero que tenía muchas ganas de platicar, se levantó de la cama y se acomodó de tal manera que quedó sentado frente a mí.

Nuevamente trato de proporcionar información útil para la investigación, comenzó a contar chistes y anécdotas, buscaba hacerme reír, lo cual me pareció que es una muestra de que trata de agradar.

Comentó que se siente harto que ya quiere salir del hospital pero su médico le dijo que es necesario que cumpla 10 días de tratamiento, el lunes 14 de Febrero termina el tratamiento, ese día se le va a realizar un estudio de tórax para ver como va la neumonía y probablemente el mismo lunes o a mas tardar el martes lo den de alta.

El paciente comenzó a tener frío y nuevamente se acostó y se tapó, debido a la tos, no pudo hablar mucho ya que si lo intentaba le daban ataques de tos.

Nuevamente el médico de guardia interrumpió la sesión y comentó que era pertinente dejar descansar al paciente, el médico habló con la esposa de J.L.R y le comunicó que aunque en esta ocasión había resultado bien el tratamiento, era necesario que cada mes se le realizaran estudios de sangre para evitar que la Bicitopenia se complicara aún más, también le comentó que aunque el bazo ya estaba desinflamado en cualquier momento le podía reventar y que era necesario que se le sometiera a una intervención quirúrgica. 
Tanto la esposa como el paciente dicen estar concientes de lo que puede pasar a futuro, pero J.L.R comentó que no quiere operarse ya que siente que puede morir en plena operación, también comentó que no le da miedo la muerte porque ya tiene todos sus asuntos arreglados tanto personales, como económicos y sociales.

Esto suena contradictorio, por lo que le dije que me aclarara mejor este punto. Me comentó que a pesar de no tenerle miedo a la muerte no se iba a arriesgar a morirse en una operación y que prefería seguir con esos dolores pero vivir más tiempo para poder estar con su esposa.

La sesión terminó ya que el médico indicó que era mejor que el paciente descansara.

\section{Sesión \#6}

\section{Fecha: 14 de Febrero -2005.}

El paciente se encontraba bañado, aliñado y peinado, estaba desayunando, no tenía temperatura ni mareos, la tos ya casi se le quita, se encontraba tapado con su bata de hospital, pijama abajo y un suéter encima color rojo, se encontraba acompañado de su esposa.

La enfermera entró a colocarle el suero y se lo tuvo que poner en el otro brazo (en el derecho), debido a que el izquierdo ya esta morado e inflamado.

Después de que salió la enfermera, entró su médico tratante, el cual le hizo una serie de preguntas y vio que J.L.R. ya no tiene molestias, ni dolor, ni temperatura, ya no hay flemas y la tos esta cediendo, el médico le dio los resultados de sus análisis de sangre los cuales salieron bien, el único problema que le encontraron es que tiene un poco elevado el ácido úrico por lo que debe evitar comer carne roja y alcohol, y llevar una dieta baja en sales.

El médico le hizo una revisión para ver como se encontraban sus pulmones y comentó que al parecer la neumonía ya cedió, para corroborar esto el paciente tuvo que ir para que se le sacara nuevamente una placa toráxica y dependiendo de los resultados el paciente será dado de alta el día de hoy o mañana.

Antes de irse a la sala de rayos x, agradeció el tiempo brindado y comentó que aproximadamente cada mes o mes y medio iba a estar viniendo al hospital para realizarse sus análisis y que esperaba que si vuelve a internarse en el hospital, se pueda dar continuidad al tratamiento ya que quería más sesiones. 
También me pidió que no le cambiara el nombre y que pusiera su verdadera identidad y sin abreviaturas en la investigación, esto es una forma de querer trascender y fue algo con lo que me identifique ya que yo hubiera pedido lo mismo, por esta razón voy a cumplir la petición del paciente dando su nombre real y completo el cual es: Juan Luna Ramírez.

La despedida fue emotiva ya que el paciente se paró, me abrazó y me dio las gracias, yo no esperaba esa reacción por parte de él ya que a mi parecer era una persona poco expresiva con la gente que no conoce, me sentí bien durante todas las sesiones con él, hubo empatía, respeto y congruencia, sin embargo algo que me costó trabajo tener con él fue consideración positiva incondicional, el aceptarlo tal cual es se me dificultó sobretodo en la primera sesión ya que me pareció un hombre muy serio y enojón lo cual me molestó en un principio pero después comprobé que tenía buen carácter y que su volubilidad se debe a su estado de salud lo cual en un principio me costó trabajo aceptar.

\section{Análisis de resultados del Paciente \#1:}

Tipo de paciente: Demandante ya que constantemente trato de agradar proporcionando información necesaria para esta investigación, además de que pidió que se pusiera su nombre completo en esta tesis, es decir pidió algo a cambio después de ayudar en la investigación, esto también lo hizo con la finalidad de trascender.

El paciente es cristiano por lo que la idea de muerte no le espanta ya que él se siente tranquilo de que le espera la vida eterna.

Necesidades del paciente: Se vieron principalmente las siguientes necesidades, tiene necesidad de compañía, no le gusta sentirse solo, necesidad de contar con alguien y de expresar sus miedos, sentimientos y dudas, necesidad de sentirse útil, necesidad de compartir lo que piensa con alguien ajeno a la familia, necesidad de estar enterado de que le esta pasando y que hacen los médicos por él.

El paciente no mostró necesidad de saber algo relacionado con el tema de la muerte ya que según lo que él dijo en no tiene miedo a lo que pueda pasarle y mucho menos a la muerte, comenta que siempre su filosofía de muerte ha sido la misma: El que se muere no sufre, solo los que se quedan, y que por esta razón no le teme, comenta que no quiere morirse todavía pero que si llega a pasar, no le espanta.

Tipo de apoyo brindado: En todo momento se brindó apoyo con enfoque humanista ya que hubo empatía con el paciente, se logro tener una condición positiva incondicional y me acerque a él, tendiendo siempre la mayor congruencia posible entre lo que decía y pensaba.

En cuanto al acompañamiento tanatológico, el paciente se encontraba en un principio en la etapa de ira ya que tenía coraje en cuanto a sus sentimientos de inutilidad, se acompañó al paciente y se le permitió que expresar sus sentimientos y pensamientos, al final, terminó en la etapa de aceptación, no se le brindó apoyo tanatológico ya que no se 
trató de influir en que cambiara de ideas, además de que en un principio estaba en la fase de ira y en esta etapa no se le brinda apoyo tanatológico a un paciente, nunca se le vio en la etapa de negociación, negación o depresión esto quizás a que fueron pocas sesiones con él y quizá en algún momento las vivió antes de estar en la etapa de ira que fue en la que se empezó a trabajar con él.

Por otra parte para minimizar sus sentimiento de inutilidad se le dio un poco de terapia ocupacional, haciendo sopa de letras y crucigramas.

\section{PACIENTE \#2:}

\section{Sesión 1}

\section{Febrero- 2005.}

M.C.L, de sexo femenino, de 83 años de edad, viuda, ya que su esposo murió por cáncer de pulmón y cirrosis debido a que era alcohólico, la paciente se encontraba bañada, aliñada, es una mujer de aprox. $1.75 \mathrm{~m}$ de estatura y de peso aproximado de $45 \mathrm{Kg}$., tiene labios delgados, tez morena clara, se le veía un tono amarillo en la cara, ojos café, ceja poblada color negro, cabello lacio, canoso y se encontraba despeinada.

La paciente se encontraba sentada en una silla a lado de la ventana, la cual tiene vista a la calle, sentía mucho frío y estaba tapada con varios suéteres y una cobija, estaba muy callada, pensativa y se encontraba cansada ya que constantemente se le saca sangre para análisis y se sentía debilitada, a pesar de esto mostró sentido del humor durante toda la sesión.

Ingresó al hospital Darío Fernández ya que se le diagnosticó Pancitopenia, es decir tiene bajos los 3 elementos principales de la sangre: plaquetas, glóbulos rojos y glóbulos blancos.

Su hija, se encontraba con ella en el cuarto, comentó que M.C.L, siempre ha padecido de Anemia, y que debido a esto tuvo 8 abortos, pero que ahora ya se le había complicado.

La paciente también padece Hipertensión arterial sistémica (HAS), es decir tiene presión alta.

Se estableció un buen Rapport con ella, y de inmediato se mostró cooperadora y platicadora, siempre con buen humor.

Durante la sesión comentó que esta en espera para que la trasladen a otro hospital ya que necesita que se le realicen unos estudios que no tienen en este hospital, pero aún esta en lista de espera y de acuerdo a los médicos probablemente sea trasladada en 2 semanas más.

M.C.L dice tener 5 hombres y 3 mujeres:

Varones de 70 años, 60 años, 50, 45 y 43. 
Mujeres de 59 años, 58 años y 48 años.

Las edades de los hijos no coinciden ya que ella se casó a los 17 años y tiene 80 años por lo que no puede tener un hijo de 70 años, esto hace pensar que las edades de los otros hijos también puedan ser incorrectas, pero estos son los datos que menciono la paciente y como solo hable con sus hijas no pude corroborar las edades de los varones.

Comenta que su segundo hijo varón es una persona muy delicada y exagerada con la limpieza, dice que es una persona muy amargada y que por esa razón ni su esposa lo aguantó y lo dejó, la paciente tiene en total 12 nietos y 4 bisnietos, de sus otros hijos no habló, solo comentó que con quienes lleva una relación mas estrecha es con sus 3 hijas. Durante esta sesión se le aplico el instrumento de detección de necesidades y los resultados fueron los siguientes:

La paciente ha recibido un trato humano en el hospital, tanto el personal de enfermería como los médicos residentes la han tratado con amabilidad y siempre acuden cuando necesita algo, su médico tratante le parece una persona profesional y ética y siempre le dice lo que tiene en términos que ella pueda entender, comenta que su médico siempre le ha hablado con la verdad, en cuanto a la higiene del hospital dice que no es muy buena ya que no siempre hacen su cuarto y menos los fines de semana, en cuanto a la dieta que tiene dentro del hospital, comenta que no le gusta ya que no tiene sal pero sabe que es importante evitarla debido a su enfermedad, también sabe que esa dieta es la adecuada para la enfermedad que padece.

Sabe que enfermedad padece y las consecuencias que puede traerle, el diagnóstico lo comparte con sus seres queridos, los cuales siempre la han apoyado, principalmente sus 3 hijas.

No presenta sentimientos de soledad, ni enojo, ni tristeza, pero si se siente incapaz de realizar las actividades que hacía antes como cocinar, cocer, tejer y bordar.

M.C.L, sabe que su enfermedad puede causarle la muerte, tiene miedo de lo que pueda pasarle, tiene miedo a sufrir y a morir, por lo que le gustaría contar con una persona ajena a su familia para compartir estos miedos ya que no quiere alarmar a sus seres queridos, también le gustaría que dentro del hospital hubiera algún tipo de actividad ya que comenta que en ocasiones se aburre.

Después de la aplicación del instrumento quise saber porque le asustaba la muerte y dice que no es tanto a la muerte ya que ella había estado a punto de morir varias veces, comentó que una vez al dar a luz tuvo preeclampsia es decir le subió mucho la presión y estuvo a punto de morir, ella comentó haber tenido una experiencia de cuasi muerte y que sintió mucha paz y tranquilidad y dejo de tener miedo, afortunadamente la preeclampsia fue controlada y ella salió adelante, comenta que después de esta experiencia no le teme tanto a la muerte sino más bien al dolor, ella tiene la creencia del cielo y del infierno y dice tener mucho miedo de no llegar al cielo. 
Le pregunté porque cree que no va a llegar al cielo y dijo que quería resolver algunos pendientes con sus hijos en especial con el que había estado en la cárcel ya que desde este acontecimiento comenzaron los problemas entre ellos y ella decidió dejarle de hablar durante un tiempo, comenta que si no arregla los problemas con su hijo seguro ira al infierno y que en realidad lo que le da miedo es morir sin hablar con su hijo antes. La sesión se dio por terminada ya que llegó el personal de enfermería para el chequeo de rutina.

\section{Sesión \#2}

\section{5- Febrero- 2005.}

La paciente se encontraba dormida debido a que se le acababa de realizar unos análisis de sangre. Cada $8 \mathrm{hrs}$. se le extrae una muestra de sangre, debido a esto no había dormido bien durante la noche ya que constantemente tuvo visitas médicas, debido a que durante la noche se le subió la presión, por esa razón no se encontraba bañada ni aliñada.

Se encontraba acompañada de otra de sus hijas, la menor de ellas, una persona abierta y platicadora, la cual sabe el diagnóstico de su mamá y tiene conciencia de lo que puede pasarle sino se cuida, lo único que la hija desconocía es que la madre padece presión alta.

M.C.L. comentó que el día de mañana se le va a realizar un estudio por lo que solo va a poder desayunar y ya el resto del día no puede comer alimentos, solo agua ya que le van a hacer un estudio de colon, debido a que los médicos quieren descartar cáncer.

Comenta que lleva varios días sin comer bien ya que tiene una escara en la lengua, M.C.L sabe que tiene que comer ya que tiene anemia, por esa razón lo intenta.

Dijo que la anemia empeoró cuando uno de sus hijos, el más chico de todos estuvo en el reclusorio ya que lo acusaron de abuso sexual. Según la paciente y la hija de ésta, fue una acusación falsa, y salió bajo fianza; a consecuencia de esto, la anemia se le complicó, este hijo es al mismo al que le dejo de hablar después de este acontecimiento. También dijo que se sentía cansada y que se siente incapaz de hablar mucho porque además le duele la escara de la lengua, por lo que prefirió realizar terapia ocupacional y realizó sopas de letras y crucigramas, con ayuda de su hija ya que la paciente esta aprendiendo a leer.

La sesión se vio interrumpida por el personal de enfermería quienes checaron que la paciente hubiera desayunado ya que iba a ser su último alimento en varias horas. Le revisaron la presión la cual ya se encontraba normal. Posteriormente se la llevarón a bañar, para luego llevarla varón a realizar unos estudios, por lo que la sesión se dio por terminada. 


\section{Sesión \#3}

\section{6- Febrero-2005.}

La paciente se encontraba sentada en su silla de ruedas, sin bañar y sin aliño, se encontraba tapada ya que tenía mucho frío, estaba acompañada de su hija mayor, tenía expresión de miedo, al preguntarle que le pasaba comentó que estaba nerviosa ya que le iban a realizar su estudio de colon y unos estudios de sangre.

El personal médico me informó que en los últimos estudios que le realizaron a la paciente encontraron una baja de células aún más severa por lo que va ser necesario que se le empiecen a dar transfusiones.

La paciente esta conciente de que va a necesitar transfusiones y va a informarle a sus familiares, ya que necesita 7 donadores.

La primera transfusión se le va a realizar el día de hoy ya que según lo médicos la anemia esta muy severa, debido a que la paciente casi no come.

Otro de los estudios que se le realizará el día de hoy es un electrocardiograma ya que los médicos comentan que probablemente ya esté afectado o se esté forzando demasiado.

Antes de los estudios la paciente comentó que no se siente deprimida pero que si tiene miedo a los estudios porque tiene miedo de que le duela, comenta que lo que mas le causa miedo es sufrir, dice que sabe que va a morir por lo que esta tratando de arreglar todos sus asuntos pendientes como el testamento, ya que no quiere dejarle problemas a sus hijos cuando muera.

El día de hoy pidió que si podía escribir un pequeño cuento, dijo que no sabía escribir muy bien pero que quería dictarme algo:

"Cada día estoy mas cerca de mi último viaje, afortunadamente en este camino estoy acompañada, en ningún momento he estado sola ya que tuve mucho hijos, sin ellos mi vida estaría vacía, primero perdí a mi papá, después a mi mamá y finalmente a mi esposo, gracias a él no me quede sola ya que fui madre 8 veces y otras 8 me quede a la mitad del camino ya que mis hijos murieron, pero pronto los voy a alcanzar."

Con este pequeño cuento que la paciente me dictó se ve claramente que la paciente esta conciente de que pronto va a morir, también se ve que se siente acompañada y que le encanta la idea de haber tenido varios hijos.

Después de que terminó el cuento, la paciente me dio una recomendación me dijo que me apurara a tener hijos y que tuviera muchos para que nunca este sola y para que en caso de que me enfermara siempre tuviera a alguien que me cuidara. 
La sesión se vio interrumpida ya que el personal de enfermería fue por ella para realizarle sus estudios.

Los médicos comentan que la paciente no tiene mas de 6 meses de vida ya que su anemia esta muy avanzada por lo que su corazón se esta forzando mucho y esperan que en cualquier momento la paciente tenga un paro cardiaco.

De los problemas cardiacos no esta conciente la paciente ya que antes de comentarle quieren corroborarlo con los estudios, la sesión terminó ya que durante los estudios la paciente se encontraba muy nerviosa por lo que se le tuvo que suministrar un tranquilizante.

\section{Sesión \#4}

\section{7 de Febrero- 2005.}

La paciente se encontraba bañada, aliñada y peinada, estaba sentada junto a la ventana ya que comenta que le gusto mucho ver hacia la calle, se encontraba de buen humor y acompañada de su hija mayor, comentó que ayer se le realizó su primera transfusión y que se sentía un poco mejor.

M.C.L, se quejaba de los dolores que tenía a causa de sus estudios, comenta que ya quieres irse a su casa ya que la cama la lastima mucho y más ahora después de los estudios.

Comenta que no durmió bien a causa de los dolores, asegura que lo que más le duele son los pulmones ya que le hicieron una biopsia.

La sesión se vio interrumpida ya que le llevaron el desayuno el cual comió lentamente debido a su escara de la lengua la cual se encuentra todavía mas abierta.

Mientras desayunaba, nuevamente me contó la historia de su hijo, el cual había estado en el reclusorio durante 9 meses, al salir estaba cortado y quemado de la cara.

La paciente decidió que su hijo se fuera a vivir con ella después de que salio del reclusorio, M.C.L, actualmente vive con él aunque no le habla dice que por lo menos viviendo con ella lo puede controlar más, también vive con su hijo de 60 años y su esposa (los cuales no tuvieron hijos y adoptaron a un varón que actualmente tiene 30 años y según la paciente se olvidó de sus padres adoptivos porque ya no los busca)

Después de contarme esto, me pidió tiempo ya que quería que su hija le cortara el cabello, mientras fui aunque algo enojada porque me sentí manipulada, en ese tiempo fui con el personal médico para conocer los resultados de los estudios, lo médicos comentaron que la paciente tiene un cáncer muy avanzado de pulmón, y que por esa razón se le había tenido que realizar varios estudios para ver si el cáncer no se había propagado. 
De acuerdo a los médicos ella sabe que tiene cáncer de pulmón desde hace tiempo.

Posteriormente regrese con la paciente la cual se encontraba ya con el cabello corto y peinada, le pregunté sobre su enfermedad y me comentó lo de la HAS y la Pancitopenia, la cuestione sobre si padecí alguna otra enfermedad y me comentó que tenía cáncer de pulmón, al preguntarle porque no me lo había comentado antes, dijo que era porque no quería que su hija menor se enterara.

En eso la hija mayor que se encontraba aun con ella comento que su madre ya tenía mucho tiempo con cáncer de pulmón pero que no le preocupaba que tuviera esa enfermedad ya que su madre era muy fuerte, comentó que la enfermedad había matado a su padre pero que no podía matar a su madre, ya que para ella era una enfermedad simple.

El día de hoy la paciente pidió hacer barcos de papel y comentó que de joven siempre le hizo barquitos a sus hijos y le gustaba acordarse de sus hijos cuando eran niños, ahora hizo 8 barcos, dijo que le iba a dar un barco a cada hijo, después me pidió una hoja para hacer un barco más, comentó que en ese barco iba a viajar a un lugar mejor, cuando le pregunte a que lugar se refería dijo que era el cielo, y que ese iba a ser su último viaje, le pregunte si faltaba mucho para ese viaje y contestó que no, que ella cada día estaba más preparada para ese viaje y que cada día le teme menos.

Cuando empezó a comentar esto nunca perdió la sonrisa ni el sentido del humor, en su expresión se veía tranquilidad.

La sesión se vio interrumpida ya que llegó su médico tratante el cual quería hablar con ella y con su hija, para informarles los resultados de los estudios, también le informaron que aún no hay cuartos en el hospital donde la quieren enviar por lo que tendrá que permanecer en el hospital aproximadamente 1 semana más.

Cuando entró el médico tratante le preguntó como se sentía y si seguía con dolor en el pulmón la paciente dijo que aun estaba molesta pero le pidió que no le pusieran más sedantes ya que no quería seguir durmiendo todo el día, que quería sentirse útil, le pidió que por favor se retirara ya que estaba en una sesión y que no quería que la interrumpiera, aún así el médico le suministró sedantes ya que consideró pertinente sedarla para que el dolor no aumentara sino sería más difícil controlarlo, posteriormente se le dio la segunda transfusión. 


\section{Sesión \#5}

\section{Febrero- 2005.}

La paciente se encontraba bañada, aliñada y peinada, se encontraba sentada junto a la ventana, desayunando y estaba escuchando el radio, se encontraba sola, y nuevamente se mostró cooperadora y de buen humor.

Tenía una expresión de cansancio, al preguntarle si estaba cansada comentó que si ya que no durmió bien por las constantes visitas médicas durante la noche.

En esta ocasión la paciente quiso contarme un poco sobre su historia, comentó que es de Guanajuato y que su esposo también era de allá, comentó que lo conoció en una fiesta de pueblo cuando ella tenía 17 años y el 47 años y se casarón a los 8 meses de conocerse para que ella cumpliera la mayoría de edad, vivieron 2 años en Guanajuato y posteriormente vendieron sus terrenos, casas y animales para venirse a vivir al D.F, se vinieron para acá ya que debido a las constantes inundaciones perdieron las cosechas, lo cual era su principal ingreso económico y decidieron cambiarse al D.F, ya que la hermana de su esposo vivía aquí y vivieron con ella un tiempo.

Posteriormente compraron una casa y se fueron de la casa de la hermana del esposo de la paciente, M.C.L comentó que su esposo era alcohólico. Y que 2 de sus hijos también toman mucho el quinto de sus hijos que tiene 45 años y su hijo mas chico que tiene 43 años.

Comentó que debido a tantos hijos nunca pudo estudiar, no sabe ni leer ni escribir, actualmente esta empezando a leer ya que su hija la esta enseñando, dice que no tiene ni la primaria ya que su madre murió de un paro cardiaco cuando ella era muy niña, a su padre no lo conoció ya que cuando su madre tenía 3 meses de embarazo el padre fue asesinado con un puñal.

La paciente no recuerda mas detalles, no recordó su fecha de nacimiento y cambia las edades de sus hijos, dice que con la edad se ha vuelto "tarada", la verdad cuando me dijo esto me dio risa. Esto puede explicar que los datos sobre las edades de sus hijos no coincidan.

Nuevamente contó la historia de su hijo, el que estuvo en el reclusorio porque lo acusaban de abuso sexual, y de acuerdo a la paciente su hijo era inocente.

Comentó que a pesar de que su esposo falleció cuando ella tenía 40 años, nunca se sintió sola ya que tuvo muchos hijos y nunca ha estado sola, comentó que ella tuvo que trabajar para mantener a su familia, todos sus hijos estudiaron hasta la secundaria ya que no pudo seguir pagándoles los estudios, sus tres hijas tejen y bordan y eso lo venden para sacar dinero, sus hijos de 50, 45 y 43 años son policías.

La sesión se vio interrumpida ya que llegó su hija, la de en medio y como tenía mucho tiempo de no verla y querían platicar, la sesión terminó. 
Los médicos comentaron que por la tarde se le aplicaría la tercera transfusión.

\section{Sesión \#6}

\section{1-Febrero-2005.}

La paciente se encontraba acostada y tapada con varias cobijas y suéteres ya que tenía mucho frío, M.C.L no estaba bañada ni aliñada ya que estaba en espera de su visita médica, y comenta que si se va y pasa el médico, este ya no regresa y tendría que esperar hasta la visita vespertina, también tenía que esperarse ya que le estaban transfundiendo sangre, con ésta ya es la cuarta transfusión.

Se encontraba con una pijama de franela que le regaló su hija, en esta ocasión estaba acompañada de su hija mayor y ambas estaban viendo la T.V.

No tiene ningún dolor, se sentía bien, lo único que le molestaba es la escara de la lengua que cada día tiene más abierta y la gripa que le empezó el fin de semana.

Comentó que durante el fin de semana no hubo ningún cambio importante en su salud y que aún sigue en espera de su traslado al otro Hospital para que le realicen su estudio, la paciente se encontraba muy cansada ya que todo el fin de semana se quedo con su hija, la cual no veía desde hace tiempo y se desvelaron platicando y que por esa razón tenía mucho sueño.

Los médicos comentan que esa gripa, puede ser un síntoma de Neumonía Nosocomial, es decir que fue adquirida dentro del hospital (nosocomio), también consideran que ya con las 4 transfusiones que lleva han visto una buena mejoría en las células de la sangre.

La hija salió a desayunar y mientras se aprovecho el momento para continuar con la sesión.

El día de hoy la paciente no quiso hablar mucho sobre su vida, prefirió realizar terapia ocupacional, en esta ocasión decidió hacer figuras con plastilina, lo que la paciente realizó fue un barco color morado sobre una base azul, la paciente dijo que es el agua en donde navega el barco para llegar a su último destino.

Le pregunté quien viajaba en ese barco, a lo que contesto que ella, le pregunte si iba acompañada y dijo que no, pero que al lugar a donde llegaría si estaría acompañada por los 8 hijos que perdió y por sus padres, le pregunte si también estaría su esposo y dijo que no, que el estaba en otra isla, al preguntarle como

era esa isla dijo que era un lugar a donde iban las personas agresivas y alcohólicas, comento que no le guardaba rencor por haberla golpeado pero que Dios envía a esa gente a otro lugar y que ella iba a ir a otro muy diferente, comentó que espera un día encontrarlo en la misma isla porque lo extraña. 
Lo que expresó con este barco fue lo mismo que con el cuento, nuevamente habla de un viaje y se ve la conciencia de muerte que tiene la paciente, con el cuanto de sesiones anteriores no me sentí tan mal pero cuando hizo el barco y me empezó a explicar que se iba a su ultimo viaje me sentí un poco triste por ella, también note que se le llenaron sus ojos de lagrimas, le pregunte si estaba triste y comento que si ya que se le estaba acabando el tiempo y aun no hablaba con su hijo y el barco estaba a punto de zarpar.

Después de esto la hija de la paciente llego y ella se me quedo viendo con una expresión de que ya no podía seguir hablando sobre esto, en cuanto llegó su hija la paciente prendió la TV.

La sesión se dio por terminada ya que el médico llegó a ver a la paciente, y le dijo que en 3 días la van a trasladar al otro hospital, también le extrajo una muestra de sangre para analizarla, me despedí de ella y pidió que siguiéramos con las sesiones, dijo que por lo menos se conforma con hablar aunque no hagamos más terapia ocupacional.

\section{Análisis de resultados del Paciente \#2:}

Tipo de paciente: Dependiente ya que constantemente me preguntaba cuantas sesiones nos quedaban, el día de la despedida me dijo que quería seguir viéndome, las hijas comentaron que a cada rato preguntaba si iba a ir a verla o no porque le gustaba mucho platicar conmigo.

Necesidades del paciente: Se vieron principalmente las siguientes necesidades, tienes necesidad de realizar otras actividades dentro del hospital para no sentirse aburrida, necesidad de que le aclaren que es lo que le puede pasar ya que tiene miedo, necesidad de compartir lo que siente y piensa no solo con sus seres queridos sino con alguien ajeno a la familia. Necesidad de hablar sobre el tema de la muerte con alguien ajeno a la familia ya que este tema le causa miedo y no quiere lastimar a sus seres queridos hablando de este tema, finalmente necesidad de arreglar asuntos pendientes con su familia.

La paciente muestra una gran necesidad de exteriorizar su miedo a la muerte, ella acepto temerle a este hecho y también teme a la incertidumbre, ya que no sabe lo que va a pasar y eso le asusta, comento de su necesidad de expresar estos temores con alguien ajeno a la familia, ya que aunque cuenta con ellos y comparte el diagnóstico con sus seres queridos no sabe como van a responder ante el tema de la muerte ya que la filosofía que sus hijos (as) tienen sobre este tema es muy diferente, ya que ellos no creen en el infierno y ella si y tiene miedo de morir e irse al infierno.

Tipo de apoyo brindado: En todo momento se brindo apoyo con enfoque humanista ya que hubo empatía con el paciente, se logro tener una condición positiva incondicional aunque en ocasiones me costo trabajo ya que me sentí manipulada en ciertos momentos y sentía que ella manejaba mis tiempos, después fui aceptando esto y logre aceptarla 
incondicionalmente, al igual que con el paciente anterior hubo me acerque a ella teniendo siempre la mayor congruencia posible ente lo que decía y pensaba.

En cuanto el acompañamiento tanatológico, la paciente se encontraba siempre estuvo en la etapa de aceptación sabia lo que le iba a pasar pero aun así tenia miedo, el acompañamiento permitió que M.C.L expresara sus miedos, sentimientos y pensamientos, en cuanto a la terapia ocupacional la paciente realizo sopa de letras, así como cuentos en donde manifestaba sus temores de muerte y su aceptación en cuanto a este hecho que es inevitable y próximo para ella debido a su estado de salud. Con ella tampoco se realizó apoyo tanatológico ya que no se le trato de ayudar a cambiar sus ideas y además no era necesario ya que estaba en la fase de aceptación, solo se le dio contención para que no regresara a otra etapa de duelo.

\section{PACIENTE \# 3: \\ Sesión \#1}

\section{4- Febrero- 2005}

Este paciente me fue asignado por la trabajadora social del hospital, quien me pidió que apoyara al paciente ya que éste se encontraba muy deprimido y no quería hablar, comentó que es un paciente muy triste ya que su familia no lo visita en especial sus hijos.

Le comentó a la trabajadora social que sus hijos no lo visitan ya que no tienen tiempo para verlo ya que tienen cosas más importantes que ver a su padre, también comentó que otros de sus hijos no lo vienen a ver ya que viven en Estados Unidos y ni siquiera están enterados de su situación porque no lo quieren.

Le dijo que los hijos que tiene aquí en el D.F, solo lo visitan cuando necesitan arreglar papeles de la herencia y las escrituras de los terrenos que tiene el paciente, (en total 3), le comentó que lo único que quieren es su dinero y su herencia y que la única persona que realmente lo quiere y lo comprende es su hija mayor, la cuál es psicóloga, dice que ella es la única de todos sus hijos que lo ha apoyado en todo momento.

La trabajadora social me pidió que le diera apoyo a este paciente ya que éste siempre se encontraba muy solo y que por esta razón no habla, según la trabajadora social el paciente lleva 3 días sin decir ni una palabra y que ya ni siquiera con ella quiere hablar, comenta que solo saluda y después evade y no contesta nada de lo que se le pregunta.

Acepté verlo ya que consideré que cumplía con las características necesarias para la investigación ya que padece una enfermedad terminal y va a estar internado aproximadamente 1 mes más por lo que se podían realizar las 6 sesiones con él, otro motivo por el que acepte el caso fue porque ya había visto a ese paciente y siempre esta solo. 
En esta primera sesión con el paciente llegue después de haber hablado con la trabajadora social, se encontraba sentado en una silla de ruedas, se encontraba bañado, aliñado, I.D.H es un paciente del sexo masculino, de 68 años de edad, casado, jubilado y con estudios hasta la primaria, de $1.65 \mathrm{~m}$ y $50 \mathrm{Kg}$. aproximadamente, cabello negro, con algunas canas, corto y no estaba peinado, ojos café, nariz respingada, labios delgados, ceja poblada y tez blanca.

Está internado en el hospital ya que padece Diabetes Tipo 2, Hipoglucemia, Hipertensión arterial (presión alta), infección de vías urinarias, úlcera duodenal, $H$. Pylori (una bacteria en el colon) y es alcohólico por lo que también padece gota, el paciente ingresó al hospital ya que fue a consulta externa y se encontraba con el azúcar muy elevada por lo que decidieron internarlo.

Cuando llegué solo me miraba fijamente, saludó y después no quiso decir nada por lo que en esta primera sesión no hubo muchos avances, llegué, me presenté, le expliqué lo que hacía y traté de establecer el rapport, le empecé a preguntar como se sentía, tenía una expresión de enojo, solo dijo que se sentía mal, que estaba enojado con el mundo y no quiso hablar más.

Trate de empatizar con él y viendo su situación pensé que probablemente lo estaba molestando y le pregunté que si quería que me fuera y que mañana lo visitaría, el paciente se me quedo viendo fijamente durante un tiempo aproximado de 5 minutos, posteriormente me tomó de la mano y dijo que quería hablar conmigo pero que no podía hacerlo debido a las constantes secreciones que tiene de flemas, las cuales le imposibilitan hablar mucho ya que tiene que estarlas expulsando constantemente.

I.D.H me pidió que no me fuera que iba a tratar de hablar y pidió que se le aplicara un poco de terapia ocupacional, empezamos con unos ejercicios físicos para sus brazos y sus piernas ya que se encontraban inflamadas debido a la retención de líquidos ya que el paciente casi no se mueve debido a los dolores que le produce la gota, durante la sesión constantemente expulsaba flemas por lo que tenía varios papales sucios sobre él y sobre su cama por lo que se me ocurrió que el paciente jugara canasta, le coloqué el bote de basura frente a él y le dije que aventara cada uno de los papeles al bote para ver cuantos papeles lograba meter, el paciente cambió su expresión y se le veía mas animado tratando de meter los papeles al bote de basura.

Finalmente agradeció el tiempo que había estado con él y dijo que por lo menos ya tenía en que entretenerse ya que en el hospital se aburre mucho y más si no lo visitan, me pidió que regresara mañana que quería contarme algo sobre su familia. 


\section{Sesión 2:}

\section{5- Febrero- 2005.}

El paciente se encontraba bañado, aliñado y peinado y acababa de regresar de unos estudios, se encontraba solo, su desayuno se encontraba sobre la mesa pero no quiso comer.

El médico tratante comenta que I.D.H, lleva varios días sin querer comer, otra muestra más de que el paciente se encuentra deprimido, también comentaron que no quiere hablar con nadie y que solo dice lo necesario como para poder decir si necesita algo, si le duele algo o para saludar, comentan que es una persona muy grosera y que al parecer siempre esta enojado.

El personal de salud se encuentra preocupado ya que si no come puede provocarse una anemia.

En esta sesión al ver su expresión le pregunté si se sentía triste o enojado, me comentó que estaba triste ya que se sintió muy solo pero que no estaba enojado, comentó que todos los médicos y enfermeras piensan que está enojado ya que contesta de manera cortante pero dice que esto es por la secreción constante de flemas que le impide hablar y no porque este enojado.

Nuevamente solo se me quedaba viendo fijamente y poco a poco trató de hablar un poco más, y me dijo que se sentía peor que ayer ya que hoy tenía dolores más severos en las articulaciones (a causa de la gota).

Me comentó lo mismo que le había dicho a la trabajadora social, dijo que sus hijos no lo visitaban ya que tenían cosas más importantes que hacer que estar con él, dijo que solo lo visitan para arreglar papeles de la herencia y que sus otros hijos viven en Estados Unidos y no están al tanto de su estado de salud porque no lo quieren.

$\mathrm{Al}$ estarme contando esto el paciente empezó a llorar y dijo que estaba deprimido porque nadie lo quería, hablé con él y le dije que probablemente sus hijos tenía muchas cosas que hacer y se les dificultaba venir a la hora de visita pero que esto no quería decir que no lo quisieran, el paciente dejo de llorar y dijo que tal vez tenía razón y que probablemente sus hijos lo irían a visitar en el transcurso de la semana. 
I.D.H dijo que a él no le gustaba llorar y que de hecho no lo había hecho desde hace más de 5 años pero que yo le inspiraba confianza y me pidió que siguiera visitándolo.

Tratamos de seguir con la sesión pero debido a que el paciente no come, volvió el estómago, el personal de enfermería comentó que esto se debía a que el paciente no tenía nada en el estómago y por esa razón había expulsado pura bilis y ácidos gástricos, cuando ocurrió esto, la jefa de enfermeras empezó a regañarlo ya que había ensuciado las sábanas y tenía que volverlas a cambiar, al ver que la enfermera empezó a regañar al paciente la verdad sentí mucho enojo porque pensé que no era su culpa el haberse sentido mal, por lo que me quedé con él y le dije que no había ningún problema y que ahorita lo iban a cambiar y todo estaba bien.

Después de esto el personal de enfermería lo cambiaron, lo asistieron y consideraron pertinente ponerle al paciente una sonda naso gástrica, es decir una sonda que va de la nariz directamente al estómago y sirve para suministrarle alimentos líquidos y estos llegan directamente al estómago.

Por esta razón las enfermeras consideraron pertinente dar por terminada esta sesión ya que el I.D.H además de cansado se encontraba incómodo con la sonda y adolorido.

\section{Sesión \#3:}

\section{8- Febrero-2005.}

El día de hoy el paciente se encontraba acostado, bañado, aliñado y peinado, se encontraba solo y tenía expresión de dolor y de cansancio, le pregunté que le dolía y comento que las rodillas y la espalda, dijo que tenía un dolor insoportable y que ni los sedantes le disminuían el dolor.

I.D.H dijo que estaba cansado ya que no pudo dormir por miedo a jalarse la sonda y lastimarse, me preguntó para que le habían puesto eso ya que no le habían explicado para que servía eso y que le parecía muy incómodo, le explique que se la habían puesto porque así era más fácil suministrarle el alimento ya que se estaba debilitando mucho porque no quería comer y que así la comida iba a llegar directamente al estómago y ya no iba a tener tantas náuseas ni vómito.

Nuevamente dijo que se sentía muy incómodo y que no podía dormir por miedo a lastimarse, le dije que podía dormir sin problemas ya que con el roce no le iba a pasar nada a menos que jalara con fuerza la sonda, el paciente cambio su expresión y dijo que ya se sentía más tranquilo, comentó que se sentía molesto por la sonda pero que le tranquilizaba el saber para que se la habían puesto, me pidió tiempo para dormir y me pidió que ya que se sintiera mejor le aplicara un poco de terapia ocupacional.

Después de un rato regresé para continuar con la sesión, en esta ocasión quiso jugar dominó y posteriormente memorama, ya se le veía de mejor humor, ya sonreía a pesar de que todavía se sentía cansado, I.D.H se la pasó riendo y comentó haberse divertido, dijo 
que se la estaba pasando muy bien, la sesión se vio interrumpida ya que llegó la esposa del paciente a visitarlo, una mujer de aproximadamente $1.55 \mathrm{~m}$ y $65 \mathrm{Kg}$., cabello lacio, largo, peinado de color castaño entrecano, tez morena clara, ojos café, de 65 años de edad .

Hable con la esposa ya que era la primera vez que la veía, me presenté y le comenté que estaba dando apoyo psicológico y tanatológico a su esposo ya que había estado muy deprimido, la esposa comentó que casi no visita a su esposo debido a que ella también está enferma y constantemente está en reposo ya que padece reumatismo, también comentó que ella vive muy lejos del hospital y no siempre tiene quien la lleve a ver a su esposo.

Al ver que tenía la visita de su esposa, consideré pertinente dejarlo con ella ya que según la trabajadora social y las palabras del mismo paciente se siente solo ya que casi no lo visitan, la verdad es que cuando vi a su esposa sentí enojo con ella ya que casi no lo visita y siempre está solo.

Cuando iba a salir del cuarto para dejarlos solos, me agarró la mano y su expresión era de que no lo dejara solo, me preguntó que a donde iba y le conteste que los iba a dejar un rato para que platicaran, I.D.H no soltaba mi mano, en eso llegó su hija mayor, una mujer de aproximadamente $1.65 \mathrm{~m}$ y $60 \mathrm{Kg}$., cabello castaño claro, corto y peinado, tez blanca, ella es psicóloga y como se mencionó anteriormente la persona más querida para él ya que es la única que lo comprende.

A la hija se le veía preocupada por su padre y muy cariñosa con él, las visitas estuvieron aproximadamente 20 minutos y posteriormente se fueron.

Cuando se fueron regresé con I.D.H y me comentó que no le gustaba quedarse solo con su esposa ya que está siempre lo regaña y que ya esta cansado de ella, pero que al ver que también venía su hija mayor no le importo que lo dejara con ellas ya que su hija siempre lo apoya y lo defiende cuando su esposa lo regaña o le llama la atención, comentó que es la única de sus hijos que lo apoya y que seguramente lo entiende porque ella si tiene estudios y es psicóloga y conoce la mente humana.

Al querer saber mas sobre su familia, en especial de sus hijos hubo un silencio y después dijo que prefería no hablar de ellos ya que todos son unos malagradecidos, solo me dijo que tiene 8 hijos, 4 de ellos hombres y otras 4 mujeres, de los cuales los cuatro hombres viven en Estados Unidos y que ni siquiera han venido a visitarlo porque no les interesa lo que le pasa a su padre, comentó que su hija mayor le dijo que ya se había puesto en contacto con sus hermanos y que estos le dijeron que no pensaban venir a ver a su padre porque no lo quieren.

Por otra parte las 4 hijas del paciente viven en el D.F, 2 de ellas son estilistas, la mayor es psicóloga y la menor se dedica a estudiar la Biblia. 
La sesión se dio por terminada ya que el personal médico llegó para llevárselo a realizar una tomografía.

\section{Sesión \#4:}

\section{2- Marzo-2005.}

El paciente se encontraba peinado, aliñado y bañado, estaba solo, acostado con frío, I.D.H tenía temperatura y se encontraba con bolsas de hielo en la cabeza, pies y en el abdomen ya que tenía 39 grados de temperatura.

I.D.H dijo que se sintió peor que nunca y que ya quería irse a su casa porque en el hospital solo esta empeorando, en esta sesión le aplique el cuestionario de necesidades y los resultados fueron los siguientes:

Dice que dentro del hospital no se le ha dado un trato humano, que el personal de enfermería constantemente lo lastima y considera que son muy bruscas y que no saben tratar a los enfermos, comentó que constantemente lo regañan, dijo que cuando volvía el estomago las enfermeras lo regañaban, lo cual me consta, sin embargo dice que cuando necesita algo siempre acuden y aunque se tardan mucho en traer lo que pide, al menos siempre se lo llevan.

Por otra parte dice que los médicos residentes son personas preparadas y eficientes al igual que su médico tratante el cual es una persona ética y profesional, comentó que los médicos le hablan con la verdad y en términos que él entiende y que está enterado de lo que padece y de las consecuencias que puede traerle las enfermedades que padece.

I.D.H dice que no lo revisan constantemente, dice que siempre hay enfermeras en el cuarto pero que en muchas ocasiones se lo saltan y no lo revisan.

Por otra parte la higiene dentro del hospital le parece mala ya que no hacen la limpieza diario y menos si es fin de semana.

En cuanto a la dieta que le dan considera que la que le daban anteriormente era adecuada para su enfermedad pero que no le gustaba y ahora que su dieta es líquida y se la dan por sonda considera que es aún más apropiado ya que cuando le daban sólidos no podía comerlos porque le daban nauseas por tanta flema.

Tanto él como sus familiares, conocen el diagnóstico y están concientes de las consecuencias que puede traerle las enfermedades que padece; de los familiares que mencionó solamente fueron su esposa, su hija mayor que es psicóloga y la hija menor con la cual dice no llevarse bien porque siempre la regaña.

Dice que comparte sus miedos, pensamientos y sentimientos solo con su hija mayor ya que con su esposa y el resto de sus hijos no se lleva muy bien y no se siente apoyado y comprendido por ellos. 
I.D.H considera que tiene muchos asuntos pendientes que arreglar con su familia en especial con sus hijos ya que están muy distanciados y le gustaría hablar con ellos para arreglar asuntos pasados, no quiso hablar más sobre este tema.

Comenta que se siente solo y triste, solo porque sus hijos no lo visitan lo cual hace que también se sienta triste, también se siente incapaz de realizar algunas actividades que antes podía hacer con facilidad como trabajos de albañilería, dice que lo que lo incapacita para hacer las cosas es la gota ya que en ocasiones tiene dolores insoportables que lo imposibilitan para realizar trabajos pesados.

Dice que no tiene miedo a lo que pueda pasarle ni tiene miedo a la muerte, pero quiere que esta ocurra en su casa y no en el hospital, también dijo que le gustaría tener a una persona ajena a la familia con la que pueda compartir lo que piensa y lo que siente, comentó que afortunadamente para él ya había encontrado a alguien así y que era yo, señalando que se sentía muy bien conmigo y que le gustaba que le hiciera compañía, también esta contento con las actividades de tipo ocupacional que a veces realizamos ya que así se distrae y no se aburre.

La sesión terminó después de la aplicación del cuestionario ya que el paciente se veía y dijo sentirse muy cansado y además me pidió que siguiéramos mañana.

\section{Sesión \#5}

\section{3- Marzo. 2005.}

El paciente se encontraba sin aliño, solo, sentado con sus piernas estiradas ya que tenía retención de líquidos y se encontraba muy hinchado de sus piernas y brazos, esto es debido a la infección de vías urinarias que padece el paciente, se encontraba con una sonda, tenía expresión de dolor y comentó que no aguantaba la sonda y que prefería que le pusieran pañal, también dijo que le dolían las articulaciones y que se sentía muy mal y muy cansado, la sesión se vio interrumpida ya que se lo llevaron a bañar.

Posteriormente regresé y nos pusimos a jugar Dominó, en eso llegó la trabajadora social la cual le dijo a I.D.H que su hija menor estaba afuera y que quería verlo, a lo que contestó que no quería recibirla, la trabajadora social le pidió que la recibiera y que si había cualquier problema le pediría que se fuera, aún así no quiso recibir a su hija.

La trabajadora social consideró pertinente que no entrara la hija ya que quiere evitar que el paciente se altere por miedo a las bajas y altas de azúcar que en ocasiones presenta sobre todo si se altera.

Cuando se fue la trabajadora social le pregunté a I.D.H porque no recibió a su hija y dijo que era una persona que siempre hablaba de Dios y que él ya no creía porque esta enojado con él, tampoco la quiso recibir ya que según él, la hija siempre lo regaña y solo quiere su herencia, y que de hecho le había robado un terreno. 
La sesión se vio interrumpida ya que se lo llevaron a realizar unos estudios de sangre, rayos x y un ultrasonido, mientras me quedé platicando con la trabajadora social, la cual me pidió que hablara con la hija de I.D.H.

La hija menor se encontraba en espera de que su padre la recibiera y se encontraba llorando, llegué con ella me presenté y le comenté que había estado con su padre brindándole apoyo psicológico y tanatológico, se estableció el rapport rápidamente.

Comentó que ella siempre ha tenido la idea de que todos los psicólogos están locos, sobretodo por su hermana mayor la cual es psicóloga.

Al preguntarle porque creía esto, dijo que su hermana había puesto a su padre en contra de todos sus hijos, comenta que le lavó el cerebro con la idea de que

todos quieren su dinero cuando la que quiere todo es ella, dijo que su hermana todo el tiempo le da al papá por su lado, comenta que como psicóloga debería de ponerlo con los pies en la tierra en lugar de darle el avión porque esto lo único que hace es que crezca el coraje y el rencor que le tiene a sus hijos.

Le pregunté si todos los hijos de I.D.H saben que esta enfermo, dijo que si, que su hermana mayor nunca les avisó a sus hermanos que viven en los Estados Unidos sino que ella les había avisado pero que ellos no quieren venir a verlo ya que éste cosechó lo que sembró, según ella el padre los corrió de la casa porque ya no los quería ver y ya no quería mantenerlos, debido a esto se fueron a probar suerte a los Estados Unidos y le guardan rencor, a pesar de esto diario le hablan a ella para informarse en cuanto a la salud de su padre, están al pendiente desde lejos pero no quieren verlo por miedo a que les haga mas groserías y que los vuelva a rechazar.

Al preguntarle cuantos hijos eran en total me dijo que 12, lo cual es contradictorio con lo que el paciente le dijo a la trabajadora social y a mi, ya que decía tener 8 hijos.

De acuerdo a la hija de I.D.H, uno de sus hermanos esta en la cárcel, el otro esta desaparecido desde hace 3 años después de que su papá lo corrió de la casa, la mayor es psicóloga, 2 de sus hermanas son estilistas, ella se dedica a dar platicas sobre el cristianismo y a cuidar a su hija la cual es discapacitada, uno de sus hermanos murió a los 14 años ya que lo atropellaron y los otros 5 viven en Estados Unidos.

Yo le comenté que el paciente me había dicho que eran 8 hijos, a lo que la hija me contestó que siempre "mata" a 4 hijos, al que está en la cárcel, al que está desaparecido, a ella debido a que tiene una hija discapacitada, y al que murió.

También comentó que su padre siempre ha sido alcohólico y que cuando llegaba borracho golpeaba a su madre y que inclusive les llegó a pegar a sus hijas y a 2 de sus hijos, el que murió en un accidente y al que corrió de la casa, comentó que en una ocasión su padre llegó borracho y la madre lo corrió y éste desapareció por más de 7 meses. 
Ella se siente traumada porque no puede superar los golpes que recibían su madre y ella pero dice que a pesar de esto no le guarda rencor y quiere verlo, me enseñó unas fotografías en donde el paciente se estaba bautizando bajo la religión cristiana, quería enseñárselas para que ya no siga enojado con Dios, pero no la recibió.

Le pregunté sobre el terreno que según su padre le robó, comentó que ese terreno ni siquiera es de él, es de la amante de su padre, la cual siempre le dijo que lo iba a poner a su nombre pero nunca lo hizo, comenta que la hermana mayor le dijo que es ella quien le quitó el terreno ya que le lavó el cerebro a la amante y ella decidió dejárselo a ella y no al paciente.

Esta es otra de las razones por las que su padre no quiere verla ya que la acusa de ratera y mala hija.

Comenta que lleva más de 4 años con su amante y que tanto los hijos como la esposa están enterados, afirma que su madre ya no quiere al paciente pero que lo va a ver al hospital para no quedarse con remordimientos en caso de que este muera.

Después de esta plática con la hija la cual se dio por terminada ya que ella tenía que ir a ver a su hija dándome su numero de celular para que en caso de que su padre quisiera verla le avisara, fui para ver si I.D.H ya había regresado de sus estudios, pero aun se encontraba en rayos x por lo que terminó esta sesión.

Cuando terminé de hablar con la hija de I.D.H la verdad me sentí mal, ya que yo tenía una imagen del paciente y con todo lo que me enteré esa imagen desapareció, me sentí enojada e incapaz de volverlo a ver ya que estaba realmente molesta por esa razón la última sesión fue hasta después del fin de semana.

\section{Sesión \#6}

\section{7- Marzo.2005.}

Ya que se me había pasado el enojo, traté de seguir teniendo una consideración positiva incondicional con él, aceptarlo tal cual es, y volver a empatizar con él, pensé que tal vez me había mentido por la necesidad de compañía, después de pensar esto pude regresar para terminar las sesiones.

El paciente se encontraba sentado con las piernas estiradas debido a la inflamación y a los dolores causados por la gota, se encontraba solo, sin aliño y sin bañarse.

Cuando llegué lo primero que me preguntó fue que si había platicado con su hija, le dije que si, que había estado platicando con ella y que me había enseñado unas fotos en donde él se estaba bautizando bajo la religión cristiana y que su hija venía a enseñarle esas fotos, después de decirle esto I.D.H. me preguntó si su hija no venía a regañarlo, le contesté que no que solo venía a platicar con él y a enseñarle algunas fotografías. 
Hubo un momento de silencio, se le veía pensativo, le pregunté en que estaba pensando y comenzó a llorar, dijo que sus hijos no lo querían y que él se lo había ganado por haberlos golpeado cuando eran niños, comentó que no me lo había dicho por temor a que yo no lo aceptara y no quisiera seguir viéndolo.

Siguió llorando y me comentó que ha sido muy duro con sus hijos en especial con su hija menor, pero dice que es una ladrona porque le quitó un terreno y que eso no se lo va a perdonar, cuando dijo esto le pregunté si realmente le constaba que su hija era una ladrona a lo que contestó que no, pero dijo que tenía muy buenas fuentes de información que le habían dicho que su hija se quería quedar con ese terreno y que ella tenía las escrituras, le pregunté quien era la fuente y me dijo que era su hija mayor.

Le sugerí que hablara con sus otros hijos y que no los juzgara sin realmente saber si era cierto todo lo que su hija mayor le decía, dijo que iba a intentar hablar con sus hijos y dejar su rencor atrás pero que ahora el problema sería que sus hijos acepten hablar con él; comentó que se arrepentía por no haber aceptado la visita de su hija el día de ayer, le pregunté si quería ver a su hija y de inmediato dijo que si.

Hablé con la trabajadora social para que localizara a la hija menor de I.D.H, la localizaron y le pidieron que viniera ya que su padre quería verla.

Le dije al paciente que ya habían localizado a su hija y que venía en camino, se le veía contento y pidió que lo bañaran para estar presentable para su hija, por esta razón la sesión se vio interrumpida.

Después de haberse bañado, se peinó y se arregló para ver a su hija, se le veía nervioso, le pregunté si se encontraba preocupado o nervioso a lo que contestó que si, ya que no sabía como hablar con su hija, no sabía si decirle que la quería, que la perdonaba, no sabía por donde empezar.

Me preguntó que hacer a lo que le contesté que se dejara llevar por lo que sentía pero que no la ofendiera ni la juzgara, que la dejara hablar y que la escuchara y que dejara atrás esa idea de que él siempre tiene la razón, después de decirle esto se rió y dijo que a él siempre le gustaba tener la razón y que le enojaba cuando alguien le hacía ver que estaba mal, pero que iba a intentar hablar bien con su hija.

La sesión nuevamente se vio interrumpida ya que llegó su hija, entró saludó a su papá y a mi, les dije que los dejaba solos para que platicaran, antes de salir, la hija me abrazó y me dio las gracias, me dijo "yo se que gracias a ti, mi papá me quiso recibir"; me sonrió y se fue a platicar con su papá.

Después de un rato, la hija me fue a buscar y me volvió a dar las gracias, comentó que había platicado muy bien con su padre y que ya habían arreglado muchas cosas, la hija se fue y dijo que ya había cambiado de opinión en cuanto a los psicólogos, dijo que ya no le parecían tan locos. 
Al terminar de hablar con la hija menor del paciente fui con él y se le veía contento, me comentó que se sentía muy bien ya que había arreglado las cosas con su hija.

Le pregunté si pensaba arreglar las cosas con sus otros hijos a lo que contestó que lo pensaría porque tenía miedo de que lo rechazaran.

Por otra parte en cuanto a su esposa dijo que no la quería y que ya le había pedido que no lo fuera a ver mas porque no la soportaba, comentó que ya no la quería y que le guardaba mucho rencor porque había hecho cosas que aun le causaban enojo y no pensaba perdonarla, le pregunté que cosas había hecho la esposa y dijo que no quería entrar en detalles porque le causaba mucha ira hablar de su esposa pero comentó que por todas las cosas que ella había hecho, el se había ido un tiempo de la casa con su amante y que gracias a ella había olvidado a su esposa.

El paciente no quiso entrar en más detalles respecto a este tema.

Después de esto me despedí de él, comentó que se había sentido muy bien y que lo había ayudado mucho, dijo que gracias a mi se le había quitado la depresión y ahora tenía mas ganas de salir adelante y que iba a intentar hablar con sus hijos para no tener asuntos pendientes y poder morir tranquilamente.

\section{Análisis de resultados del Paciente \#3:}

Tipode paciente: Demandante ya que constantemente pedía favores y cosas, a cada rato quería que yo estuviera con él, también tenía características de orgulloso ya que veía a los demás como inútiles y decía que no lo sabían ayudar ni lo comprendían, veía al personal médico como incompetentes en especial a las enfermeras, también mostraba este orgullo con sus familiares ya que decía que no hacían nada por él y que por esa razón no quería verlos.

Necesidades del paciente: De acuerdo al instrumento que se le aplicó al paciente y lo observado en las entrevistas se detectaron las siguientes necesidades: Necesidad de recibir un trato humano en el hospital ya que las enfermeras lo han lastimado y siente que no lo revisan constantemente para ver que es lo que le falta, este ultimo punto es contradictorio ya que primero dijo que el personal de enfermería acudía siempre que el lo necesitaba y lo trataban con amabilidad, esto puede ser debido a que el paciente es orgulloso y probablemente le cueste trabajo aceptar que realmente le dan un buen trato en el hospital. 
También tienen necesidad de sentirse apoyado por su familia, en el transcurso de las entrevistas y en el instrumento se comprobó que tiene la necesidad de sentirse apoyado por sus seres queridos y sus familiares ya que el siente que solo cuenta con el apoyo de su hija mayor, tienen necesidad de arreglar asuntos pendientes con sus seres queridos, el paciente no lo acepta así debido a su orgullo, es un paciente que se siente solo y triste, tiene la necesidad de sentirse útil, por lo que quiere que dentro del hospital haya actividades para distraerse, también tiene la necesidad de compartir sus miedos, dudas, sentimientos y pensamientos con una persona ajena a la familia.

Tipo de apoyo brindado: Al igual que con los otros dos pacientes, se le brindó apoyo con enfoque humanista ya que hubo empatía con él, en todo momento se trató de ponerse en los zapatos del paciente y entender su situación, se logró tener una condición positiva incondicional la cual no se mantuvo en todo momento ya que cuando hablé con la hija del paciente y me enteré del pasado de éste, me costó trabajo mantener esa condición positiva incondicional, me fue difícil aceptar esa situación ya que me sentí traicionada por él, después de lo ocurrido también me fue difícil ser congruente ya que no quería verlo pero sabía que tenía que completar las sesiones con él.

En cuanto al acompañamiento tanatológico, el paciente se encontraba en un principio en la etapa de depresión ya que se sentía solo y triste por no recibir apoyo de sus seres queridos, después paso a la etapa de ira ya que las cosas no le salieron como el quería, y por la relación que el llevaba con sus hijos, el acompañamiento que se le brindó fue de contención ya que se le dejó que expresara lo que sentía, se le acompañó en los momentos de soledad, se le llamaba al personal médico cuando él necesitaba algo, en cuanto a la terapia ocupacional el paciente jugó dominó y memorama, durante estas sesiones se le veía contento.

Después de haber realizado un análisis de los resultados de cada uno de los pacientes, se puede concluir que sus necesidades principales son las siguientes:

Necesidad de sentirse acompañados

Necesidad de expresar sus miedos, sentimientos y dudas con sus seres queridos, así como compartir su diagnostico y las consecuencias con ellos.

Necesidad de estar informados sobre su estado de salud, desarrollo de la enfermedad y el tratamiento.

Necesidad de sentirse útiles

Necesidad de expresar lo que sienten y piensan con una persona ajena a la familia

Necesidad de arreglar sus asuntos pendientes tanto en el aspecto legal (como testamento, escrituras, etc.), social (con sus amistades), familiares (ver a sus seres queridos, despedirse de ellos, arreglar disputas familiares, perdonar, etc.) y espirituales (ver al sacerdote, rebino, etc. y hacer todo aquello que su religión les 
indique, dudas en cuanto a lo que les va a pasar, lo que es la muerte, que hay después de esta, etc.)

Necesidad de sentirse comprendidos

Necesidad de que el personal medico y de enfermería les hable con la verdad y en términos que ellos entiendan

Cada una de estas necesidades pueden ser satisfechas, las físicas fueron satisfechas por el personal medico y de enfermería, así como por el acompañamiento tanatológico brindado por la investigadora, y las psicológicas, mediante el apoyo psicológico con enfoque humanista como base, así como con terapia ocupacional, acompañamiento y/o apoyo tanatológico.

\section{DISCUSIÓN DE RESULTADOS:}

La finalidad de esta investigación fue el detectar las necesidades físicas y psicológicas de los pacientes con enfermedad terminal para que una vez detectadas se les pudiera apoyar y/o acompañar para que pudieran satisfacer dichas necesidades y mejorar su calidad de vida, esto se realizó con 3 pacientes con enfermedad terminal es decir con personas que clínicamente tengan no una vida mayor a 1 año, sin importar la edad, sexo, causa o tipología de la enfermedad.

El trabajar con pacientes terminales, no es trabajo de una sola persona, es multidisciplinario, ya que se necesita de médicos, quienes desde los estudios clínicos están con el paciente terminal, enfermeras, psicólogos, tanatólogos, seres queridos y familiares del paciente, así como personas que ayuden en el área espiritual como sacerdotes, rabinos, etc.

No es fácil trabajar con el tema de la muerte ya que aunque es un hecho universal, la forma de vivirlo es muy particular, cada paciente tiene su propio concepto y filosofía de muerte, así como diferentes creencias religiosas, de acuerdo a Wolfelt (2003), la fé ofrece seguridad de saber que la muerte aporta paz y serenidad, por lo que la religión puede ser un factor positivo al trabajar con personas terminales, por lo que es necesario tener conocimientos básicos sobre cada religión.

De acuerdo a Valera (1990), todas las culturas han elaborado rituales regulados por mitos de esa cultura y pueden servir para el trabajo de la elaboración del duelo, todo esto influye en su manera de enfrentar este momento, hay a quienes sus ideas y creencias les ayuda a tener una mejor aceptación, y hay otros a los que les incrementa el miedo a morir, también influyen factores como la edad, el tipo de enfermedad que tenga el paciente, así como su personalidad.

Independientemente de esto, cada paciente va a pasar por un proceso llamado duelo, el cual se compone de varias fases mencionadas por Kübler Ross (1975), las cuales son 
negación, ira, negociación, depresión y finalmente la aceptación, en cada fase se mantiene la esperanza de cura o de salvación, cuando esta desaparece de según la misma autora es sinónimo de que la muerte ya esta cerca.

Este proceso tampoco se vive de la misma forma en cada paciente, ya que en algunos se pueden presentar todas las fases pero en otros solo se presentan algunas, además es importante mencionar que no se presentan en un determinado orden y que el hecho de haber pasado ya una etapa no quiere decir que no se pueda volver a ella.

El duelo es una reacción completamente normal no solo en los pacientes sino también en los familiares, el duelo es personal por lo cual no se le debe juzgar a la persona que lo este viviendo ya que cada quien reacciona diferente, se debe permitir que el doliente se exprese libremente sin hacer juicios de valor ni contradecirlos, hay que dejar que lo vivan y no decirles como deben hacerlo, de acuerdo a Roccatagliata (2000), el duelo es un proceso activo de adaptación.

En las etapas de negación e ira solo se puede realizar acompañamiento tanatológico con el paciente, es decir se le escucha y se le da contención siempre respetando sus pensamientos, ideas y sentimientos, manteniendo siempre que sea posible la empatía, aceptar al paciente tal cual es y siendo congruentes.

Cuando el doliente se encuentra en la fase de negociación, depresión y aceptación ya se le puede brindar apoyo tanatológico.

En cualquiera de las fases de duelo debemos acercarnos al paciente conforme a los criterios básicos de la psicología humanista con empatía, congruencia y condición positiva incondicional, en cuanto a la terapia ocupacional también puede ser brindada en cualquier etapa de duelo siempre y cuando el paciente quiera realizarla.

Al trabajar con el paciente terminal no solo se trabaja con el proceso de duelo, también es importante considerar los siguientes puntos:

Trabajar para que el paciente acepte su realidad

Trabajar con las emociones

Tratar de que se adapte a las nuevas circunstancias

Cerrar círculos

Tratar de mejorar su calidad de vida

Prepararlos para la muerte

Es importante saber que el paciente terminal según Rebolledo (2000), es aquella persona que tiene no más de 1 año de vida. 
Gil (1998), considera como paciente terminal a aquel que tenga los siguientes elementos:

Presencia de una enfermedad avanzada, progresiva e incurable

Falta de posibilidades razonables de respuesta al tratamiento específico

Presencia de numerosos problemas o síntomas intensos, múltiples, multifactoriales y cambiantes

Las características mencionadas anteriormente son las que tenían los pacientes que participaron en esta investigación, los 3 tenían una enfermedad avanzada e incurable, así como varios síntomas y poca respuesta a los tratamientos.

Esta investigación se basó principalmente en el apoyo psicológico con enfoque humanista, este enfoque de acuerdo a Kopp (1971), es la tercera fuerza de la psicología, la cual se utilizó con los 3 pacientes que participaron en esta investigación, en todo momento se busco mantener una relación en donde se aceptara al paciente tal cual es independientemente de sus ideas o formas de comportamiento, religión o ideología, también trate de mantener la empatía y ponerme los zapatos del paciente para percibir el mundo como el lo percibía y en todo momento traté de mantener una congruencia entre lo que decía, hacia y pensaba.

Con cada uno de los pacientes se buscó tener los elementos necesarios para una buena relación con el paciente los cuales según Rogers (1962), son: congruencia, consideración positiva incondicional y empatía.

Por otra parte también este trabajo se basó en el apoyo tanatológico, ya que la Tanatología de acuerdo a Sánchez (2005) aborda el fenómeno de la muerte desde varias perspectivas: humanista, religiosa, social, familiar y psicológica de lo que significa morir, y la finalidad de esta es disminuir el miedo a la muerte, mejorar la calidad de vida.

Considero que la Tanatología fue una herramienta muy buena en esta investigación ya que se acompaño a los pacientes, se le brindo apoyo y/o acompañamiento tanatológico con la finalidad de detectar sus necesidades y así mejorar su calidad de vida.

Desgraciadamente no a todos los pacientes se les pudo dar acompañamiento tanatológico ya que algunos estaban en la fase de ira lo cual imposibilita que se le pueda brindar este tipo de apoyo, en cuanto al apoyo tanatológico también se empleo con todos los pacientes ya que al estar enfermos y en espera de su muerte siempre van a tener necesidades físicas y psicológicas que mediante el apoyo tanatológico pueden ser satisfechas, ya que el acompañamiento tanatológico es recorrer con el paciente un trayecto hasta su muerte, lo que hace que nos demos cuenta de lo que él necesita.

Es importante concientizarnos y saber que no porque una persona este llegando al final de su vida, este no tiene necesidades y derechos y es importante respetar estos últimos y ayudarlo a satisfacer sus necesidades, no solo las físicas sino también las psicológicas. 
Hay varios autores que mencionan ciertas necesidades que los pacientes terminales pueden presentar.

Cacoub (1992), menciona las siguientes:

Necesidad de decir lo que quiere y tener el control de lo que quiere hacer

Necesidad de tener a sus amigos y familiares

Necesidad de arreglar sus cosas personales y tener la seguridad de que sus cosas estarán cuidadas.

Necesidad de expresar sus inquietudes, sin importar lo insignificante que puedan parecer.

Necesidad de que se le tome en serio, sobre todo sus quejas de dolor o incomodidad

Necesidad de ser escuchado

Por otra parte Kübler,Ross (1975), menciona las siguientes:

a) Necesidad de seguridad: es importante que se haga todo lo posible para que el paciente no se sienta rechazado o abandonado.

b) Necesidad de estar acompañado por aquellas personas que le son más afines, como sus seres queridos.

c) Necesidad de información concreta sobre la evolución de su enfermedad, el tiempo disponible, los trámites necesarios, etc.

d) Necesidad de resolver sus asuntos pendientes: Según Kübler-Ross (1975), lo que más angustia a los enfermos terminales son sus «asuntos pendientes», aquellas relaciones interpersonales no resueltas satisfactoriamente; la reconciliación con un pasado no aceptado que ahora, a las puertas de su muerte, no les deja en paz. La muerte ya no acepta más aplazamientos para afrontar los problemas realmente importantes que, quizás, hace años se esquivan.

e) Necesidad de ser escuchado, de comunicar sus dudas y miedos.

En esta investigación se detectaron varias necesidades en cada uno de los pacientes, estas necesidades fueron las siguientes:

Necesidad de sentirse acompañados, los tres pacientes expresaron el deseo de ver a sus familiares y seres queridos, y en el momento en que estaban solos se les veía tristes y preguntando constantemente a que hora es el momento de visita.

Necesidad de expresar sus miedos, sentimientos y dudas con sus seres queridos, así como compartir su diagnostico y las consecuencias con ellos, los pacientes manifestaron sentirse bien al compartir sus miedos y sentimientos con sus seres queridos ya que de esta forma se sentían liberados, entendiendo por esto que sentían que la carga era mas leve al poderse apoyar en alguien que los quisiera. 
Necesidad de estar informados sobre su estado de salud, desarrollo de la enfermedad y el tratamiento, afortunadamente los 3 pacientes conocían su estado de salud y las consecuencias de las enfermedades que padecían, todo esto porque se le informaba constantemente sobre la evolución de la enfermedad, no siempre se los decía el personal de salud ya que estos consideraban que es importante que la familia este de acuerdo en decir no solo la enfermedad sino el curso de esta y las consecuencias que puede traer.

Los pacientes constantemente preguntaban a los médicos como iba la evolución de la enfermedad y esto desde mi punto de vista es bueno porque por mas amenazante que sea el informe medico, esto puede ayudar al paciente a prepararse para la muerte, para cerrar ciclos y para mejorar su calidad de vida, además de que el hecho de mantener informados a los pacientes sobre su estado de salud es un derecho para ellos y debe de ser respetado. Necesidad de sentirse útiles

Necesidad de expresar lo que sienten y piensan con una persona ajena a la familia, los pacientes comentaron que se sienten bien al recibir apoyo familiar y de sus seres queridos pero que muchas veces por miedo a lastimarlos no siempre expresan todo lo que piensan o sienten, por miedo a ser juzgados o por pena.

También comentaron que en ocasiones la familia no quiere hablar sobre la muerte y que siempre es bueno contar con una persona con la que se pueda hablar sobre este tema, pienso que esto ocurre porque no solo el paciente le teme a la muerte, también los familiares y por lo tanto prefieren evadir el tema, por esta razón es bueno contar con un terapeuta con conocimientos en Tanatología para que pueda orientar al paciente, la familia es un excelente apoyo para el paciente pero no siempre es necesario.

Necesidad de arreglar sus asuntos pendientes tanto en el aspecto legal (como testamento, escrituras, etc.), social (con sus amistades), familiares (ver a sus seres queridos, despedirse de ellos, arreglar disputas familiares, perdonar, etc.) y espirituales (ver al sacerdote, rebino, etc. y hacer todo aquello que su religión les indique, dudas en cuanto a lo que les va a pasar, lo que es la muerte, que hay después de esta, etc.), muchas veces estas necesidades son expresadas pero en otras ocasiones es necesario explorar mas a fondo mediante entrevistas o platicas con el paciente, a veces son expresadas a la familia y en otras a seres queridos, al personal de salud, al psicólogo, etc....

Es importante hacerle sentir al paciente que se le va a ayudar a resolver estos asuntos, muchos pacientes desperdician el poco tiempo de vida que tienen pensando en estos problemas, en los legales, en que pasara con sus cosas al morir, en los problemas familiares, por esta razón no le dan calidad de vida a sus días, se la pasan con preocupaciones, por eso es necesario apoyarlos y ayudarlos, sin hacer promesas que nunca pensamos cumplir, y hay que tratar de descubrir que es lo que les preocupa para ayudarlo a cerrar ciclos. 
Necesidad de sentirse comprendidos, muchos pacientes piensan que no se les entiende y que son prácticamente un cero a la izquierda es importante ayudarlos y apoyarlos para que se sientan comprendidos, saber que cuentan con alguien.

Necesidad de que el personal medico y de enfermería les hable con la verdad y en términos que ellos entiendan, esta es una necesidad que debe ser cubierta principalmente por el personal de salud, quienes deben de hablarle al paciente con la verdad y tratando de expresarse de manera que el paciente entienda que es lo que tiene y lo que le va a pasar, así como el tratamiento que va a tener.

Necesidad de sentirse útiles, esto lo mostraron los 3 pacientes ya que intentaban realizar terapia ocupacional, jugar, etc. Cada uno de ellos trató de realizar una actividad con tal de minimizar sus sentimientos de inutilidad.

Cada una de estas necesidades pueden ser satisfechas, las físicas fueron satisfechas por el personal medico y de enfermería, así como por el acompañamiento tanatológico brindado por la investigadora, y las psicológicas, mediante el apoyo psicológico con enfoque humanista como base, así como con terapia ocupacional, acompañamiento y/o apoyo tanatológico, como se explicara mas adelante.

En esta investigación realmente me sorprendió el como apoyar y/o acompañar a un paciente con enfermedad terminal puede cambiarles la vida, y como el brindarles un poco de tiempo y escudarlos los puede ayudar no solo a sentirse queridos, apoyados y comprendidos, sino a detectar sus necesidades y ayudarlos a satisfacer esas necesidades tanto las físicas como psicologías, es importante sabe que independientemente del lugar en donde se encuentre el paciente, ya sea en hospitales, clínicas, hospicios o en su hogar, se le puede dar este tipo de apoyo y/o de acompañamiento.

Hay que tratar de entender a este tipo de pacientes ya que nadie esta exento de padecer una enfermedad terminal, la cual puede darnos en cualquier etapa de nuestra vida, ya que enfermedad terminal no es sinónimo de vejez, también considero que es necesario tomar conciencia de que estar enfermo no es sinónimo de que no se pueda tener calidad de vida. 


\section{CONCLUSIONES:}

Esta Investigación tuvo como finalidad el detectar las necesidades del paciente terminal con la finalidad de apoyarlo mediante terapia con enfoque humanista, apoyo y/o acompañamiento tanatológico así como terapia ocupacional en caso de que el paciente quisiera realizarla.

Se detectaron varias necesidades las cuales se trato de satisfacer para que el paciente tuviera una mejor calidad de vida, para esto se requirió de apoyo multidisciplinario: médicos, enfermeras, trabajadoras sociales, personal de alud, etc.

Trabajar con pacientes terminales no es fácil, se requiere tiempo, paciencia, tolerancia y sobre todo estar abiertos ya que al apoyar a este tipo de pacientes no puedes ser cerrado en cuanto a horarios, tiempos, etc., el trabajo con ellos no es fácil pero si te deja un gran crecimiento y te enseñan a valorar la vida.

Es importante tomar en cuenta que estamos vivos y que es mejor tener calidad de vida que cantidad de vida, no hay que esperar a tener una enfermedad terminal o un diagnostico fatal para valorar la vida; a continuación se presenta una poesía realizada por Jhonny Welch (2003) y fue atribuído a Gabriel García Márquez, la historia trata sobre el cierre del ciclo vital en donde las personas suelen ver la vida de forma diferente: 


\section{SE DESPIDE UN GENIO}

"Si por un instante Dios se olvidara de que soy una marioneta de trapo y me regalara un trozo de vida, aprovecharía ese tiempo lo mas que pudiera. Posiblemente no diría todo lo que pienso, pero en definitiva pensaría todo lo que digo.

Daría valor a las cosas, no por lo que valen sino por lo que significan, dormiría poco, soñaría más, entiendo que por cada minuto que cerramos los ojos, perdemos sesenta segundos de luz.

Andaría cuando los demás se detienen, despertaría cuando los demás duermen. Si Dios me obsequiara un trozo de vida, vestiría sencillo, me tiraría de bruces al sol, dejando descubierto no solamente mi cuerpo, sino mi alma. A los hombres les probaría cuan equivocados están al pensar que dejen de enamorarse cuando envejecen, sin saber que envejecen cuando dejan de enamorarse.

A un niño le daría alas, pero le dejaría que el solo aprendiese a volar.

A los viejos les enseñaría que la muerte no llega con la vejez, sino con el olvido.

Tantas cosas he aprendido de ustedes, los hombres... He aprendido que todo el mundo quiere vivir en la cima de la montaña, sin saber que la verdadera felicidad esta en la forma de subir la escarpada.

He aprendido que cuando un recién nacido aprieta con su pequeño puño por primera vez el dedo de su padre, lo tiene atrapado por siempre.

He aprendido que un hombre solo tiene derecho a mirar al otro hacia abajo cuando ha de ayudarle a levantarse.

Son tantas cosas las que he podido aprender de ustedes, pero realmente de mucho no habrán de servir, porque cuando me guarden dentro de esa maleta, infelizmente me estaré muriendo.

Siempre di lo que sientes y haz lo que piensas, si supiera que hoy fuera la última vez que te voy a ver dormir, te abrazaría fuertemente y rezaría al seños para poder ser el guardián de tu alma.

Si supiera que estos son los últimos minutos que te veo diría: " te quiero", y no asumiría tontamente que ya lo sabes.

Siempre hay un mañana y la vida nos da otra oportunidad para hacer las cosas bien, pero por si me equivoco y hoy es todo lo que nos queda, me gustaría decirte cuanto te quiero y que nunca te olvidare.

El mañana no le esta asegurado a nadie, joven o viejo. 
Hoy puede ser la ultima vez que veas a los que amas, por eso no esperes mas, hazlo hoy, ya que si el mañana nunca llega, seguramente lamentaras el día que no tomaste tiempo para una sonrisa, un abrazo, un beso y que estuviste muy ocupado para concederles un ultimo deseo.

Mantén a los que amas cerca de ti, diles al oído lo mucho que los necesites, quiérelos y trátalos bien, toma tiempo para decirles "lo siento", "perdóname", y todas la palabras de amor que conoces.

Nadie te recordará por tus pensamientos secretos, pide al señor la fuerza y sabiduría para expresarlos, demuestra a tus amigos y seres queridos cuanto te importan."

\section{Jhonny Welch (2002)}

\section{LIMITACIONES:}

Al trabajar con el tema de la muerte se requiere de apoyo multidisciplinario, lo que complica este tipo de trabajo ya que no siempre es fácil llegar a acuerdos, establecer los mismos tiempos o aceptar la forma de trabajo de cada uno, aceptar reglas de los hospitales o clínicas en donde se realiza este tipo de labor.

Difícilmente se pueden fijar tiempos ya que en ocasiones el paciente puede estar o sentirse imposibilitado para realizar la sesión debido a su estado físico, lo que hace que constantemente las sesiones tengan que ser canceladas.

En este tipo de trabajo hay constantes interrupciones por parte del personal médico, así como de visitas familiares.

Se cancelan las sesiones a causa de los estudios médicos que se les tiene que realizar a los pacientes, algunos son programados pero otros ocurren de momento, ya sea antes de que inicie la sesión o a la mitad de ésta.

Falta de privacidad; a pesar de que en esta investigación se buscaron pacientes que se encontraran en cuarto aislado para tener mas privacía, las constantes visitas médicas, revisiones y visitas de familiares y amistades de los pacientes, hacían que las sesiones se interrumpieran.

\section{SUGERENCIAS:}

Al trabajar con pacientes terminales me di cuenta que es muy importante trabajar con los familiares ya que estos pasan por un doble duelo, el primero al recibir el diagnóstico de su ser querido y el segundo cuando este ha muerto, por lo que es necesario que reciban apoyo. 
Sería conveniente que se realizara un manual de intervención para pacientes terminales.

Hacer un seguimiento del apoyo que se le dio a los pacientes de tercera edad, para analizar si puede ayudar a enfermos de otras edades.

\begin{abstract}
ANEXOS:
FICHA DE IDENTIFICACIÓN:
\end{abstract}

NOMBRE:

EDAD:

SEXO: F $\mathbf{M}$

ESTADO CIVIL:

OCUPACIÓN:

ESCOLARIDAD:

DIAGNÓSTICO MÉDICO Y CAUSAS DEL INTERNAMIENTO:

ETÁPA DE DUELO EN LA QUE SE ENCUENTRA EL PACIENTE:

ETÁPA DE DUELO EN LA QUE SE QUEDO EL PACIENTE DESPUÉS DEL APOYO:

\title{
TIPO DE APOYO BRINDADO:
}

- Apoyo Tanatológico

- Acompañamiento tanatológico

- Apoyo Psicológico con enfoque Humanista

- Terapia ocupacional:

- Manualidades

- Dibujo

- Cuento

o Otros: 
Lugar donde se realizó la investigación: Hospital Darío Fernández Fierro. I.S.S.S.T.E.

Área donde se realizó: Medicina Interna.

Médico responsable: Dr. Mario Colinabarranco González.

\section{INSTRUMENTO PARA LA DETECCIÓN DE NECESIDADES EN PACIENTES TERMINALES.}

\begin{tabular}{|l|l|l|}
\hline Tipo de necesidad & SI & NO \\
\hline Siento que me han dado un trato humano dentro del hospital & & \\
\hline El personal de enfermería me ha lastimado porque son bruscas & & \\
\hline El personal de enfermería siempre acude cuando necesito algo & & \\
\hline Los médicos residentes me tratan con amabilidad & & \\
\hline Los médicos residentes son personas preparadas y eficientes & & \\
\hline Mi médico tratante es una persona profesional y ética & & \\
\hline El personal médico me habla con la verdad & & \\
\hline El personal médico me explica lo que tengo en términos que yo entiendo & & \\
\hline Constantemente nos revisan para ver que nos falta & & \\
\hline La higiene dentro del hospital es buena & & \\
\hline La dieta que me proporciona la nutrióloga es la adecuada para mi enfermedad & & \\
\hline Se que enfermedad padezco & & \\
\hline Estoy consciente de las consecuencias que puede traer mi enfermedad & & \\
\hline Mi familia sabe cual es mi diagnóstico y conoce las posibles consecuencias & & \\
\hline Comparto con mis seres queridos mis miedos, pensamientos y sentimientos & & \\
\hline Siento que mis seres queridos me apoyan & & \\
\hline Tengo asuntos pendientes que arreglar con mi familia & & \\
\hline Me siento solo (a) & & \\
\hline Me siento triste & \\
\hline Me siento enojado (a) & \\
\hline Me siento incapaz de realizar algunas actividades que antes solía hacer & \\
\hline Tengo miedo de lo que pueda pasarme & \\
\hline Tengo miedo a la muerte & \\
\hline $\begin{array}{l}\text { Me gustaría tener contar con una persona ajena a mis seres queridos con quien } \\
\text { compartir lo que siento y pienso. }\end{array}$ & \\
\hline $\begin{array}{l}\text { Me gustaría que dentro del hospital hubiera algún tipo de actividad para } \\
\text { distraerme. }\end{array}$ & \\
\hline
\end{tabular}


FICHA DE IDENTIFICACIÓN:

\section{Paciente\#1}

NOMBRE: J.L.R

EDAD: 62

SEXO: F $\quad$ M: X

ESTADO CIVIL: Casado

OCUPACIÓN: jubilado

ESCOLARIDAD: preparatoria

\section{DIAGNÓSTICO MÉDICO Y CAUSAS DEL INTERNAMIENTO:}

Bicitopenia, es decir baja de 2 elementos de la sangre.

Neumonía

Plenomegalia, es decir inflamación de bazo.

ETÁPA DE DUELO EN LA QUE SE ENCUENTRA EL PACIENTE: Ira

ETÁPA DE DUELO EN LA QUE SE QUEDO EL PACIENTE DESPUÉS DEL APOYO:

Aceptación

\section{TIPO DE APOYO BRINDADO:}

Apoyo tanatológico

Acompañamiento Tanatológico

Apoyo Psicológico con enfoque Humanista

Terapia ocupacional: Sopa De letras y crucigramas (juego)

Manualidades

Dibujo

Cuento

Otros:

Lugar donde se realizó la investigación: Hospital Darío Fernández Fierro. I.S.S.S.T.E. Área donde se realizó: Medicina Interna.

Médico responsable: Dr. Mario Colinabarranco González. 


\section{INSTRUMENTO PARA LA DETECCIÓN DE NECESIDADES EN PACIENTES TERMINALES.}

\begin{tabular}{|l|l|l|}
\hline Tipo de necesidad & SI & NO \\
\hline Siento que me han dado un trato humano dentro del hospital & & $\mathbf{X}$ \\
\hline El personal de enfermería me ha lastimado porque son bruscas & & $\mathbf{X}$ \\
\hline El personal de enfermería siempre acude cuando necesito algo & $\mathbf{X}$ & \\
\hline Los médicos residentes me tratan con amabilidad & $\mathbf{X}$ & \\
\hline Los médicos residentes son personas preparadas y eficientes & $\mathbf{X}$ & \\
\hline Mi médico tratante es una persona profesional y ética & $\mathbf{X}$ & \\
\hline El personal médico me habla con la verdad & $\mathbf{X}$ & \\
\hline El personal médico me explica lo que tengo en términos que yo entiendo & $\mathbf{X}$ & \\
\hline Constantemente nos revisan para ver que nos falta & $\mathbf{X}$ & \\
\hline La higiene dentro del hospital es buena & $\mathbf{X}$ & \\
\hline La dieta que me proporciona la nutrióloga es la adecuada para mi enfermedad & $\mathbf{X}$ & \\
\hline Se que enfermedad padezco & $\mathbf{X}$ & \\
\hline Estoy consciente de las consecuencias que puede traer mi enfermedad & $\mathbf{X}$ & \\
\hline Mi familia sabe cual es mi diagnóstico y conoce las posibles consecuencias & $\mathbf{X}$ & \\
\hline Comparto con mis seres queridos mis miedos, pensamientos y sentimientos & $\mathbf{X}$ & \\
\hline Siento que mis seres queridos me apoyan & $\mathbf{X}$ & \\
\hline Tengo asuntos pendientes que arreglar con mi familia & & $\mathbf{X}$ \\
\hline Me siento solo (a) & & $\mathbf{X}$ \\
\hline Me siento triste & & $\mathbf{X}$ \\
\hline Me siento enojado (a) & & $\mathbf{X}$ \\
\hline Me siento incapaz de realizar algunas actividades que antes solía hacer & $\mathbf{X}$ & \\
\hline Tengo miedo de lo que pueda pasarme & & $\mathbf{X}$ \\
\hline Tengo miedo a la muerte & & $\mathbf{X}$ \\
\hline $\begin{array}{l}\text { Me gustaría tener contar con una persona ajena a mis seres queridos con quien } \\
\text { compartir lo que siento y pienso. }\end{array}$ & $\mathbf{X}$ & \\
\hline $\begin{array}{l}\text { Me gustaría que dentro del hospital hubiera algún tipo de actividad para } \\
\text { distraerme. }\end{array}$ & $\mathbf{X}$ & \\
\hline
\end{tabular}


FICHA DE IDENTIFICACIÓN:

\section{Paciente\#2}

NOMBRE: M.C.L

EDAD: 83

SEXO: F: X

$\mathbf{M}$

ESTADO CIVIL: Viuda

OCUPACIÓN: jubilada

ESCOLARIDAD: primaria

DIAGNÓSTICO MÉDICO Y CAUSAS DEL INTERNAMIENTO:

Pancitopenia

Hipertensión arterial sistémica

Neumonía nosocomial,

Cáncer pulmonar

ETÁPA DE DUELO EN LA QUE SE ENCUENTRA EL PACIENTE: Aceptación

ETÁPA DE DUELO EN LA QUE SE QUEDO EL PACIENTE DESPUÉS DEL APOYO:

Aceptación

\section{TIPO DE APOYO BRINDADO:}

Acompañamiento tanatológico

Apoyo Tanatológico

Apoyo Psicológico con enfoque Humanista

Terapia ocupacional: Juegos (sopa de letras).

Manualidades

Dibujo

Cuento

Otros:

Lugar donde se realizó la investigación: Hospital Darío Fernández Fierro. I.S.S.S.T.E.

Área donde se realizó: Medicina Interna.

Médico responsable: Dr. Mario Colinabarranco González. 


\section{INSTRUMENTO PARA LA DETECCIÓN DE NECESIDADES EN PACIENTES TERMINALES.}

\begin{tabular}{|l|l|l|}
\hline Tipo de necesidad & SI & NO \\
\hline Siento que me han dado un trato humano dentro del hospital & $\mathbf{X}$ & \\
\hline El personal de enfermería me ha lastimado porque son bruscas & $\mathbf{X}$ & \\
\hline El personal de enfermería siempre acude cuando necesito algo & $\mathbf{X}$ & \\
\hline Los médicos residentes me tratan con amabilidad & $\mathbf{X}$ & \\
\hline Los médicos residentes son personas preparadas y eficientes & $\mathbf{X}$ & \\
\hline Mi médico tratante es una persona profesional y ética & $\mathbf{X}$ & \\
\hline El personal médico me habla con la verdad & $\mathbf{X}$ & \\
\hline El personal médico me explica lo que tengo en términos que yo entiendo & $\mathbf{X}$ & \\
\hline Constantemente nos revisan para ver que nos falta & $\mathbf{X}$ & \\
\hline La higiene dentro del hospital es buena & $\mathbf{X}$ & \\
\hline La dieta que me proporciona la nutrióloga es la adecuada para mi enfermedad & & $\mathbf{X}$ \\
\hline Se que enfermedad padezco & $\mathbf{X}$ & \\
\hline Estoy consciente de las consecuencias que puede traer mi enfermedad & $\mathbf{X}$ & \\
\hline Mi familia sabe cual es mi diagnóstico y conoce las posibles consecuencias & $\mathbf{X}$ & \\
\hline Comparto con mis seres queridos mis miedos, pensamientos y sentimientos & $\mathbf{X}$ & \\
\hline Siento que mis seres queridos me apoyan & $\mathbf{X}$ & \\
\hline Tengo asuntos pendientes que arreglar con mi familia & $\mathbf{X}$ & \\
\hline Me siento solo (a) & & $\mathbf{X}$ \\
\hline Me siento triste & & $\mathbf{X}$ \\
\hline Me siento enojado (a) & & $\mathbf{X}$ \\
\hline Me siento incapaz de realizar algunas actividades que antes solía hacer & $\mathbf{X}$ & \\
\hline Tengo miedo de lo que pueda pasarme & $\mathbf{X}$ & \\
\hline Tengo miedo a la muerte & $\mathbf{X}$ & \\
\hline $\begin{array}{l}\text { Me gustaría tener contar con una persona ajena a mis seres queridos con quien } \\
\text { compartir lo que siento y pienso. }\end{array}$ & $\mathbf{X}$ & \\
\hline $\begin{array}{l}\text { Me gustaría que dentro del hospital hubiera algún tipo de actividad para } \\
\text { distraerme. }\end{array}$ & $\mathbf{X}$ & \\
\hline
\end{tabular}


FICHA DE IDENTIFICACIÓN:

\section{Paciente\#3:}

NOMBRE: I.D.H

EDAD: 68

SEXO: F M: X

ESTADO CIVIL: Casado

OCUPACIÓN: Jubilado

ESCOLARIDAD: Primaria

\section{DIAGNÓSTICO MÉDICO Y CAUSAS DEL INTERNAMIENTO:}

Diabetes Tipo 2

Hipoglucemia

Hipertensión arterial

Úlcera duodenal

Alcoholismo

Infección de vías urinarias

H. pylori

Gota

ETÁPA DE DUELO EN LA QUE SE ENCUENTRA EL PACIENTE: Depresión.

ETÁPA DE DUELO EN LA QUE SE QUEDO EL PACIENTE DESPUÉS DEL APOYO:

Ira.

\section{TIPO DE APOYO BRINDADO:}

Apoyo Tanatológico

Acompañamiento tanatológico

Apoyo Psicológico con enfoque Humanista

Terapia ocupacional: juegos (domino y memorama)

Manualidades

Dibujo

Cuento

Otros:

Lugar donde se realizó la investigación: Hospital Darío Fernández Fierro. I.S.S.S.T.E.

Área donde se realizó: Medicina Interna.

Médico responsable: Dr. Mario Colinabarranco González. 


\section{INSTRUMENTO PARA LA DETECCIÓN DE NECESIDADES EN PACIENTES TERMINALES.}

\begin{tabular}{|l|l|l|}
\hline Tipo de necesidad & SI & NO \\
\hline Siento que me han dado un trato humano dentro del hospital & & $\mathbf{X}$ \\
\hline El personal de enfermería me ha lastimado porque son bruscas & $\mathbf{X}$ & \\
\hline El personal de enfermería siempre acude cuando necesito algo & $\mathbf{X}$ & \\
\hline Los médicos residentes me tratan con amabilidad & $\mathbf{X}$ & \\
\hline Los médicos residentes son personas preparadas y eficientes & $\mathbf{X}$ & \\
\hline Mi médico tratante es una persona profesional y ética & $\mathbf{X}$ & \\
\hline El personal médico me habla con la verdad & $\mathbf{X}$ & \\
\hline El personal médico me explica lo que tengo en términos que yo entiendo & $\mathbf{X}$ & \\
\hline Constantemente nos revisan para ver que nos falta & & $\mathbf{X}$ \\
\hline La higiene dentro del hospital es buena & & $\mathbf{X}$ \\
\hline La dieta que me proporciona la nutrióloga es la adecuada para mi enfermedad & $\mathbf{X}$ & \\
\hline Se que enfermedad padezco & $\mathbf{X}$ & \\
\hline Estoy consciente de las consecuencias que puede traer mi enfermedad & $\mathbf{X}$ & \\
\hline Mi familia sabe cual es mi diagnóstico y conoce las posibles consecuencias & $\mathbf{X}$ & \\
\hline Comparto con mis seres queridos mis miedos, pensamientos y sentimientos & $\mathbf{X}$ & \\
\hline Siento que mis seres queridos me apoyan & & $\mathbf{X}$ \\
\hline Tengo asuntos pendientes que arreglar con mi familia & $\mathbf{X}$ & \\
\hline Me siento solo (a) & $\mathbf{X}$ & \\
\hline Me siento triste & $\mathbf{X}$ & \\
\hline Me siento enojado (a) & & $\mathbf{X}$ \\
\hline Me siento incapaz de realizar algunas actividades que antes solía hacer & $\mathbf{X}$ & \\
\hline Tengo miedo de lo que pueda pasarme & & $\mathbf{X}$ \\
\hline Tengo miedo a la muerte & & $\mathbf{X}$ \\
\hline $\begin{array}{l}\text { Me gustaría tener contar con una persona ajena a mis seres queridos con quien } \\
\text { compartir lo que siento y pienso. }\end{array}$ & $\mathbf{X}$ & \\
\hline $\begin{array}{l}\text { Me gustaría que dentro del hospital hubiera algún tipo de actividad para } \\
\text { distraerme. }\end{array}$ & $\mathbf{X}$ & \\
\hline
\end{tabular}




\section{BIBLIOGRAFÍA}

Arnold, R. (1985). El juego de los niños. Barcelona, Herder.

Basave, A. (1983). Metafísica de la muerte. México: Limusa.

Behar, D. (2003). Un buen morir; Encontrando sentido al proceso de muerte. México: Pax.

Blanck, F. y Cerejido, M. (1997). La muerte y sus ventajas. México: Fondo de cultura económica

Bonilla, M. y García. G. (2002). La perspectiva cualitativa en el quehacer social. México: CADEC.

Borges, J. (1956). Instantes. Madrid: Alianza.

Bowlby, J. (1990). La pérdida afectiva, tristeza y depresión. Buenos Aires: Paidós.

Cacoub, D (1992). No quiero que me olviden, El diario de una adolescente que murió de leucemia a los 17 años. México: Martínez Roca

Canales. L, Mallet. L y otros. (2003). Memorias del Tercer Simposium de Tanatología: El niño y el duelo. México.

Cayrol, A. (1984). Mente sin límites. Barcelona: Robin Book.

Díaz I. (2002) Técnica de la entrevista psicodinámica. México: Pax

Fernández, R. (2000). La muerte y el paciente terminal. Proyecto Final. España: Universidad de Salamanca.

Figueroa, G. (1999). Apoyo psicológico a pacientes terminales. Tesis de Licenciatura en Psicología, Facultad de Psicología. México: Universidad Intercontinental.

Frankl, V. (1979). El hombre en busca de sentido. España: Herder.

Friburgo, H. (1910). Antología Universal: ÜNEMAN 
García, A. (2002). Aproximación al sufrimiento, la muerte y el duelo en pacientes y familias en situaciones de urgencia y cuidados críticos. México: Trillas.

Gil, A. (1998). Ansiedad ante la muerte en el paciente oncológico terminal. Tesis de la Escuela Universitaria de Enfermería. España: Universidad de Valencia.

Gómez, L. (2003). Enfermedades en los niños, Manual del Diplomado de Tanatología. Instituto Mexicano de Tanatología: México.

Grecco, E. (1998). Muertes inesperadas. Argentina. Ediciones continente.

Grollman, E. (2000). Vivir cuando un ser querido ha muerto. Barcelona: Ediciones 29.

Gutierrez, R. (1990). Historia de las doctrinas filosóficas. (21ª) edición. México: Esfinge.

Jaramillo, I. (1988). Death in Colombia, Encyclopedia on Death and dying, Colombia: Morgan.

Jaramillo, I. (2001). De cara a la muerte. Colombia. Andrés Bello.

John, B. (1990). Tristeza y depresión, Buenos aires: Paidos

Kopp,S. (1971). GURU. Metáforas de un psicoterapeuta. Barcelona: Gedisa.

Kübler Ross, E. (1975). Sobre la muerte y los moribundos. Barcelona: Grijalbo.

Kübler Ross, E. (1983). Los niños y la muerte. Barcelona: Luciérnaga

Kübler Ross, E. (1985).Una luz que se apaga. México: Luciérnaga

Kübler Ross, E. (1996). Conferencias. México: Luciérnaga

Mallet, L. (2003). Manual del diplomado en Tanatología, Modulo 5.

México: Instituto Mexicano de Tanatología.

Markham, U. (2000). Como afrontar la muerte de un ser querido. México: Martínez Roca. 
Martínez, A. (1999). Comportamiento humano. México: Trillas.

Martínez, Y. (2002). Los atributos existenciales como una Metaestrategia Psicoterapéutica. Una revisión de la aplicación de los fundamentos del existencialismo en la práctica clínica. Revista Figura y Fondo. México: Instituto Humanista de Psicoterapia Gestalt. 5 (1).

Martínez, Y. (2004). La fenomenología. Inédito.

Melgoza, M.(2001), Adolescencia, espejo de la sociedad actual: el suicidio en los adolescentes. Argentina: Lumen.

Meza, D. y Colunga P. (1997). Programa vivencial para mujeres sobre imagen corporal y autoestima desde la psicología humanista. morir. Tesis de la Licenciatura en Psicología. Facultad de Psicología. México: Universidad Intercontinental.

Mila, R. (2003). Teoría y técnica de la terapia ocupacional. España: Universidad de Salamanca.

Montoya, J. (Recuperado en Septiembre del 2003). Las reglas del duelo. Disponible en red en www.homeostad.com/montedeoya/reglas.html

Muñoz, M. (1990). Marco Teórico. Programa de formación. Enfoque centradoenlapersona. México: Instituto Humanista de Psicoterapia Gestalt.

O’Connor, N. (2003), Déjalos ir con amor, la aceptación del duelo. México: Trillas.

Owen.R. y cols. (1988). La muerte y el morir, desafio y cambio. Puerto Rico: Fondo Educativo Interamericano.

Petrillo, M. y cols. (1972). Cuidado emocional del niño hospitalizado. México: Fournier.

Rebolledo, L. (2000). Manual de Tanatología I. México: Asociación Mexicana de Tanatología.

Riojas, R. (1999). Modelo psicoterapéutico de corte psicoanalítico, para el manejo de la angustia generada ante el proceso de morir. Tesis de doctorado en psicoterapia. Facultad de Psicología. México: Universidad Intercontinental. 
Roccatagliata, S. (2000). Un hijo no puede morir, la experiencia de seguir viviendo. Chile: Grijalbo.

Rogers, C. (1962). La relación interpersonal: El núcleo de la orientación. México: Harvard Educational Review.

Rogers, C. (1978). Condiciones necesarias y suficientes del cambio terapéutico de la personalidad. México: Trillas.

Rüssel. A. (1985). El juego de los niños. Barcelona: Herder.

Sánchez, M. (2005). La Tanatología, el acompañamiento y la consejería. Manual del curso de Consejería y acompañamiento tanatológico. México: Instituto Mexicano de Tanatología.

Sherr. L. (1992). Agonía, muerte y duelo. México: Manual Moderno

Speck, P. (1978). Loss and Grief in Medicine. London: Bailliere Tindall.

Tolstoi, L.(1975). Cuentos escogidos: La muerte de Iván Ilich. México: Porrua

Unikel, A. (2001). La actitud fenomenológica en la comprensión empática Revista Figura y Fondo, Vol. 5, No. 1. México: Instituto Humanista de Psicoterapia Gestalt.

Valera, V.M (1990). El hombre y su muerte, preparación para la vida. México: Jus Editorial

Vincent, L. (1992). Antropología de la muerte. México: Fondo de cultura económica.

Vincent, L. (1980). La muerte. México: Fondo de cultura económica.

Welch, J. (Recuperado en Diciembre del 2003). Poemas. Disponible en red en www.poemas.com.mx

Wilber, K.(1995). Gracia y coraje. España: Gaia.

William W. (1997), El tratamiento del duelo: Asesoramiento psicológico y terapia. México: Paidos.

Wolfelt. A. (2003). Consejos para jóvenes ante el significado de la muerte. Barcelona: Diagonal. 
Yalom, I. (1984). Psicoterapia existencial. Barcelona: Herder.

Yalom, I. (2002). El Don de la terapia. México: Emece.

Zuleta, C. (2004). Factores psicológicos intervinientes en la calidad de vida de las personas en la etapa de la vejez. México: Fondo de Cultura Económica.

\section{(9) (1)}

Este texto está protegido por una licencia Creative Commons

Usted es libre para Compartir — copiar y redistribuir el material en cualquier medio o formato - y Adaptar el documen- to -remezclar, transformar y crear a partir del material- para cualquier propósito, incluso comercialmente, siempre que cumpla la condición de:

Atribución: Usted debe reconocer el crédito de una obra de manera adecuada, proporcionar un enlace a la licencia, e in- dicar si se han realizado cambios. Puede hacerlo en cualquier forma razonable, pero no de forma tal que sugiera que tie- ne el apoyo del licenciante o lo recibe por el uso que hace. 